\title{
The
}

\section{Influence of Scale on the Measurement of the Vertical Price Transmission}

\author{
Dissertation \\ to obtain the Ph. D. degree \\ in the International Ph. D. Program for Agricultural Sciences in Goettingen (IPAG) \\ at the Faculty of Agricultural Sciences, \\ Georg-August-University Göttingen, Germany
}

presented by

TIFAOUI SAID

born in Algeria

Göttingen, May 2016 
D7

1. Name of supervisor: Prof. Dr. von Cramon-Taubadel Stephan

2. Name of co-supervisors: Prof. Dr. Bernhard Brümmer

3. Name of a further member of the examination committee: Prof. Dr. Thomas Kneib Date of dissertation: July 6, 2016 


\section{Acknowledgements}

First of all, I would like to thank my supervisor Prof. Stephan von Cramon-Taubadel for giving me this great opportunity to get my PhD. Thank you very much for being supportive during the hard times of writing this dissertation. I would also like to thank both Prof. Bernhard Brümmer and Prof. Thomas Kneib for accepting to evaluate my PhD thesis.

I give credit to Prof José Maria Gil, Chema, director of the CREDA, who introduced me to the great world of academic research. Thank you very much.

My empirical analysis would not have been possible without the funding of the German Research Foundation (DFG). Thank you also for funding my PhD and my business trips. I am also thankful for the professional work of the scientific coordinators of the Research Training Program (RTG) 1644 scaling problems in statistics: Dr. Barbara Strauss, Dr. Monika Carlsson, and Dr. Lisa Reinecke, thank you. I cannot express all my thanks for the unlimited assistance of Dörte Dede, the secretary of the RTG 1644, thank you very much.

I am also grateful to Simon Kofoed-Dam for excellent research assistance.

Words cannot express how grateful I am to my friend Arnika Peselmann. She provided me with unconditional support whenever I needed help. Thank you Obidjon Yunusov and Dilfuza for the great time and tasty Uzbek food. Many thanks for my colleagues at the chair of Agricultural Economics of the University of Geottingen for the nice moments that I shared with you.

I am most grateful to my family who supported me all these years to follow my dream. In particular, thank you father for the 10 Euros per month that helped me to get my bachelor's degree. Thank you. In July 2009, I quit my job to follow a dream of studying abroad. So, I would not forget to thank myself that I made this big decision. Today, July 2016, I am so proud to be Herr Dr. Tifaoui. 


\section{Table of Contents}

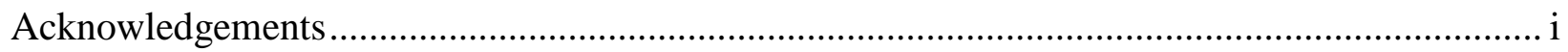

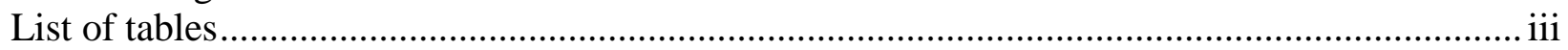

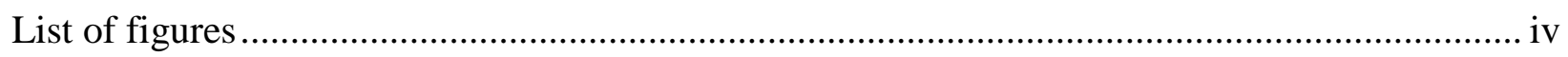

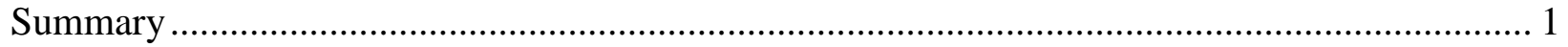

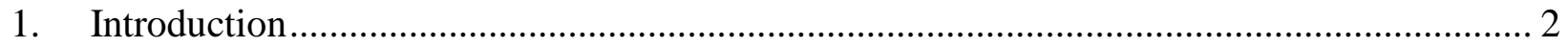

2. Temporary sales prices and asymmetric price transmission ....................................... 7

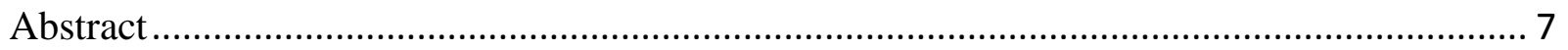

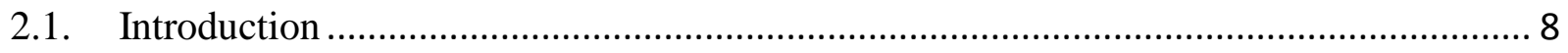

2.2. Review of the empirical literature on data aggregation and VPT ............................... 9

2.3. Methods and data ............................................................................................. 12

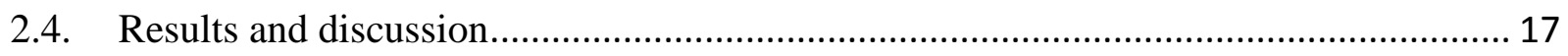

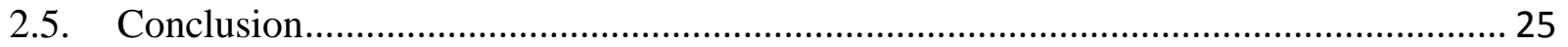

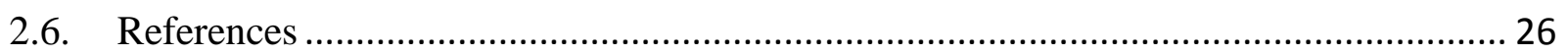

3. Factors explaining asymmetric price transmission from wholesale to retail prices ............ 27

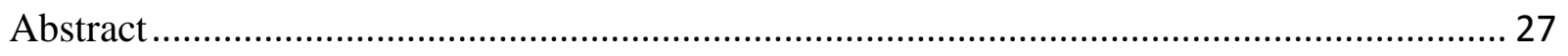

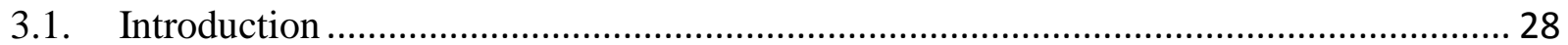

3.2. Processing and retailing of dairy products in Germany ........................................ 32

3.3. Related literature on the factors that explain asymmetry in VPT .............................. 36

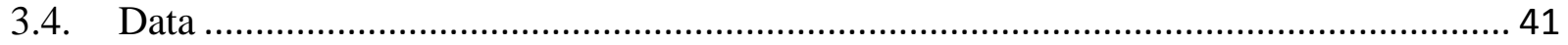

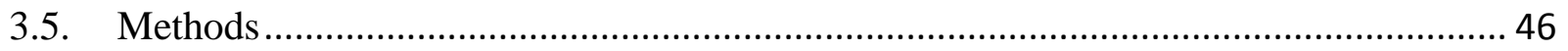

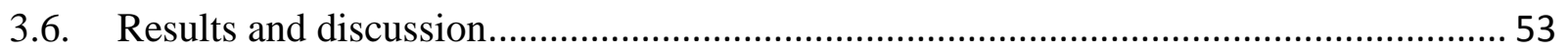

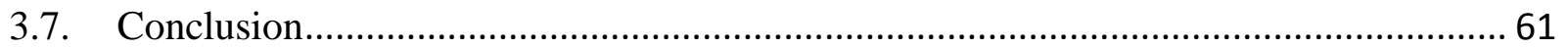

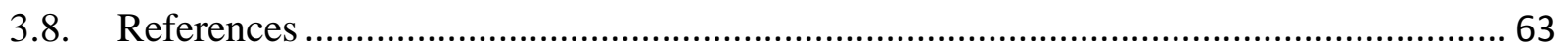

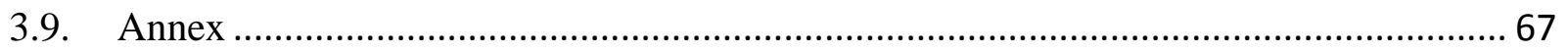

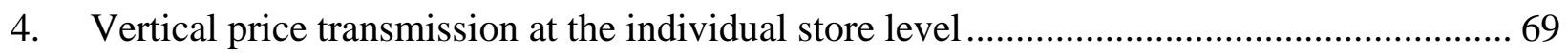

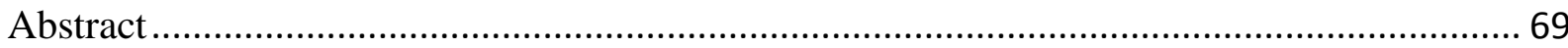

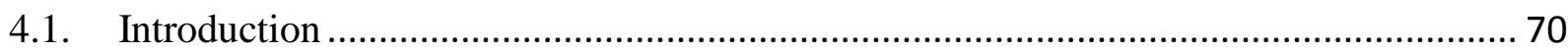

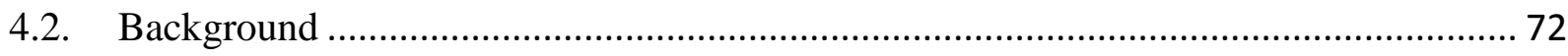

4.3. Related literature on the different theories of price setting .................................... 76

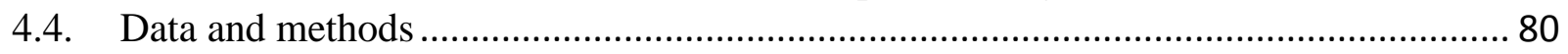

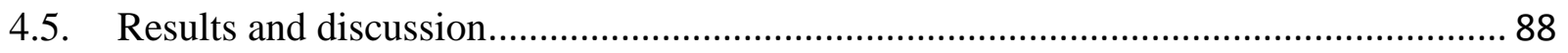

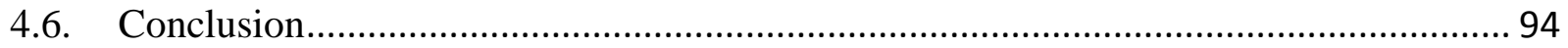

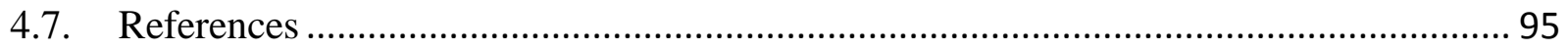

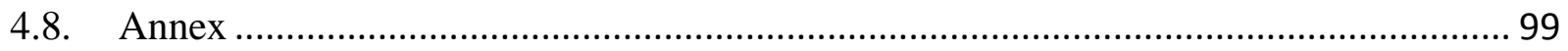

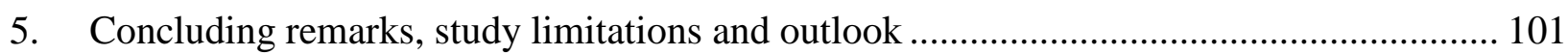

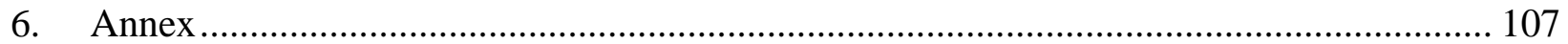

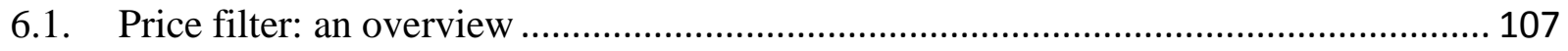




\section{List of tables}

Table 2.1 Descriptive statistics and the representativeness of the sample ............................................................17

Table 2.2 Unit root and cointegration tests for the spatially aggregated butter prices..............................................18

Table 2.3 Results of the estimation of the symmetric and the asymmetric ECM with spatially aggregated prices.....19

Table 2.4 Unit root test results for the individual raw and filtered retail butter prices ..............................................21

Table 2.5 Results of the estimation of symmetric and asymmetric vector error correction models with raw and

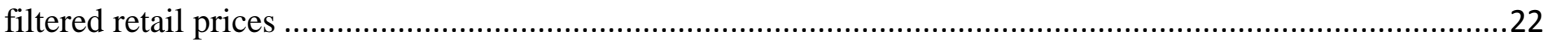

Table 3.1 Descriptive statistics of the variables of interest........................................................................................4

Table 3.2 Factors that explain the asymmetry in VPT using GLMs and GLMMs ...................................................55

Table 3.3 Features of the chains that are distributed in the tails of the posterior distribution of the random effects...59

Table 4.1 Summary statistics for some variables of interest................................................................................

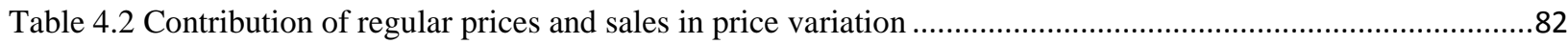

Table 4.3 Variance decomposition of frequency of price change including and excluding sales..............................83

Table 4.4 Estimation results of random intercepts and random slope models ............................................................90

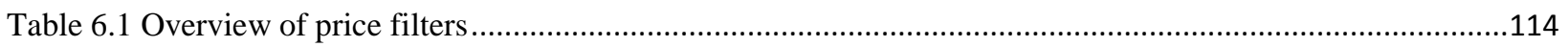

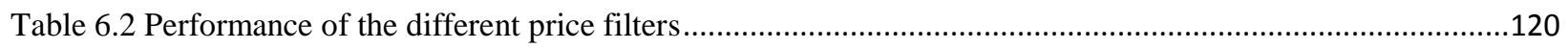




\section{List of figures}

Figure 2.1 Identifying the filtered (reference) price for a typical retail butter price using fixed and rolling window methods

Figure 2.2 Retail butter prices at different levels of spatial aggregation

Figure 2.3 The distribution of the adjustment parameters in 1087 symmetric ECMs that link the wholesale price to raw retail prices, and in 1087 ECMs with the corresponding filtered prices.

Figure 2.4 The effect of temporary sales prices on estimates of asymmetric price transmission with a typical retail price series .24

Figure 3.1 Revenue of the leading dairy companies in Germany in 2014 …..........................................................32

Figure 3.2 Market structure in the German food retail sector, 2014 ...........................................................................34

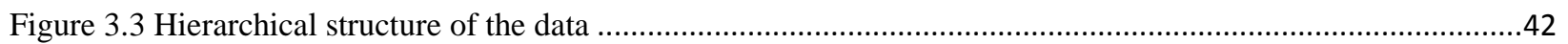

Figure 3.4 Stock keeping units and duration per store format ..........................................................................

Figure 3.5 The fitted probabilities of asymmetry in VPT as a function of duration for different chains.....................57

Figure 3.6 Kernel density of random effects associated with the factor chain ........................................................58

Figure 4.1 Factors that might explain changes in prices at the smallest possible scale ............................................73

Figure 4.2 Histogram margins to wholesale and reference prices .........................................................................74

Figure 4.3 Simple schema of price setting at chain level....................................................................................76

Figure 4.4 Contribution of regular price changes and sales in price variation by retail chain ...................................82

Figure 4.5 Fitted probabilities of regular price change for same product between stores within the same chain........85

Figure 4.6 Fitted probability of price change against the marketing margin .........................................................91

Figure 4.7 Sensitivity to retail marketing margin and frequency of changing retail prices by retail chain .................92

Figure 6.1 Illustration the changes is prices due to TSP and regular price changes. .............................................109

Figure 6.2 Retail prices at different levels of spatial aggregation..................................................................110

Figure 6.3 The link between the number of TSP and the finding asymmetries in the VPT....................................111

Figure 6.4 The use of Temporary Sale Prices (TSP) by format of store...................................................................112 


\section{Abbreviations}

$\begin{array}{ll}\text { ADF } & \text { Augmented Dicky-Fuller } \\ \text { AFC } & \text { Autocorrelation Function } \\ \text { AES } & \text { Agricultural Economics Society } \\ \text { AIC } & \text { Akaike Information Criterion } \\ \text { AVECM } & \text { Asymmetric Vector Error Correction Models } \\ \text { BVE } & \text { Bundesvereinigung der Deutschen Ernährungsindustrie } \\ \text { CR } & \text { Concentration Ratio } \\ \text { EAAE } & \text { European Association of Agricultural Economists } \\ \text { EAN } & \text { European Article Number } \\ \text { ECT } & \text { Error Correction Term } \\ \text { EDLP } & \text { Every Day Low Pricing } \\ \text { GEWISOLA } & \text { Gesellschaft für Wirtschafts- und Sozialwissenschaften des Landbaues e.V } \\ \text { GLM } & \text { Generalized linear models } \\ \text { GLMM } & \text { Generalized Linear Mixed Model } \\ \text { Hi-Lo } & \text { High-Low } \\ \text { KPSS } & \text { Kwiatkowski-Phillips-Schmidt-Shin } \\ \text { MCMC } & \text { Markov Chain Monte Carlo } \\ \text { OLS } & \text { Ordinary Least Squares } \\ \text { SBKB } & \text { Süddeutsche Butter- und Käse-Börse (German Butter and Cheese Exchange) } \\ \text { SKU } & \text { Stock Keeping Units } \\ \text { TSP } & \text { Temporary Sales Prices } \\ \text { VECM } & \text { Vector Error Correction Models } \\ \text { VPT } & \text { Vertical Price Transmission }\end{array}$




\section{Summary}

Measuring vertical price transmission (VPT) has become a widespread means to evaluate the performance of food value chain. To do so, agricultural economists employ time series methods on spatially aggregated data of prices at a regional/ national level. The conclusions of these studies are sometimes used to derive conclusions on the behavior of individual economic agents, e.g. retailers. This is based on a strong (implicit) assumption that the results derived from the studies using aggregated data apply, at least on average, at the disaggregated level. Two main issues could result from this assumption. First, measuring VPT using aggregated data to derive conclusions on individual behavior can be misleading on the real performance of the value chain. For instance, the retail sector can be studied as an aggregate by using weighted averages on retail prices to check how the sector transmits changes in prices from the upstream (wholesale) to the downstream of the value chain. The results of such studies can only provide an imprecise picture on how every retail store included in the weighted averages transmits its prices individually. Second, units under statistical investigation are likely to behave very differently when studied on different scales (e.g., aggregated/ disaggregated). For instance, while aggregated retail prices display unit root behavior, a typical retail price at the store level tends to persist and most deviations from the "regular" price are negative. This is often because of temporary sales prices (TSP) or promotions. The magnitude of the use of these marketing tools varies across store formats. For instance, hypermarket use High-Low pricing strategy, whereas the discount stores employ everyday low pricing strategy. These differences in the pricing strategies of the chains can lead to different outcomes on how they transmit the prices. Therefore, academic research has recently started to use disaggregated scanner data to assess VPT, which can help to cast light on how prices are transmitted at the individual retail chain; however, finding consistent methods to employ is a challenge. For instance, to capture price dynamics, the most common approach is the use of first difference in prices, which are mostly zero at the individual retail stores because at this level retail prices are rigid.

This dissertation addresses these literature gaps by studying the VPT at the individual retail store. Building up on three paper, each paper deals with each of the aforementioned issues. The first paper explicitly studies the impact of TSP on VPT processes. The results of this paper show that TSP increase the speed and asymmetry of VPT, which add a potential cause of asymmetry to those that have already been identified in the literature. The second paper builds on the results of the first one. After filtering out the TSP, we investigate why VPT for the same product is symmetric within some retail chains and asymmetric within others. We show that asymmetric pricing depends on store membership to a specific chain and that market power expresses itself in the adoption of a specific pricing strategy, namely: Every Day Low Pricing or High-Low, which in turn can lead to different outcomes, including asymmetric pricing in VPT. Finally, in the third paper of this dissertation, we provide some new insights on how prices are determined and transmitted at the individual retail store. We employ an approach which consists in linking dichotomous retail chains' decision of changing prices versus displaying rigid prices to factors such as retail marketing margins. 


\section{Introduction}

Food products move from farmers to consumers. The two economic agents are connected by markets and agro-food marketing provides all functions between them. The retailing sector plays an important role in connecting the upstream to the downstream of the same value chain. However, retailers are often blamed for the (ab)use of market power to increase their marketing margins and markups (Meyer \& Cramon-Taubadel, 2004). Thus, the study of the dynamic relationships of prices between two levels of the value chain are useful for a better understanding of market functioning. A commonly used and flexible tool to measure the dynamic relationships of prices is price transmission analysis. When employed between two levels of the same value chain, price transmission is then referred to as vertical price transmission (VPT). Agricultural economists study VPT processes to gain insights into the interactions between prices at different levels of a marketing chain. The nature of VPT processes can cast light on the nature of competition in the marketing chain. For instance, VPT allows an assessment of the degree and the necessary time for an adjustment to a shock at one level of the value chain, e.g. wholesaler to another level of the value chain e.g. retailer.

Measuring VPT along the food chain has become a widespread means for evaluating the efficiency and the degree of competition in food processing and marketing. An important measure and commonly used in the literature to assess the efficiency of value chains is the presence or absence of asymmetries in VPT. The presence of asymmetry in VPT is of special interest because it could have welfare implications (Meyer \& Cramon-Taubadel, 2004). Asymmetry in VPT refers to a situation where price transmission varies depending on whether prices are increasing or they are decreasing. This phenomenon is concisely defined in Tappata (2009, p. 673) : "prices rise like rockets but fall like feathers.” This stylized fact is found in several empirical applications of VPT. For instance, in a meta-analysis of 70 studies, with 87 different model specifications, Frey \& Manera (2007) find asymmetry is the rule with $87 \%$ of the cases. Among factors that lead to the prevalence of asymmetries, Frey \& Manera (2007) include temporal data aggregation as an issue. That is, asymmetry is more prevalent in studies that employ lower frequency data, i.e. monthly and weekly; thus, temporal aggregation plays an important part. 
Typical applications of VPT, including those 70 studies surveyed in Frey \& Manera (2007) link average (wholesale) prices for an agro-food product in a region or country to average (retail) prices for the same product or processed product in the same region or country. In addition to the impact of temporal aggregation, the results of VPT analysis can also be influenced by crosssectional aggregation. The impact of cross-sectional aggregation on VPT is explicitly studied for the first time in von Cramon-Taubadel et al (2006). The authors find that VPT analysis with aggregated data tends to point to slower VPT processes than does analysis with disaggregated (i.e., individual retail store) price data. They also find the prevalence of asymmetries in VPT at the disaggregated level without going in details.

A striking difference between aggregated and disaggregated prices is in the characteristics of time series. At store level, prices are rigid and most deviations from the "regular" is a result of temporary sales prices (TSP). The first paper of this dissertation addresses this gap by studying explicitly the impact of TSP on VPT processes. We hypothesize that TSP might bias the results of VPT analysis towards findings of asymmetric price transmission. We test this hypothesis using scanner data on retail butter prices in Germany. We first use filters to identify the underlying "regular" retail prices; thus we remove TSP. We then compare estimates of VPT from the wholesale to the retail level that are generated with raw and with filtered retail prices. An earlier version of this study was presented at the $89^{\text {th }}$ Annual Conference of the Agricultural Economics Society.

A final version of the paper is published in the Agribusiness: An International journal, with the title: “Temporary sales prices and findings of asymmetric vertical price transmission”. The results of the first paper confirm that TSP increase the speed and asymmetry of VPT. These results add a potential cause of asymmetry to those that have already been identified in the literature. Moreover, we contribute to the literature in many ways. First, we add a potential cause of asymmetry to those that have already been identified in the literature (Meyer and von Cramon-Taubadel, 2004; Frey and Manera, 2007). Second, we can further explain the mechanism. More specifically, we find that the type of asymmetry caused by TSP is the same type that is often attributed to the abuse of market power in the food chain. Third, even though the application of VPT using scanner data are scare in the literature, we recommend for future research to check for possible bias due to TSP, where findings of asymmetric VPT in 
disaggregated retail price data are found, before any hasty conclusions are drawn about competition and market power.

It is often hypothesized that market power will enable retailers in the food marketing chain to engage in asymmetric VPT. Academic research has recently started to use disaggregated scanner data with a rich cross-sectional component to test this hypothesis. The studies of Richards et al. (2014) and Loy et al. (2015) are pioneers, and their findings point towards considerable variations in price dynamics and asymmetries in VPT across products, stores, and chains. The procedure in both studies consist of testing the traditional market power hypothesis against consumer search costs to explain the prevalence of asymmetric VPT at the disaggregated level. The hypothesis that consumer search costs influence VPT process has its genesis in the theoretical works of Tappata (2009), Yang \& Ye (2008), and Yuan \& Han (2011). The findings of both studies point toward reconsidering market power as the only/major explanation for the prevalence of asymmetries in VPT. The hypothesis of consumer search costs was tested with conclusive effects in Richards et al. (2014), but with small effects in Loy et al. (2015). However, both Richards et al. (2014) and Loy et al. (2015) do not account for an important feature of scanner data: their hierarchical structure. This is curious because store membership in a chain might influence VPT processes within a chain and between chains. We address this gap in the second paper of this dissertation.

The second paper of this dissertation builds on the findings of first paper. Each retail price is first filtered to remove TSP that would otherwise bias the results of asymmetry tests. Then we investigate why VPT for the same product is symmetric within some retail chains and asymmetric within others. We hypothesize that asymmetric pricing depends on store membership to a specific chain and that market power expresses itself in the adoption of a specific pricing strategy, namely: Every Day Low Pricing (EDLP) or High-Low (HiLo), which in turn can lead to different outcomes, including asymmetric pricing in VPT. We employ multilevel modeling to explore the hierarchical structure of scanner data in order to gain insights into the heterogeneity in the prevalence of asymmetric pricing. Multilevel models allow for the systematic distinction between the stores/chains that are likely to employ asymmetric pricing and those that employ symmetric pricing. The results of the second paper show that when chains that employ HiLo mimic chains that employ EDLP and display rigid prices, to avoid markup variation because they 
can, then price rigidity leads to an increase in the likelihood of asymmetric pricing. An earlier version of this second paper has been presented at the at the $148^{\text {th }}$ seminar of the EAAE, with title: "Factors explaining the findings of asymmetric vertical price transmission in hierarchically structured data".

Data characteristics are not the only challenge of VPT application at the disaggregated level. The methods employed to capture the price dynamics are also important. Indeed, at the country or regional scale, prices typically display unit root behavior. Hence, agricultural economists employ time series methods such as VECMs and non-linear variants of these models to depict complex, regime dependent VPT processes (e.g., asymmetric, threshold VECMs). As data have become available for academic research, recent studies employ the potential of panel data in order to improve the power estimates of some variants of VECMs (Empen, 2014; Holm, 2013; Loy et al., 2015; Richards et al., 2014). However, in VECMs or non-linear VECMs, price dynamics are captured by employing first difference $\left(\Delta P_{t}=P_{t}-P_{t-1}\right)$ on prices. Since at individual retail stores prices for individual food products, e.g. dairy products are rigid, most $\Delta P_{t}$ are zero. Previous studies do not provide any alternative for the information loss that could result from using first differences on rigid prices. In the third paper of this dissertation, we apply an alternative approach to capture dynamic relationships of prices between wholesaler and retailers with disaggregated retail price data. An earlier version of this third paper has been presented as a poster presentation at the $6^{\text {th }}$ EAAE PhD Workshop and the $55^{\text {th }}$ Gewisola annual meeting 2015, with title: "heterogeneity in price settings in the German butter market".

Our approach consists of analyzing dichotomous choices of retail chains for changing their prices or displaying rigid prices. More specifically, we try to connect the retail chains' dichotomous decisions to some factor underling retail chain decisions, such as the effect of marketing margins and the level of price at the competing retail chains for the same product. We hypothesize that an increase in marketing margins would lead to a decrease in the likelihood of introducing a price change. We also expect that retail chains that are sensitive to changes in their marketing margins will adjust their prices more frequently than the retail chains that are insensitive to their marketing margins. The findings of the third paper indicate that retail chains react to the wholesale prices with temporary sales price (TSP). To changes of competing retail prices, retail chains react with changing their regular prices. We also find that it is more likely to 
change new prices than to change old prices; thus a result that is at odds with the conventional theories of costly price adjustment. Our approach consisting of modelling dichotomous choices can be used to complement the standard cointegration methods that are used with aggregated prices.

The rest of this dissertation is organized as follows. Chapter 2 presents the first paper on the impact of TSP on the VPT processes. Chapter 3 presents the second paper, where investigate the factors that can help to explain the prevalence of asymmetries in VPT at the smallest possible sale. In Chapter 4, we present the findings of the third paper. The conclusions and outlook are summarized in Chapter 5. Finally, supplementary material on how do we calculate filtered retail prices are found in Chapter 6. 


\title{
2. Temporary sales prices and asymmetric price transmission
}

\begin{abstract}
We hypothesize that temporary sales might bias the results of vertical price transmission analysis towards findings of asymmetric price transmission. We test this hypothesis using scanner data on retail butter prices in Germany. We first use filters to identify underlying reference retail prices and thus remove temporary sales prices. We then compare estimates of vertical price transmission from the wholesale to the retail level that are generated with raw and with filtered retail prices. Our results confirm that temporary sales prices increase the speed and asymmetry of vertical price transmission. These results add a potential cause of asymmetry to those, such as market power, that have already been identified in the literature.
\end{abstract}

Keywords: Aggregation, Vertical Price Transmission, Reference Prices, Scanner Data 


\subsection{Introduction}

Most empirical studies of vertical price transmission have employed regional or national average producer, wholesale and retail prices. These studies assume, usually implicitly, that results derived from such spatially aggregated data are representative, at least on average, of the behavior of the individual actors (e.g., farmers, wholesalers or retailers) whose prices were aggregated. For example, if estimation indicates that it takes ' $\mathrm{X}$ ' weeks for a wholesale price shock to be transmitted to the average retail price, then it is assumed that on average it will take ' $\mathrm{X}$ ' weeks for this wholesale price shock to be transmitted to the prices in individual retail stores.

Aggregation results in a loss of information, however, and it changes the time series characteristics of the data thus processed. Using price data from a set of individual retail stores in Germany, von Cramon-Taubadel et al.(2006) show that spatial aggregation affects the results of vertical price transmission analysis. Specifically, they first estimate price transmission from a wholesale price to each of the individual retail prices. Second, they estimate price transmission from the same wholesale price to the average of the retail prices. Their results show that on average the individual estimates of vertical price transmission are considerably faster than the estimate generated using average retail prices.

To explain these results, von Cramon-Taubadel et al.(2006) point out that unlike spatial averages, which typically display random walk behavior, retail prices at the individual store level tend to change infrequently and adhere to psychological pricing rules (i.e. generally end with the digit “9”). However, von Cramon-Taubadel et al.(2006) do not account for an additional typical characteristic of retail food prices, which is promotional pricing. Loy, Holm, Steinhagen, \& Glauben (2015, p. 451) state that: “...price promotions are not part of the cost pass-through or the price transmission between wholesale and retail prices”. Hence, they argue that the presence of promotions in retail price data might affect the measurement of price transmission.

In this paper we confirm that the presence of price promotions affects estimates of vertical price transmission. Promotional prices can take several forms ${ }^{1}$, of which temporary sales prices (TSP) are the most prevalent in food retail (Hosken \& Reiffen, 2001). We study the impact of TSP on estimates of vertical price transmission using disaggregated retail price data. To this end we first

\footnotetext{
1 Other forms include 'two-for-one' and similar discounts, as well as discounts for members of loyalty programs.
} 
employ several methods that have been proposed to filter out TSP by identifying underlying "reference" retail prices (Chahrour, 2011; Eichenbaum et al., 2011; Kehoe \& Midrigan, 2007; A. O. Nakamura, Nakamura, \& Nakamura, 2011; E. Nakamura, 2008). We then compare estimates of vertical price transmission from the wholesale to the retail level that are generated with raw and with filtered retail prices. This enables us to test whether the estimated speed and symmetry of price transmission from the wholesale to the retail level is affected by the presence of TSP in retail price data. Our results show that TSP in retail price data do indeed bias empirical results towards findings of asymmetric price transmission. Asymmetric price transmission is often considered to be a symptom of market power in the food chain, but our results suggest that empirical findings of asymmetry in disaggregated data may be due to TSP and, thus, that caution is required before reaching conclusions about the presence and implications of market power.

The remainder of the chapter is organized as follows. In Section 2.2 we briefly summarize previous studies of the effects of data aggregation on vertical price transmission. In Section 2.3 we describe the methods and data that we employ. In Section 2.4 we present results, and Section 2.5 concludes.

\subsection{Review of the empirical literature on data aggregation and VPT}

We focus on spatial or cross-sectional data aggregation whereby price data from individual actors such as producers or retailers is used to produce regional or national averages. ${ }^{2}$ Hence, we do not consider possible impacts of temporal aggregation on the estimation of vertical price transmission processes.

Several studies have considered the effects of spatial data aggregation on the results of vertical price transmission analysis. Schwartz \& Schertz Willet (1994) state that the characteristics of the data collection process, such as the timing of price data collection at different levels of the marketing chain, and how these data are aggregated, might affect estimates of vertical price transmission. They also speculate whether the presence of promotions in price data might affect the estimation of vertical price transmission. Powers (1995) finds differences in the speed of price adjustment for lettuce depending on whether national (USA) or state-level data are

\footnotetext{
2 In addition to calculating the arithmetic mean, statistical authorities sometimes apply other transformations to raw data such as first eliminating individual observations that are deemed to be outliers or non-representative, for example because they deviate from the mean by more than ' $X$ ' standard deviations, or because they belong to the largest or smallest ' $Y$ ' percent of all observations.
} 
analyzed, and conjectures that these differences might be due to spatial aggregation. Schroeder (1988) considers vertical price transmission for individual cuts of pork as opposed to an aggregate of these cuts, and concludes that studies that use aggregated retail prices over-simplify the true pricing behavior of individual retailers. In his extensive study of asymmetry in vertical price transmission, Peltzman (2000) includes disaggregated price data from one supermarket chain in the Chicago area. He finds that estimated price transmission is stronger at the individual supermarket level than at the aggregated level. He also finds little evidence of asymmetric vertical price transmission in the disaggregated supermarket level, which contrasts with his finding that asymmetry is prevalent when aggregated prices are used. Peltzman (2000) points out, however, that his findings are based on only one retail chain and cannot be generalized.

von Cramon-Taubadel et al.(2006)address the effects of spatial aggregation on the measurement of vertical price transmission theoretically and empirically. They demonstrate that key parameters in an error correction model (ECM) that is specified with average prices are not the arithmetic averages but rather non-linear functions of the corresponding parameters in the ECMs that are specified with the underlying individual prices. They also present theoretical considerations that suggest that vertical price transmission processes estimated with disaggregated prices will on average be faster than the corresponding process estimated with the average of these prices. Specifically, they demonstrate that the aggregation of stationary autoregressive processes creates fractionally integrated or 'long memory' processes. They confirm these theoretical considerations using retail price data for chicken and lettuce in Germany. von Cramon-Taubadel et al.(2006) also find that while vertical price transmission appears to be symmetric at the aggregate level, vertical price transmission from the wholesale to the individual store level appears to be asymmetric for roughly one-quarter of stores in their dataset.

In summary, a few studies note that spatial aggregation affects the estimated speed and symmetry of vertical price transmission. However, most of these studies are based on comparatively small data sets (e.g. Peltzman's analysis of a single supermarket chain). Furthermore, no study to date has considered the possible influence of TSP on estimates of vertical price transmission. As described below, we estimate vertical price transmission using a 
large scanner dataset of butter prices in Germany (over 1000 series of roughly 300 weekly observations each), and we explicitly analyze the effects of TSP on this estimation.

There are theoretical reasons to expect that TSP will affect estimates of vertical price transmission. Consider the wholesale price for a food product, and the corresponding retail price in a specific store. In equilibrium the retail price will exceed the wholesale price by the amount of the retail mark-up. If the retail store drops its price for a temporary sale, the margin between the retail and the wholesale prices will be squeezed, and the two prices will no longer be in equilibrium. When the retail price is returned to its regular level in the next period, it will appear as if this squeezed margin has been rapidly and completely corrected. The more frequent the use of TSP, the more such episodes of rapid and complete correction of squeezed margins will be contained in a given sample of price data.

This could have two effects on estimates of vertical price transmission. First, we hypothesize that episodes of TSP will make vertical price transmission appear more rapid. To test this hypothesis, we compare the speed of vertical price transmission for raw retail prices that include TSP with the speed of vertical price transmission for the same retail prices that have been filtered to remove TSP. Second, since TSP by definition always involve first reducing and subsequently increasing prices, they will add to retail price data only sharp downward spikes or 'valleys' in which squeezed margins are rapidly corrected upward, and never corresponding sharp upward spikes or 'peaks' in which stretched margins are rapidly corrected downward. Hence, we hypothesize that TSP will bias the results of vertical price transmission analysis using retail prices in favor of essentially spurious findings of asymmetric vertical price transmission. This might help explain the higher prevalence of asymmetric vertical price transmission in disaggregated retail price data reported by von Cramon-Taubadel et al.(2006). We test this hypothesis by estimating asymmetric ECMs first with raw retail price data and second with corresponding retail price data that has been filtered to remove TSP. The following section explains our empirical strategy and data in greater detail. 


\subsection{Methods and data}

\subsubsection{Estimating vertical price transmission and testing for asymmetry}

We estimate bivariate vector error correction models between the individual retail prices (raw or filtered as described in subsection 2.3.2 below) and a weighted average wholesale price. In this setting the vector error correction model takes the following form:

$$
\left[\begin{array}{l}
\Delta p_{t}^{R i} \\
\Delta p_{i}^{W}
\end{array}\right]=\left[\begin{array}{l}
\varphi_{1} \\
\varphi_{2}
\end{array}\right]+\left[\begin{array}{l}
\alpha_{1} \\
\alpha_{2}
\end{array}\right]\left[p_{t-1}^{R i}-\beta_{0}-\beta_{1} p_{t-1}^{W}\right]+\sum_{j=1}^{k}\left[\begin{array}{ll}
\delta_{1 j} & \rho_{1 j} \\
\delta_{2 j} & \rho_{2 j}
\end{array}\right]\left[\begin{array}{l}
p_{t-1}^{R i} \\
p_{t-1}^{W}
\end{array}\right]+\left[\begin{array}{l}
\varepsilon_{1 t} \\
\varepsilon_{2 t}
\end{array}\right]
$$

where $P_{t}^{R i}$ is the price of an item $i$ in a given retail store, $P_{t}^{W}$ is the average wholesale price at the national level of that item, $t$ is an index of time, $\varphi, \alpha, \beta, \delta$, and $\rho$ are parameters to be estimated; $\varepsilon_{1 t}$ and $\varepsilon_{2 t}$ are white noise disturbances. In equation (1) the expression $P_{t-1}^{R i}-\beta_{0}-\beta_{1} P_{t-1}^{W}$, often referred to as the error correction term $(E C T)$, captures the deviations from the long-run equilibrium relationship between $P_{t}^{R i}$ and $P_{t}^{W}$. Hence, $P_{t-1}^{R i}-\beta_{0}-\beta_{1} P_{t-1}^{W}=E C T_{t-1}$ equals zero when these prices are in equilibrium. The parameters in equation (1) which are of greatest interest to us are the $\alpha$, which measure the rates at which deviations from equilibrium are corrected, i.e. the speed of vertical price transmission.

We estimate equation (1) using the 2-step method proposed by Engle \& Granger (1987) ${ }^{3}$. This involves first estimating the long-run relationship $P_{t}^{R i}=\beta_{0}+\beta_{1} P_{t}^{W}+u_{t}$ between the wholesale and retail prices using OLS, and second using the estimated lagged residuals $u_{t-1}$ from this estimation in place of the expression $P_{t-1}^{R i}-\beta_{0}-\beta_{1} P_{t-1}^{W}$ when estimating equation (1), again with OLS. We assume that $P_{t}^{W}$ is weakly exogenous ${ }^{4}$ (i.e. it does not respond to deviations from the long-run relationship) and therefore focus exclusively on the equation for $\Delta P_{t}^{R i}$ in (1). Hence, in the second step of the Engle-Granger method we estimate the following single-equation ECM:

$$
\Delta P_{t}^{R i}=\varphi+\alpha\left(E T C_{t-1}\right)+\sum_{j=1}^{k} \delta_{j} \Delta P_{t-j}^{R i}+\sum_{j=1}^{l} \rho_{j} \Delta P_{t-j}^{W}+\varepsilon_{t}
$$

Where $E C T_{t-1}=u_{t-1}=P_{t-1}^{R i}-\beta_{0}-\beta_{1} P_{t-1}^{W}$ as estimated in the first step.

\footnotetext{
${ }^{3}$ We could also use a systems method such as Johansen's maximum likelihood estimator. However, it is not possible to estimate the asymmetric specifications described below using this method. We do use the Johansen method to test for cointegration between wholesale and retail prices (see Results section).

${ }^{4}$ Loy et al. (2015) use the same dataset that we use in this paper for the period 2005-2008. They find that in over $90 \%$ of all retail-wholesale price combinations the wholesale price is weakly exogenous.
} 
Asymmetric price transmission describes the situation in which prices that are linked by a longrun equilibrium relationship react differently depending on whether they are pushed too close together or pulled too far apart relative to that equilibrium. In our setting, asymmetry means that the retail price responds more rapidly (or more slowly) to an increase in the wholesale price (i.e. when the margin is squeezed) than it does to a decrease in the wholesale price (i.e. when the margin is stretched). Following von Cramon-Taubadel (1998), we use a modification of the vector error correction model proposed by Granger \& Lee (1989) to test for asymmetry. This modification involves segmenting the error correction term $E C T_{t-1}=\left[P_{t-1}^{R i}-\beta_{0}-\beta_{1} P_{t-1}^{W}\right]$ into positive and negative components $E C T^{+}=\max \{0, E C T\}$ and $E C T^{-}=\min \{0, E C T\}$ and estimating the following equation:

$$
\Delta P_{t}^{R i}=\varphi+\alpha^{+} E C T_{t-1}^{+}+\alpha^{-} E C T_{t-1}^{-}+\sum_{j=1}^{k} \delta_{j} \Delta P_{t-1}^{R i}+\sum_{j=1}^{l} \rho_{j} \Delta P_{t-j}^{W}+\varepsilon_{t}
$$

Since $E C T^{+}+E C T^{-}=E C T$, equation (2) is nested in equation (3) and an F-test can be used to test the null hypothesis of symmetry $\left(\mathrm{H}_{0:} \alpha^{+}=\alpha^{-}\right)$. In the symmetric model in equation (2), the adjustment parameter $\alpha$ is expected to lie on the interval [-1,0]. $\alpha<0$ ensures that the retail price decreases $\left(\Delta P_{t}^{R i}<0\right)$ whenever it is too large relative to the wholesale price $\left(E C T_{t-1}=\right.$ $\left.\left[P_{t-1}^{R i}=-\beta_{0}-\beta_{1} P_{t-1}^{W}\right]>0\right)$, and correspondingly that the retail price increases $\left(\Delta P_{t}^{R i}>\right.$ 0 ) whenever it is too small relative to the wholesale price $\left(E C T_{t-1}<0\right)$. Furthermore, $\alpha>-1$ ensures that no more than $100 \%$ of any deviation from the long-run equilibrium is corrected in each subsequent period (e.g. $\alpha=-0.5$ means that $50 \%$ of any deviation from the long-run equilibrium in period $t-1$ is corrected in period $t)^{5}$. In the asymmetric model in equation (3) the same restriction applies to $\alpha^{+}$and $\alpha^{-}$individually, with $\left(-1<\alpha^{+}<0\right)$ and $\left(-1<\alpha^{-}<0\right)$ ensuring error correction as outlined above, and $\alpha^{+} \neq \alpha^{-}$allowing the magnitude of $\Delta p_{t}^{R i}$ to differ according to whether the deviation from long-run equilibrium $(E C T)$ is positive (margin stretched) or negative (margin squeezed).

\footnotetext{
${ }^{5}$ Theoretically $\alpha$ could also take values on the interval $[-2,-1]$, but this would entail overshooting and error correction in dampened oscillations, which we consider implausible in the context of wholesale-retail butter price transmission.
} 


\subsubsection{Reference prices}

Over the last decade a large literature has emerged on the identification of TSP in retail price data. One branch of this literature (e.g. Hosken \& Reiffen, 2004) focuses on measuring the frequency and timing of price promotions as an important dimension of retail price behavior. Another branch (e.g. Eichenbaum et al., 2011) focuses on filtering promotional prices out of retail price data to reveal underlying so-called "reference" prices that reflect fundamentals such as core inflation.

Throughout this literature, a key question is how to identify TSP empirically in retail price data. An observed retail price $P_{t}$ can be decomposed into a regular or reference price $\left(r_{t}\right)$ component and a sales price component $\left(S_{t}\right)$. Two main approaches to decompose $\left(P_{t}\right)$ into these components have been taken in the literature: one which filters out individual episodes of TSP and considers all remaining price movements as part of the reference price; and another which filters out the reference price and considers all remaining price movements as TSP and other short term features. An example of the first approach is Kehoe \& Midrigan (2007) who consider any price decrease that is followed by a price increase in the next period to be a TSP. Nakamura \& Steinsson, 2008) modify the Kehoe \& Midrigan (2007) procedure to consider only symmetric ‘valleys' as TSP; i.e. a TSP is recorded only when a price decrease is immediately reversed by a return to the previous price. Following Hosken \& Reiffen (2001), Loy et al. (2015) consider only symmetric valleys in which the price reduction amounts to at least $5 \%$ of the initial price.

All these procedures for identifying TSP share the main weakness that they are based on arbitrary definitions of what constitutes a sales price $\left(S_{t}\right)$. This has led authors such as Eichenbaum et al., (2011) to propose methods that fall under the second approach described above, which is to filter out the underlying reference price $r_{t}$. Specifically, Eichenbaum et al., (2011) calculate the reference price as the modal price over a fixed 13-week or quarterly window: ${ }^{6}$

$$
\left\{r_{1}, r_{2}, r_{3}, \ldots, r_{13}\right\}=\text { modal value }\left\{p_{1}, p_{2}, p_{3}, \ldots, p_{13}\right\}
$$

where $\left\{p_{1}, p_{2}, p_{3}, \ldots, p_{13}\right\}$ is a sequence of observed prices. Chahrour (2011) argues that this method is too restrictive because it only allows changes in the reference price to take place at the

\footnotetext{
${ }^{6}$ Eichenbaum et al. (2011) are primarily interested in studying inflation and choose a 13-week or quarterly window for their analysis to match the quarterly frequency of much macroeconomic data.
} 
beginning/end of each quarter. He therefore suggests that a moving window be used to calculate the reference price. Specifically, Chahrour's reference price $\hat{r}_{t}$ is defined as the modal price in a centred moving window of width $(2 w+1)$ :

$$
\hat{r}_{t}=\text { modal value }\left\{p_{t-w}, p_{t-w+1}, \ldots p_{t-1}, p_{t}, p_{t+1}, \ldots, p_{t+w}, p_{t+w-1}, p_{t+w}\right\}
$$

Chahrour (2011) also suggests an algorithm based on the most common price in overlapping periods to deal with multiple modal values.

\section{Figure 2.1: Identifying the filtered (reference) price for a typical retail butter price using fixed and rolling window methods}
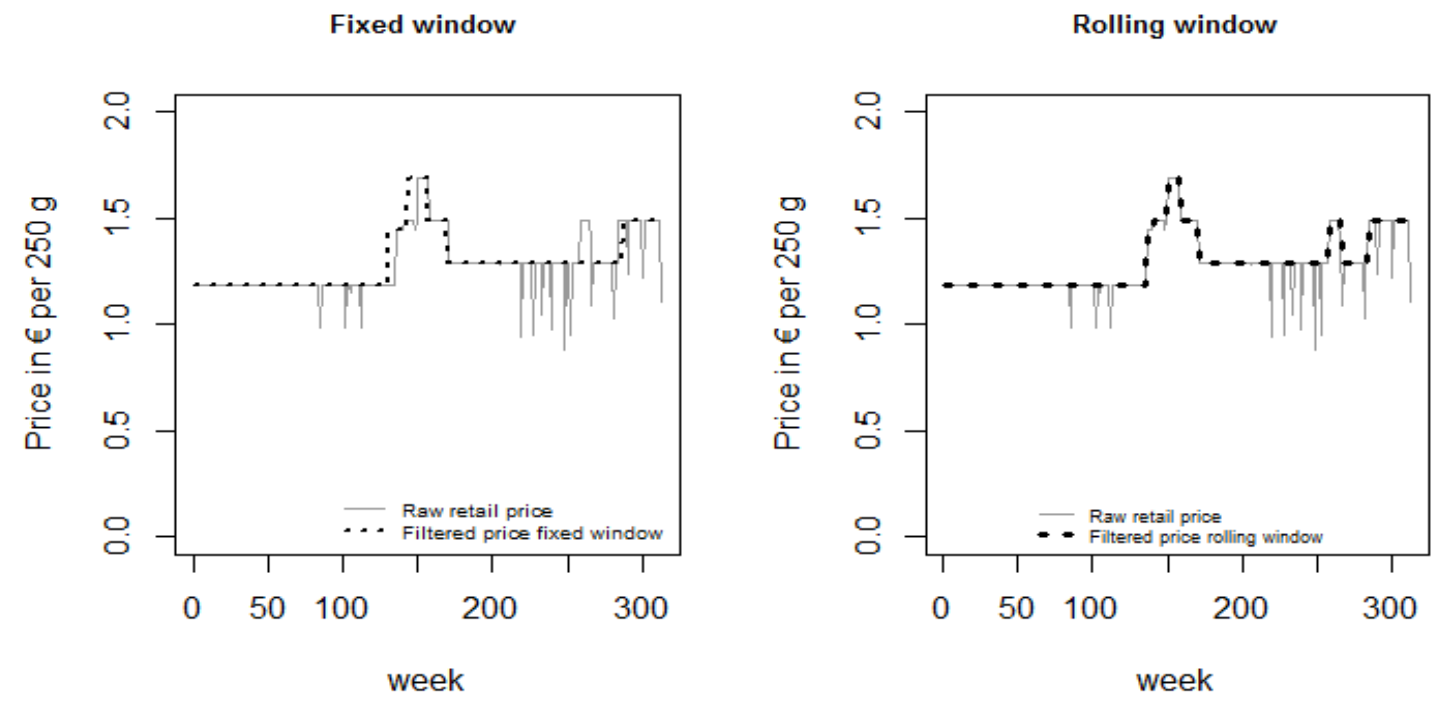

Source: Authors' calculations

In the following we employ Chahrour's rolling window method and a width of 13 weeks. We refer to the observed retail prices as "raw", and to the references retail prices produced using Chahrour's method as "filtered". Figure 2.1 compares the results of applying this method and Eichenbaum et al.'s fixed window method to a typical raw retail price series in our dataset. Overall we find that the rolling window method produces a more plausible decomposition into reference and sales components than the fixed window. In particular, the fixed window often generates a filtered price that appears to lead or lag the raw retail price (see for example weeks 120 to 150 in the left panel of Figure 2.1), and that fails to follow some raw retail price movements that are clearly not due to sales (see for example the temporary increase in raw prices around week 260 in Figure 2.1, which the fixed window in the left panel fails to follow, unlike the rolling window in the right panel). Experimentation with widths of 9 and 17 weeks (results 
available from authors) indicate that varying the size of the rolling window that we use to filter the raw retail prices does not affect our main results.

\subsubsection{Data}

To test the hypotheses and employ the methods outlined above, we use scanner data on weekly retail prices for 250-gram foil-wrapped packages of butter in Germany. We choose butter because it is a very homogeneous product across space and time, and the 250-gram format because it accounts for over $90 \%$ of the total volume of butter sales in our data. ${ }^{7}$

The data cover 459 retail stores belonging to 41 different chains, and run from the beginning of 2005 to the end of 2010 (312 observations). Individual brands of butter are identified by European Article Numbers (EAN), and we only include a price series in the subsequent analysis if the brand in question was available in the retail store in question without interruption over the entire sample period. Hence, we exclude from the analysis price series for brands that were withdrawn from or introduced to a store's shelves at some point between 2005 and 2010, and we also exclude brands that were only intermittently available due to promotions or temporary stock-outs. The result is a balanced panel of 1087 retail price series for individual store-brand combinations.

As summarized in Table 2.1 this sample of butter prices includes series from roughly $90 \%$ of the retail chains and $75 \%$ of the individual retail stores that are covered in the complete scanner dataset. Together these series cover all regions of Germany and account for roughly $25 \%$ of the total butter turnover in the complete dataset.

\footnotetext{
${ }^{7}$ These butter price data are taken from a larger dairy product scanner dataset purchased from IRI. See Loy et al. (2015) for more information on this dataset.
} 
Table 2.1 Descriptive statistics and the representativeness of the sample

\begin{tabular}{|c|c|c|c|c|c|}
\hline & \multirow{2}{*}{$\begin{array}{l}\text { Complete } \\
\text { dataset }\end{array}$} & \multicolumn{2}{|c|}{$\begin{array}{c}\text { Subset: homogenous } \\
\text { product } 250 \text {-gram } \\
\text { package }\end{array}$} & \multicolumn{2}{|c|}{$\begin{array}{c}\text { Subset: only } \\
\text { complete series } \\
\text { (no missing values) }\end{array}$} \\
\hline & & Number & $\begin{array}{l}\text { Share of } \\
\text { complete } \\
\text { dataset (\%) }\end{array}$ & Number & $\begin{array}{l}\text { Share of } \\
\text { complete } \\
\text { dataset (\%) }\end{array}$ \\
\hline Chains & 41 & 37 & 90.2 & 37 & 90.2 \\
\hline Stores & 459 & 349 & 76.0 & 345 & 75.2 \\
\hline Brands & 492 & 77 & 15.7 & 56 & 11.4 \\
\hline Price series & 24368 & 1439 & 5.9 & 1087 & 4.5 \\
\hline Units sold & $199,075,937$ & 48,986,447 & 24.6 & $46,006,635$ & 23.1 \\
\hline Turnover (€) & $194,073,794$ & $49,806,867$ & 25.7 & $46,846,572$ & 24.1 \\
\hline
\end{tabular}

At the wholesale level we employ a weekly weighted average national wholesale price for butter that is quoted by the South German Butter and Cheese Exchange: SBKB (SÜDDEUTSCHE BUTTER UND KÄSE BÖRSE) in Germany. Loy et al. (2015) explain that the SBKB's wholesale price reflects the average price for all distributional channels, and that it can be interpreted as a cost of production or minimum opportunity cost. We use a national weighted average wholesale price because disaggregated wholesale prices are not available, and because we wish to focus on the effects of aggregation and TSP at the retail level.

\subsection{Results and discussion}

\subsubsection{Estimated vertical price transmission with aggregated retail prices}

ADF and KPSS tests (Table 2.2) indicate that both the wholesale price and the average retail price are non-stationary in levels, and stationary in first differences. Furthermore, both the trace and the maximum eigenvalue tests proposed by Johansen (1988) and Johansen \& Juselius (1990) suggest that we can reject the null hypothesis of no cointegration between the wholesale and the average retail butter price. 
Table 2.2 Unit root and cointegration tests for the spatially aggregated butter prices

\begin{tabular}{|c|c|c|c|c|}
\hline \multicolumn{5}{|c|}{ Raw retail prices } \\
\hline Test & Deterministic part & Lags & Value & Critical \\
\hline ADF in levels & Drift & 6 & $\boldsymbol{\tau}=-1.90$ & -2.87 \\
\hline ADF in first difference & Drift & 5 & $\boldsymbol{\tau}=-7.07$ & -2.87 \\
\hline KPSS in levels & Drift & 7 & $\boldsymbol{\mu}=0.85$ & 0.46 \\
\hline KPSS in first & Drift & 6 & $\boldsymbol{\mu}=0.054$ & 0.46 \\
\hline \multicolumn{5}{|c|}{ Wholesale prices } \\
\hline Test & Deterministic part & Lags & Value & Critical \\
\hline ADF in levels & Drift & 4 & $\boldsymbol{\tau}=-2.31$ & -2.87 \\
\hline ADF in first difference & Drift & 3 & $\boldsymbol{\tau}=-6.45$ & -2.87 \\
\hline KPSS in levels & Drift & 5 & $\boldsymbol{\mu}=0.65$ & 0.46 \\
\hline KPSS in first & Drift & 4 & $\boldsymbol{\mu}=0.086$ & 0.46 \\
\hline \multicolumn{5}{|c|}{ Cointegration test } \\
\hline Test & $\mathrm{H}_{0}$ & Lags & Value & Critical \\
\hline \multirow[t]{4}{*}{ Johansen } & $r=0$ & 3 & 51.86 & 19.96 \\
\hline & $\mathrm{r} \leq 1$ & 3 & 5.24 & 9.24 \\
\hline & $r=0$ & 3 & 46.62 & 15.67 \\
\hline & $\mathrm{r} \leq 1$ & 3 & 5.24 & 9.24 \\
\hline
\end{tabular}

Source: Authors' calculations

Table 2.3 presents the results of the estimation of the symmetric ECM (equation (2)) and the asymmetric ECM (equation (3)) with the average retail price. The lag-lengths $\mathrm{k}$ and $\mathrm{l}$ in equations (2) and (3) are determined by the Akaike Information Criterion (AIC). The estimated adjustment parameter in the symmetric model equals -0.350 , which indicates that deviations from the long-run equilibrium are corrected by a factor of 35\% per week. However, the null hypotheses of symmetry can be rejected because the corresponding F statistic with 1 and 310 degrees of freedom equals 10.61 (p-value $=0.001)$. The estimated asymmetric ECM results indicate that positive deviations of the average retail price from the long-run equilibrium (i.e. stretched margins) are corrected by $10 \%$ per week (although the corresponding coefficient, $\alpha^{+}$, does not differ significantly from 0), while negative deviations (i.e. squeezed margins) are corrected by 54\% per week. 
Table 2.3 Results of the estimation of the symmetric and the asymmetric ECM with spatially aggregated prices

\begin{tabular}{cccccc}
\hline \multirow{2}{*}{ Coefficient } & \multicolumn{3}{c}{ Symmetry } & \multicolumn{2}{c}{ Asymmetry } \\
\cline { 2 - 6 } & Estimate & SE & Estimate & SE \\
\hline$\beta_{0}$ & 0.475 & 0.016 & 0.475 & 0.016 \\
$\beta_{1}$ & 0.723 & 0.021 & 0.723 & 0.021 \\
$\varphi$ & -0.0002 & $(0.002)$ & -0.009 & $(0.003)$ \\
$\delta_{1}$ & -0.370 & $(0.064)$ & -0.352 & $(0.06)$ \\
$\delta_{2}$ & -0.245 & $(0.062)$ & -0.268 & $(0.06)$ \\
$\delta_{3}$ & -0.086 & $(0.052)$ & -0.066 & $(0.052)$ \\
$\rho_{1}$ & 0.242 & $(0.108)$ & 0.168 & $(0.110)$ \\
$\rho_{2}$ & -0.028 & $(0.109)$ & -0.063 & $(0.108)$ \\
$\rho_{3}$ & 0.076 & $(0.107)$ & 0.030 & $(0.107)$ \\
$\alpha$ & -0.350 & $(0.057)$ & - & - \\
$\alpha+$ & - & - & -0.098 & $(0.101)$ \\
$\alpha^{-}$ & - & - & -0.539 & $(0.084)$ \\
Sum Squared Residual & \multicolumn{2}{c}{0.444} & \multicolumn{3}{c}{0.431} \\
$\mathrm{R}^{2}$ & \multicolumn{2}{c}{0.407} & \multicolumn{4}{c}{ Sour } \\
\hline
\end{tabular}

Source: Authors' calculations

\subsubsection{Estimated vertical price transmission with disaggregated retail prices}

The typical raw retail butter price series graphed in Figure 2.1 displays many of the key characteristics of retail prices: stickiness, psychological pricing (i.e. prices ending in "9"), and episodes of TSP. Figure 2.2 presents the raw butter price for another randomly selected retail store, the average retail butter price for all of the stores that belong to the same chain ${ }^{8}$, and the average retail butter price over all stores and chains. We see that increasing aggregation progressively masks the stickiness, psychological pricing and TSP which are characteristic of disaggregated retail prices.

\footnotetext{
${ }^{8}$ For each individual store in the scanner dataset, a code number indicates membership in a specific retail chain. However, the dataset does not identify the individual chains.
} 


\section{Figure 2.2 Retail butter prices at different levels of spatial aggregation}

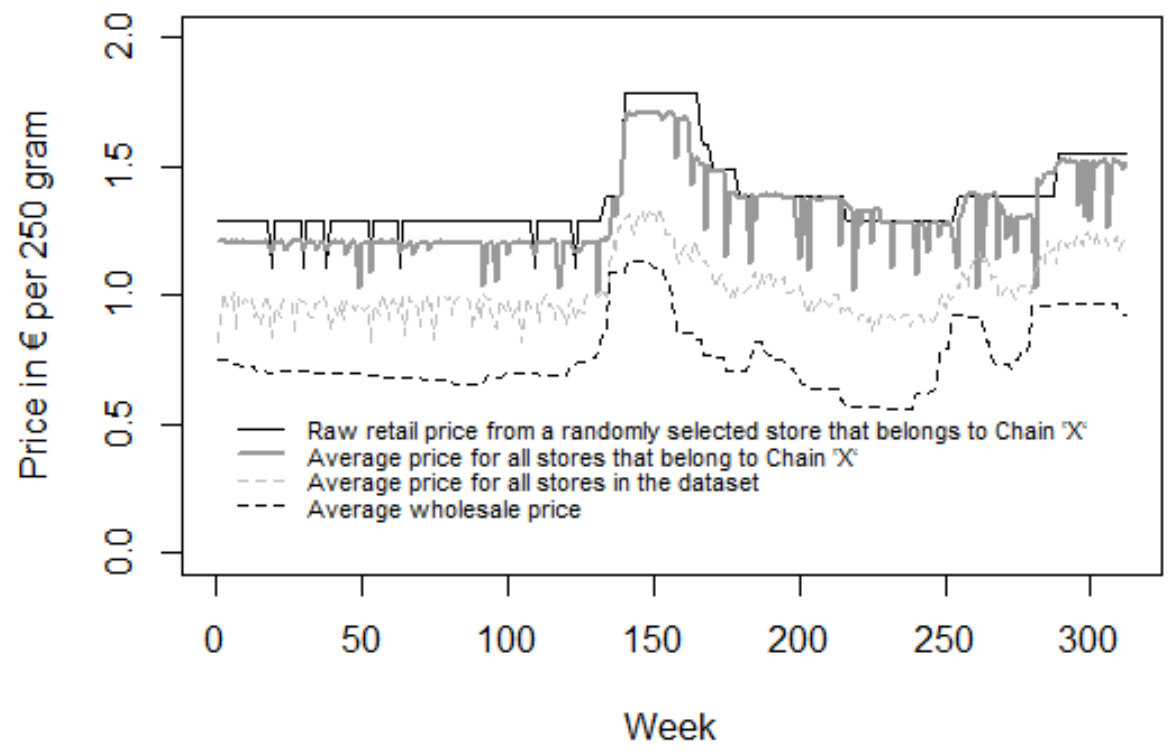

Source: Authors' calculations

Table 2.4 summarizes the results of unit root tests conducted on the 1087 individual raw retail butter prices series and the corresponding filtered prices produced by applying the Chahrour's method. The ADF and the KPSS unit root tests indicate that most of the individual raw retail butter prices are non-stationary in levels and stationary in first differences. This result is even more pronounced for the filtered prices. Although we acknowledge that neither the individual raw retail butter prices nor the corresponding filtered prices are typical random walk processes, we conclude that they are non-stationary and candidates for cointegration with the wholesale price.

Johansen cointegration tests indicate that most of the individual raw retail prices are cointegrated with the wholesale price ( $81.3 \%$ of the raw prices according to the trace test, and $77.8 \%$ according to the eigenvalue test). These shares fall when filtered retail prices are used (to 51.4\% and $41.6 \%$, respectively). This is first evidence that, as hypothesized, removing TSP from retail price data reduces the apparent speed of vertical price transmission. According to the Granger representation theorem (Engle \& Granger, 1987), if two variables are cointegrated, then the adjustment parameter in the corresponding ECM ( $\alpha$ in our notation above) should be significantly different from zero. If filtering out TSP reduces the share of retail prices that are cointegrated with the wholesale price, then it must be increasing the share of prices for which the 
adjustment parameters are not significantly different from zero, i.e. for which price transmission appears to be slower. We confirm this finding below.

Table 2.4 Unit root test results for the individual raw and filtered retail butter prices

\begin{tabular}{|c|c|c|c|c|c|}
\hline & & & & Raw prices & Filtered prices \\
\hline \multirow{3}{*}{$\begin{array}{l}\text { Unit root } \\
\text { tests }\end{array}$} & ADF in levels & & Reject $\mathrm{H}_{0}(\%)^{\mathbf{b}}$ & 14.6 & 0.5 \\
\hline & ADF in first differences & & Reject $\mathrm{H}_{0}(\%)^{\mathbf{b}}$ & 100 & 100 \\
\hline & KPSS in levels & & Reject $\mathrm{H}_{0}(\%)^{\mathbf{b}}$ & 84.1 & 91.9 \\
\hline \multirow{5}{*}{$\begin{array}{l}\text { Cointegrat } \\
\text { ion tests }\end{array}$} & KPSS first differences & & Reject $\mathrm{H}_{0}(\%)^{\mathbf{b}}$ & 0 & 0 \\
\hline & Johansen: Trace test & $r=0$ & Reject $\mathrm{H}_{0}(\%)^{\mathbf{b}}$ & 81.3 & 51.4 \\
\hline & & $r \leq 1$ & Reject $\mathrm{H}_{0}(\%)^{\mathbf{b}}$ & 4.2 & 5.2 \\
\hline & Johansen: Eigenvalue test & $r=0$ & Reject $\mathrm{H}_{0}(\%)^{\mathbf{b}}$ & 77.8 & 41.6 \\
\hline & & $\mathrm{r} \leq 1$ & Reject $\mathrm{H}_{0}(\%)^{\mathbf{b}}$ & 4.2 & 5.2 \\
\hline
\end{tabular}

Notes: Lag selection for all tests based on the AIC criterion.

a: Price series filtered using the Chahrour (2011) method to remove temporary sales prices.

b. The share (in \%) of the 1087 price series for which the null hypothesis can be rejected at the $5 \%$

Source: Authors' calculations

We next estimate the ECMs in equations (2 - symmetric) and (3 - asymmetric) for each of the 1087 individual raw retail prices with the wholesale price, and for each of the corresponding filtered prices with the wholesale price. Results are presented in Table 2.5.

Turning first to the results for the symmetric ECMs we see that the average adjustment parameter estimated with the raw prices has a higher mean (0.257) than the average adjustment parameter estimated with the corresponding filtered prices (0.089). Figure 2.3 shows that the distribution of the adjustment parameters estimated with raw data not only has a higher mean, but also includes many much larger values than the distribution of the adjustment parameters estimated with filtered prices. For example, 50\% of the adjustment parameters estimated with raw prices are greater than 0.21 ; for the filtered prices this proportion is only $8 \%$. As hypothesized therefore, vertical price transmission appears to be more rapid when raw retail prices are used, and less rapid when these prices are filtered to remove TSP. 
Table 2.5 Results of the estimation of symmetric and asymmetric vector error correction models with raw and filtered retail prices

\begin{tabular}{|c|c|c|}
\hline & Raw prices & Filtered prices \\
\hline \multicolumn{3}{|c|}{ Mean coefficients (share that differ from 0 at the $5 \%$ level) } \\
\hline$\alpha$ (symmetric ECM) & $-0.257(96 \%)$ & $-0.089(90 \%)$ \\
\hline Intercept (asymmetric ECM) & $-0.020(63 \%)$ & $-0.002(11 \%)$ \\
\hline$\alpha^{+}$(asymmetric ECM) & $-0.050(15 \%)$ & $-0.053(23 \%)$ \\
\hline$\alpha^{-}$(asymmetric ECM) & $-0.494(93 \%)$ & $-0.135(72 \%)$ \\
\hline \multicolumn{3}{|c|}{ Test of symmetry (share of rejections of symmetry) } \\
\hline $\mathrm{H}_{0}$ : Symmetry $\alpha^{+}=\alpha$ & $78 \%$ & $26 \%$ \\
\hline \multicolumn{3}{|l|}{ Diagnostic tests ${ }^{\text {a }}$} \\
\hline ARCH-LM (\%) & 62 & 88 \\
\hline Breusch-Godfrey 5 lags (\%) & 18 & 12 \\
\hline Box-Ljung. 15 lags (\%) & 7 & 4 \\
\hline Jarque-Bera (\%) & 100 & 100 \\
\hline
\end{tabular}

Figure 2.3 The distribution of the adjustment parameters in 1087 symmetric ECMs that link the wholesale price to raw retail prices, and in 1087 ECMs with the corresponding filtered prices

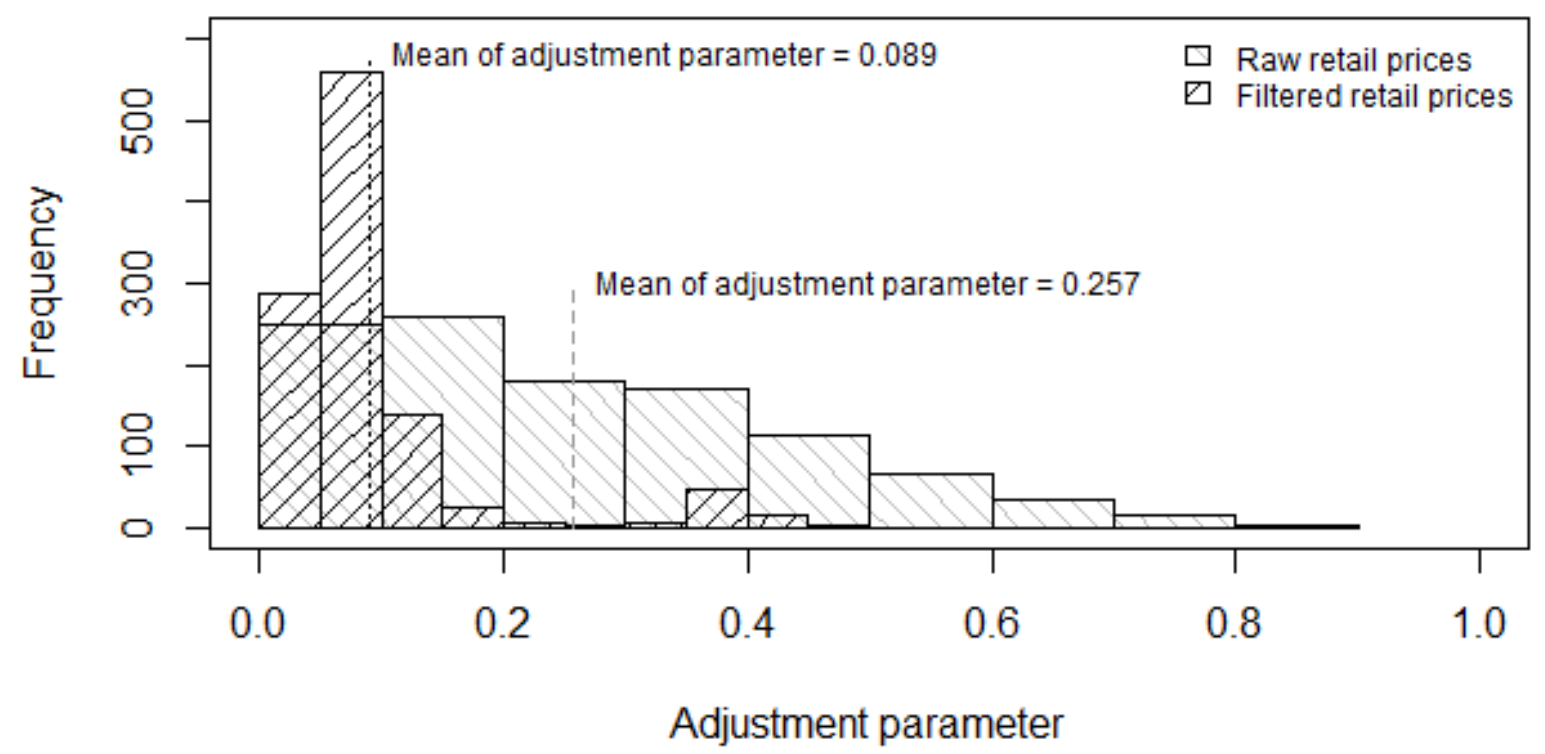

Source: Authors' calculations

The results in Table 2.5 also confirm the second hypothesis formulated above, which is that TSP bias the results of vertical price transmission analysis towards findings of asymmetry. The null hypothesis of symmetry ( $\alpha^{+}=\alpha^{-}$in equation (3)) can be rejected at the $5 \%$ level in $78 \%$ of the 
asymmetric $E C M$ estimated with raw retail prices; this proportion falls to $26 \%$ when filtered prices are employed instead.

How do TSP create the impression of asymmetric vertical price transmission? As argued above, each episode of TSP adds a sharp downward spike or 'valley' to price data. When a TSP is introduced, the retail price falls and the retail margin is squeezed, leading to a negative value of $E C T$. When the TSP is terminated in the next period, the retail price returns to its original level and it appears as if the negative ECT has been corrected rapidly and fully. Hence, each episode of TSP adds to the estimation of an asymmetric ECM a negative value of ECT that is rapidly and fully corrected. Together, these episodes will therefore bias upward the estimated value of $\alpha^{-}$, the coefficient that measures the speed with which negative values of ECT are corrected. Since TSP only add 'valleys' and no 'peaks' price data, they only affect $\alpha^{-}$in this manner.

This effect is illustrated in Figure 2.4 for the same retail price series that is depicted in Figure 2.1. Each panel of Figure 2.4 plots the change in the raw retail price in period $t\left(\Delta P_{t}^{R}\right)$ against the error correction term in the previous period $\left(E C T_{t-1}\right)$; the left panel for the raw retail price, and the right panel for the corresponding filtered price. Ignoring the other terms in the ECM in equation (3), the relationship between $E C T_{t-1}$ and $\Delta P_{t}^{R}$ determines the estimates of $\alpha^{+}$and $\alpha^{-}$. Comparing the two panels we see that the pattern of individual data points differs considerably. In both panels observations for which $\Delta P_{t}^{R}=0$ predominate, reflecting the stickiness of retail prices. However, in the bottom middle of the left panel there are several larger negative $\Delta P_{t}^{R}$ values corresponding to small positive and negative values of $E C T_{t-1}$; these observations are created by the introduction of a TSP. Moreover, at the top left of the left panel there are several large positive values of $\Delta P_{t}^{R}$

corresponding to large negative values of $E C T_{t-1}$; these observations result when a TSP is terminated. Together, these observations increase the likelihood of finding asymmetry by biasing $\alpha^{-}$upward, an effect which disappears in the right hand panel when filtered prices are used to estimate the $E C M$. When a symmetric $E C M$ is estimated with these data, the result is an estimate of $\alpha$ that is a weighted average of $\alpha^{+}$and $\alpha^{-}$. This average will be larger for the raw data in the left panel of Figure 2.4 than it is for the filtered data in the right panel. As a result, vertical price transmission will appear to be more rapid for the raw than for the filtered data. 
Figure 2.4 The effect of temporary sales prices on estimates of asymmetric price transmission with a typical retail price series

Raw retail price

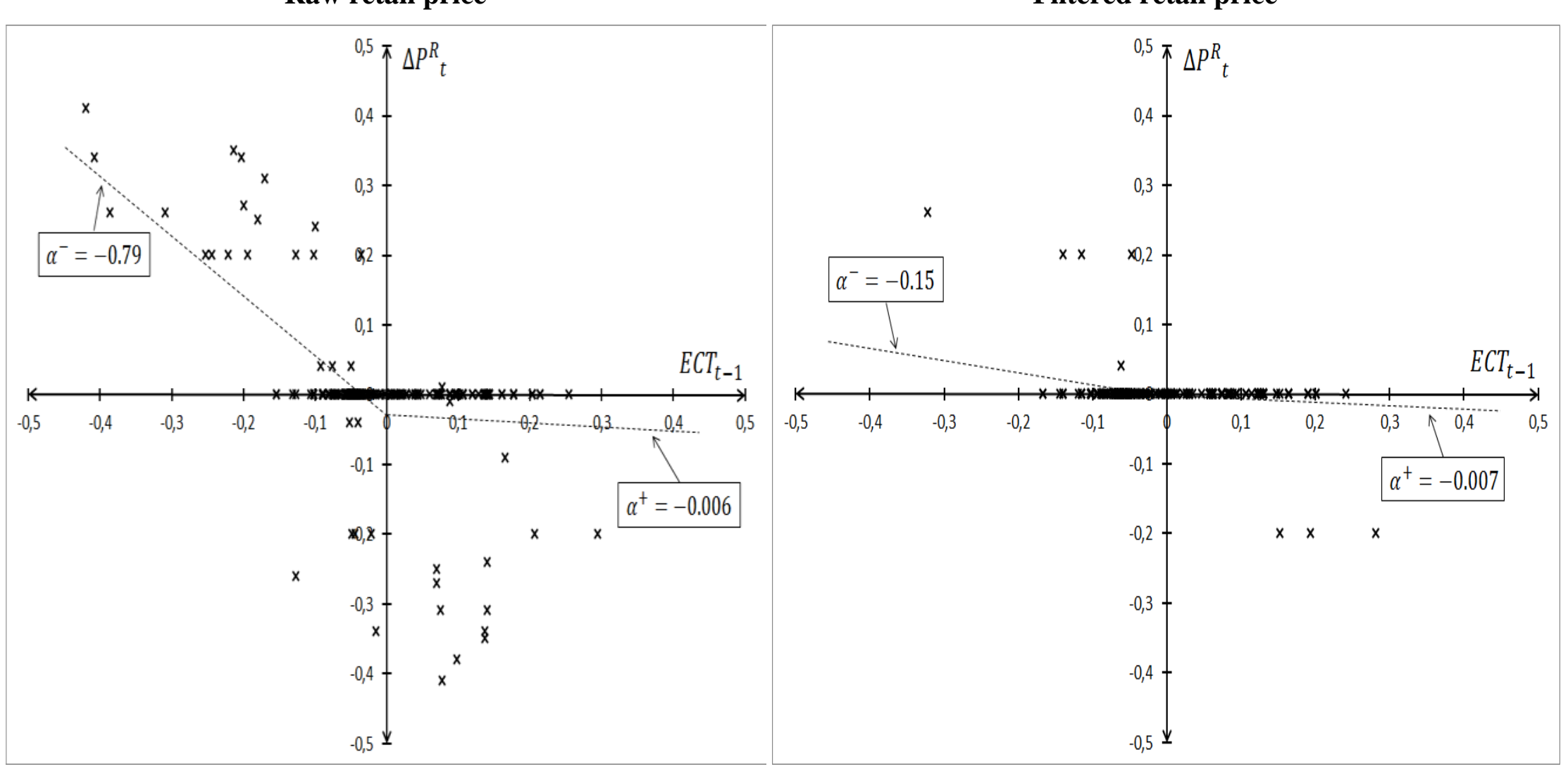

Source: Authors’ calculations
Filtered retail price 


\subsection{Conclusion}

The results presented above confirm that temporary sales prices can affect the results of empirical price transmission analysis. In particular, temporary sales prices make vertical price transmission appear more rapid and increase the likelihood that it will appear to be asymmetric. We demonstrate this effect using scanner data on butter retail prices in Germany, and we propose an explanation for it. Of course, our results are limited to butter prices, and future work will have to determine to what extent they can be generalized. For instance, if different types of retail store (discounters and hypermarkets, for example) and different retail chains pursue different pricing strategies, this might be reflected in hierarchical dependencies in the relationship between temporary sales pricing and estimates of vertical price transmission.

Our findings add a potential cause of asymmetry to those causes, such as market power, that have already been identified in the literature (Frey \& Manera, 2007; Meyer \& CramonTaubadel, 2004). The asymmetry that temporary sales prices create is of the 'rockets and feathers' variety, i.e. it appears that retail prices shoot up rapidly when the retail margin is squeezed, but fall less rapidly when the retail margin is stretched. Hence, the asymmetry caused by temporary sales prices is of the same type as is often attributed to the abuse of market power in the food chain. In the future, therefore, any findings of asymmetric vertical price transmission in disaggregated retail price data should first be checked for possible bias due temporary sales prices before possibly unfounded conclusions are drawn about competition and market power. 


\subsection{References}

Chahrour, R. A. (2011). Sales and price spikes in retail scanner data. Economics Letters, 110(2), 143-146.

Eichenbaum, M., Jaimovich, N., \& Rebelo, S. (2011). Reference Prices, Costs, and Nominal Rigidities. American Economic Review, 101(1), 234-262.

Engle, R. F., \& Granger, C. W. J. (1987). Co-Integration and Error Correction: Representation, Estimation, and Testing. Econometrica, 55(2), 251-276.

Frey, G., \& Manera, M. (2007). Econometric Models of Asymmetric Price Transmission. Journal of Economic Surveys, 21(2), 349-415.

Granger, C. W. J., \& Lee, T. H. (1989). Investigation of production, sales and inventory relationships using multicointegration and non-symmetric error correction models. Journal of Applied Econometrics, 4(S1), S145-S159.

Hosken, D., \& Reiffen, D. (2001). Multi-Product Retailers and the Sale Phenomenon. Agribusiness, 17(1), 115-137.

Hosken, D., \& Reiffen, D. (2004). Patterns of retail price variation. RAND Journal of Economics, 35(1), 128-146.

Johansen, S. (1988). Statistical analysis of cointegration vectors. Journal of Economic Dynamics and Control, 12(2-3), 231-254.

Johansen, S., \& Juselius, K. (1990). Maximum Likelihood Estimation And Inference On Cointegration - With Applications to the Demand for Money. Oxford Bulletin of Economics and Statistics, 52(2), 169-210.

Kehoe, P. J., \& Midrigan, V. (2007). Sales and the real effects of monetary policy. Working Papers.

Loy, J.-P., Holm, T., Steinhagen, C., \& Glauben, T. (2015). Cost pass-through in differentiated product markets: a disaggregated study for milk and butter. European Review of Agricultural Economics, 42(3), 441-471.

Meyer, J., \& Cramon-Taubadel, S. (2004). Asymmetric Price Transmission: A Survey. Journal of Agricultural Economics, 55(3), 581-611.

Nakamura, A. O., Nakamura, E., \& Nakamura, L. I. (2011). Price dynamics, retail chains and inflation measurement. Journal of Econometrics, 161(1), 47-55.

Nakamura, E. (2008). Pass-Through in Retail and Wholesale. American Economic Review, 98(2), 430-437.

Nakamura, E., \& Steinsson, J. (2008). Five Facts about Prices: A Reevaluation of Menu Cost Models. Quarterly Journal of Economics, 123(4), 1415-1464.

Peltzman, S. (2000). Prices Rise Faster than They Fall. Journal of Political Economy, 108(3), 466-502.

Powers, N. J. (1995). Sticky short-run prices and vertical pricing: Evidence from the market for iceberg lettuce. Agribusiness, 11(1), 57-75.

SBKB. (2011). Weekly wholesale prices. Süddeutsche Butter- und Käse-Börse e.V. Kempten (Allgäu).

Schroeder, T. C. (1988). Price linkages between wholesale and retail pork cuts. Agribusiness, 4(4), 359-369.

Schwartz, L. a, \& Schertz Willet, L. (1994). Price Transmission Theory and Applications To Agroidustry:an Annotated Bibliography. New York, 04(June).

von Cramon-Taubadel, S. (1998). Estimating asymmetric price transmission with the error correction representation: An application to the German pork market. European Review of Agricultural Economics, 25(1), 1-18.

von Cramon-Taubadel, S., Loy, J.-P., \& Meyer, J. (2006). The impact of cross-sectional data aggregation on the measurement of vertical price transmission: An experiment with 
German food prices. Agribusiness, 22(4), 505-522.

\title{
3. Factors explaining asymmetric price transmission from wholesale to retail prices
}

\begin{abstract}
Academic research has recently started to use disaggregated scanner data to assess the vertical price transmission (VPT) from wholesale to retail prices. The current findings point towards considerable variations in price dynamics and asymmetries in VPT across products, stores, and chains. In this contribution, we instigate why VPT for the same product is symmetric within some retail chains and asymmetric within others. Asymmetry in VPT is commonly assumed to result from retailers' exercise of market power regardless of their heterogeneity in pricing strategies. Instead of this generic explanation, we hypothesize that asymmetry in VPT depends on store membership to a specific chain and that market power expresses itself in the adoption of a specific pricing strategy, namely: Every Day Low Pricing or High-Low, which in turn can lead to different outcomes, including asymmetries in VPT. We employ price rigidity and consumer search costs to approximate the pricing strategy for each retail store. We employ multilevel modeling to explore the hierarchical structure of scanner data in order to gain insight into the heterogeneity in the prevalence of asymmetries in VPT. Multilevel models allow for the systematic distinction between the stores/chains that are likely to employ asymmetries in VPT and those that do not. Our results show that when consumer search costs increase within a hypermarket setting, a store format where consumers expect to benefit from search and hypermarkets respond adequately, resulting in a decrease in the likelihood of asymmetry in VPT. Further, we find that when chains that employ HiLo mimic chains that employ EDLP and display rigid prices, to avoid markup variation because they can, then price rigidity leads to an increase in the likelihood of asymmetries in VPT.
\end{abstract}

Keywords: asymmetry, vertical price transmission, hierarchical data, multilevel models and Bayesian statistics. 


\subsection{Introduction}

It is common in studies of market integration to check for the presence of asymmetries in vertical price transmission (VPT) ${ }^{9}$. Findings of asymmetries in VPT is associated to consumer welfare loss and has important policy implications. According to Peltzman's conclusion, if asymmetry in VPT is the rule rather than the exception, then it is an indication of widespread market failure or the presence of a gap in economic theory (Peltzman, 2000). This is intriguing because there is ample evidence of the prevalence of asymmetries in VPT in empirical VPT literature (Frey \& Manera, 2007). The common explanations for the prevalence of asymmetry include market power, menu costs (Azzam, 1999), consumer search costs (Tappata, 2009; Yang \& Ye, 2008), and other reasons such as government intervention (Meyer \& Cramon-Taubadel, 2004; Vavra \& Goodwin, 2005). Nonetheless, given that most of the previous studies have been conducted at the national/regional level, we know very little about the reasons behind the prevalence of asymmetries in VPT at the smallest possible scale of the value chain, i.e. the individual retail store.

It has only been recently that academic research has started to use disaggregated (scanner) data to assess VPT from the wholesale to the retail level. This signifies the change towards reconsidering retailers' market power in explaining the prevalence of asymmetries in VPT (Loy et al., 2015; Richards et al., 2014). An alternative to the retailer's market power explanation is considering consumer's rational search behavior and retailers' response to it (Tappata, 2009; Yang \& Ye, 2008; Yuan \& Han, 2011). Namely, retail prices increase rapidly when wholesale prices increase because rational consumers search more intensively, however, retail prices fall more slowly when wholesale prices fall as retailers decrease their prices only enough to cause consumers to not search for new prices. Richards et al. (2014) empirically confirm this hypothesis. Retailers react to consumers' limited information about cost shocks by setting rigid prices, which limits their markup variation (Eichenbaum et al., 2011). Concurrently, retailers do not change their prices every time they face cost shocks. Moreover, the role of double marginalization and middleman costs for national brands in explaining the prevalence of asymmetric pricing has been explained theoretically (Hong \& Li, 2015) and tested empirically (Loy et al., 2015).

\footnotetext{
${ }^{9}$ For this study we only test for the differences between the speed of adjustment toward the long rung equilibrium of price movement that squeezes the marketing margin (i.e. an increase in retail prices or a fall in wholesale prices) compared to the price movement that stretches it.
} 
In a pioneering study that investigates VPT using scanner data and focuses on a European market, Loy et al. (2015) shed light on many aspects that explain variations in retail price dynamics. Factors such as consumer search costs, differences between manufacturers in the German dairy sector (cooperatives versus non-cooperatives), and branding (national brands versus private labels) can explain the heterogeneity among the retail chains in the application of asymmetries in VPT (Loy et al., 2015). However, Loy et al. (2015) do not account for an important feature of scanner data, which is its hierarchical structure. This is curious because store membership in a chain might lead to differences in outcomes of pricing dynamic within a chain and between chains.

Working with scanner data requires specific terminology. Hereafter, a chain is defined as a retailer with a specific trademark name, e.g. Lidl and Aldi in Germany, which manages a given number of stores and a specific merchandise assortment. The chains are grouped into different classes such as those who specialize only in food or those who include a variety of non-food products. We refer to a store as being the location where different products are sold with a self-service system, but with different search environments for their customers. Stores can be of different formats, including, but not limited to, discount store, supermarket, and hypermarket.

Consider a homogeneous and well-defined product P1 that is sold in four different retail stores: $\mathrm{X} 1$ and $\mathrm{X} 2$ belonging to retail Chain $\mathrm{X}$ and $\mathrm{Y} 1$ and $\mathrm{Y} 2$ belonging to retail Chain $\mathrm{Y}$. To illustrate, the stores $\mathrm{X} 1$, Y1 could be a discount store format, and X2, Y2 could be supermarkets; additionally, each of the retail Chain $\mathrm{X}$ and Chain $\mathrm{Y}$ could follow a specific pricing strategy, e.g. Every Day Low Pricing (EDLP), High-Low (HiLo). The result is not only that these differences lead to a price dispersion for $\mathrm{P} 1$, but also in variations in price dynamics; thus the extent to which these stores display asymmetry in VPT for P1. While price dispersion, when P1 is sold at different prices in different stores, is well documented in empirical studies (Anania \& Nisticò, 2014), variations in retail price dynamics have not been sufficiently explained to date (Loy et al., 2015).

Food retailing is complex, and so are the pricing strategies followed by retail chains and stores. Food retail chains exercise different degrees of negotiation power with processors/wholesalers, depending on the structure of the retail sector in a country, the consolidation, and the competition (Jansik et al., 2014). Li et al. (2006) find inconsistency in trying to link the economic models of perfect competition to the prevalence of asymmetry in 
VPT in agro-food products. Li et al. (2006) argue that market power expresses itself in the adoption of a specific pricing strategy that can lead to different outcomes, including the presence or absence of asymmetry in VPT. Owen \& Trzepacz (2002) provide some evidence of a link between asymmetries in the incidence and the magnitude of price changes and Every Day Low Pricing (EDLP) and High-Low (HiLo) strategies.

This leads to two questions. First, whether the observed heterogeneity in price dynamics for homogenous products across stores is due to the fact that stores are of different formats that imply variant consumer search intensities and influence price dynamics. Second, to what extent is observed heterogeneity in price dynamics across stores due to their membership in different chains pursuing different pricing strategies.

We employ multilevel modeling to explore the hierarchical structure of scanner price data to gain insight into the heterogeneity in use resulting in asymmetries in VPT. A specific focus is on determining the features of retail chains that contribute to the decrease or the increase in the likelihood of finding asymmetry in VPT. As a case study, we assess VPT for 56 welldefined brands of 250-gram foil-wrapped butter in Germany. We measure VPT between their respective individual retail prices at 345 different stores that belong to 37 different retail chains and we calculate the VPT for the weighted average wholesale prices of butter in Germany. Individual brands of butter are identified by European Article Number (EAN) data, which is an exact identifier of each product at each store. The brand-store combinations in our data result in 1087 different EANs. We then employ a Bayesian approach for model estimation as a flexible tool to include random effects at each level of the hierarchy, which can in turn explain the unobserved heterogeneity in the prevalence of asymmetries in VPT.

Unlike Owen \& Trzepacz (2002), who study two chains and knew exactly which pricing strategy was followed in each chain, we were unable to directly document pricing strategy in our study. Nevertheless, we could approximate the pricing strategy followed in each retail chain based on established links in the literature between EDLP and HiLo pricing strategies, the different formats of stores combined with price rigidity for each EAN and consumer search costs in each store. More specifically, discount stores, which typically employ EDLP, represent a lower search cost environment than the other formats of stores, such as hypermarkets, which typically employ HiLo. Prices are expected to be more rigid for EANs subject to EDLP than the EANs that are subject to HiLo, which can vary among the different formats of stores, and between national and private brands. 
Our results confirm that an increase in consumer search costs lead to an increase in the likelihood of asymmetry in VPT. Further, we do not find systematic differences between the different formats of store. However, when linking consumer search costs to the different formats of store, we find an increase in search costs within hypermarkets, where consumers would expect to benefit from the search; and the hypermarkets respond adequately, as it leads to a decrease in the likelihood of asymmetry in VPT. Surprisingly, high price rigidity implies a decrease in asymmetry in VPT. However, this is the case only within chains that follow EDLP. When hypermarkets and supermarkets keep their prices constant and do not react to changes in the wholesale price to avoid markup variations, rigid prices lead to the increase in likelihood of asymmetry in VPT. Moreover, the differences between the 56 products explain $51 \%$ of the variance in the occurrence of asymmetries in VPT. We find that asymmetries in VPT are equally prevalent for both products with national brands and private labels; thus double marginalization does not necessarily lead to asymmetries in VPT. The differences between the 37 retail chains explain 9.25\% of the variance in the occurrence of asymmetries in VPT. The differences between stores explain only $0.22 \%$ of the variance in the occurrence of asymmetries in VPT.

Our contributions to the literature are twofold. First, we study the reasons behind asymmetries in VPT at the smallest possible scale, i.e., the individual retail store. This is not the first study that focuses on disaggregated data to investigate VPT, but to the best of our knowledge, it is the first time that explicitly accounts for the hierarchical structure of scanner data, which allows us to separate systematically between the chains that are likely to employ asymmetries in VPT from the chains that are not. Second, we reveal that asymmetries in VPT are systematically related to store membership in a chain, to the different store formats and some other indicators of pricing strategies, such as rigid prices and consumer search costs.

The remainder of this correspondence is organized as follows. In Section 3.2, we give an overview of the German dairy market, and show that it is concentrated both at the processing and retail levels forming a bilateral oligopoly that can lead to asymmetries in VPT. In Section 3.3, we briefly review the literature on VPT studies that test for the presence of asymmetries in VPT at the disaggregated level and underline some hypotheses regarding the possible explanation of their presence. In Section 3.4, we describe the data and we explain how we test for the presence of asymmetry in VPT. In Section 3.5, we explain our motivation for the choice of methods that we employ to estimate whether asymmetry can be explained by store 
characteristics such as their format, search costs and degree of price rigidity. In Section 3.6, we discuss our results and in Section 3.7 we conclude.

\subsection{Processing and retailing of dairy products in Germany}

The dairy processor-retail link in the milk chain is a bilateral oligopoly in Germany. This can lead to many different outcomes, e.g. asymmetries in VPT, depending on the individual and/or collective behavior of the actors. Dairies in Germany face low profit margins and often find themselves in a cost-price squeeze between milk prices and output prices that are unsatisfactory. This is due to the special structure of the German retail sector (Jansik et al., 2014), which is highly concentrated and characterized by the dominance of discounters (Loy et al., 2015). In addition, German consumers are price sensitive. Therefore dairy products, including butter, are often used by retailers as loss leaders to attract customers into the stores (Loy et al., 2015; Rondán et al, 2005).

\subsubsection{Processing and manufacturing}

The German dairy industry is the largest in Europe, with sale revenues exceeding 25 billion EUR in 2014. The concentration ratio (CR4), calculated as the market share of the four largest dairy companies is $31 \%$. The total revenues of the ten leading dairy companies in Germany totaled 10.95 billion Euros in 2014 and the four largest of these companies accounted for $70 \%$ of the 10.95 billion Euros, see Figure 3.1 .

Figure 3.1 Revenue of the leading dairy companies in Germany in 2014

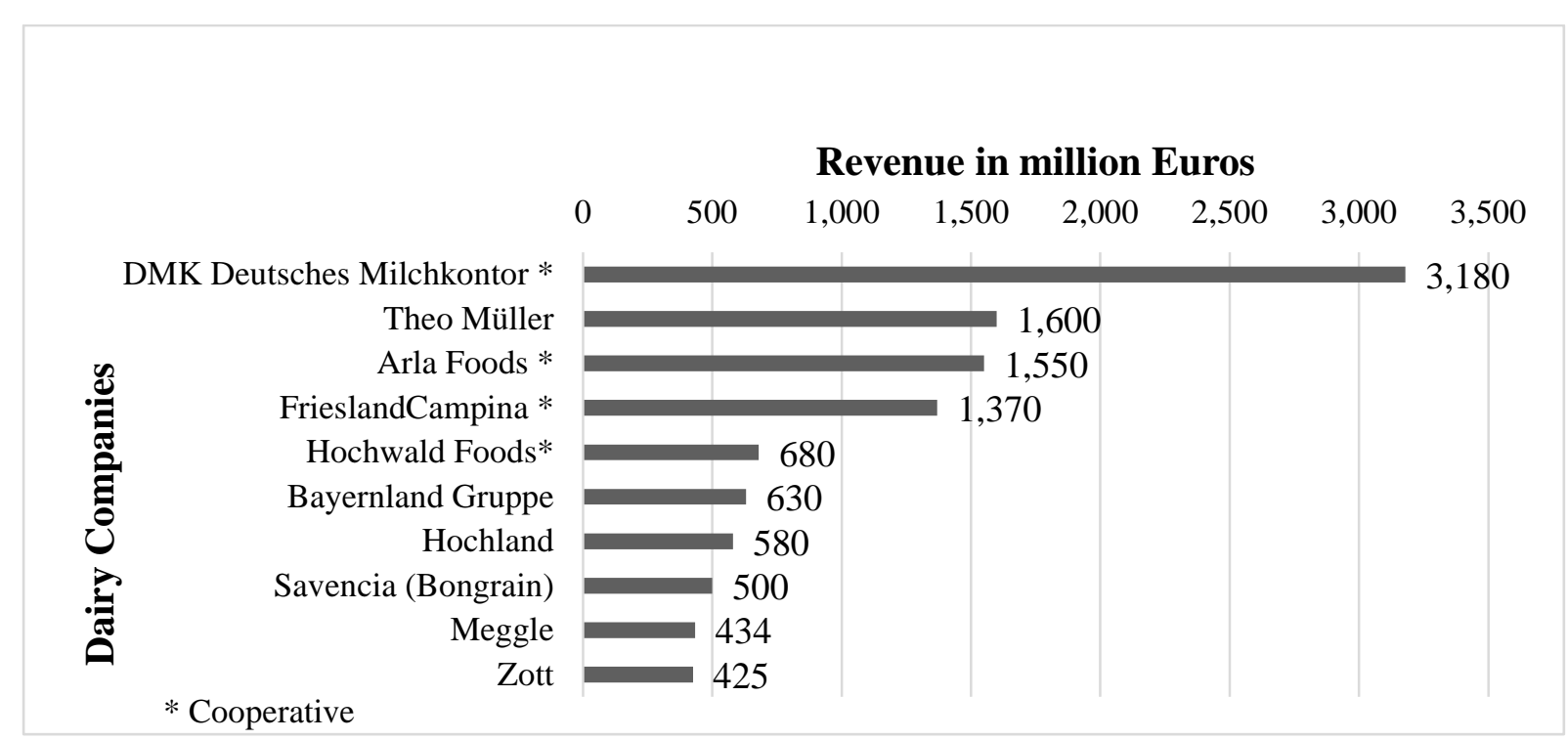

Source: Lebensmittel Zeitung (2014)

Dairy products, including butter which entails 30\% of the processed milk in Germany (Loy et al. 2015), are supplied by cooperatives and non-cooperatives. Four (Deutsches Milchkontor, 
Arla Foods, FrieslandCampina and Hochwald Foods) of the six leading dairy companies in Germany in terms of revenue are cooperatives (Lebensmittel Zeitung, 2014). The majority of the cooperatives are located in north-western regions of Germany. In general, German dairy cooperatives focus on exploiting economies of scale and achieving cost leadership, producing high-volumes of standard products, such as milk powder and butter, which are often sold with private labels at low prices (Everwand et al., 2007; Loy et al., 2015).

The non-cooperatives are mostly private companies or family-owned firms, most of which are located in Southern Germany (e.g. Bavaria). The non-cooperative dairy companies focus more on manufacturing differentiated products with high value-added and national brands, and sell them at higher prices than the standard products of the cooperatives (Loy et al., 2015). However, they face higher costs (52 cents per kg) compared to the other regions (43 cents per kg in the north) (Jürgens et al., 2013).

In terms of downstream relationships, both cooperative and non-cooperative dairies work with supplier contracts, under exclusivity requirements, with farmers. Contracts in the case of cooperatives last for one to two years. In the case of non-cooperatives, the length of contracts can vary from one to five years and sometimes ten years. The middleman activity is present downstream. It is exercised by specialized trading companies such as the Berliner Milcheinfuhr-Gesellschaft, which collects one million kg of raw milk per year and resells it to the dairies for processing (Jansik et al., 2014).

\subsubsection{Relation to the retail sector and vertical integration}

The share of dairy production which is sold directly from dairies to the retailer sector is $44 \%$. The remaining part is split between the hotel, restaurant and catering sector (Friedrich, 2010) and the food processing industry. Figure 3.2 illustrates the high concentration of food retailing in Germany. In 2014, the share of the top four food retail chains (Edeka, Rewe, Schwarz/Lidl, Aldi) in the sector's turnover was 57\% (BVE, 2014).

Processing margins are considered to be low in the German dairy industry. Jansik et al. (2014) compare the dairy sectors of Denmark, Estonia, Finland, Germany, Latvia, Lithuania, Poland and Sweden, and find Germany to be characterized by the lowest profit margins in Northern Europe. They relate these low profits to the exercise of price pressure at the retail level, in particular via the private labels, where more than $50 \%$ of the consumed butter in Germany carries a private label (Friedrich, 2010). Nonetheless, the advantages that retailers might have in terms of exercising negotiation power with the dairies are not automatically 
translated into high margins at the consumer level, because of the price sensitivity of consumers in Germany (Hellberg-Bahr et al. 2010; Jansik et al., 2014; Loy et al. 2015).

Figure 3.2 Market structure in the German food retail sector, 2014

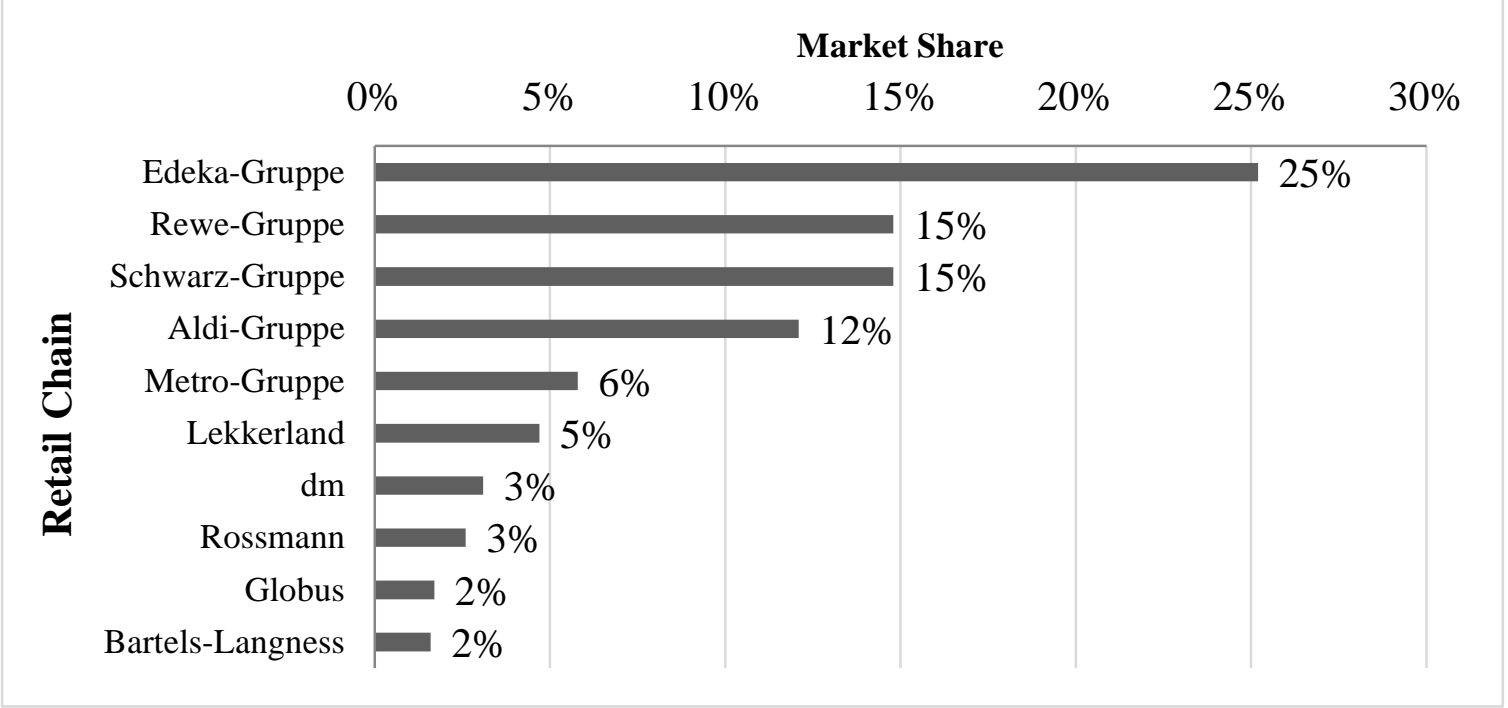

Source: (BVE, 2014)

Moreover, the exercise of market power is linked to the format of store (Weber \& Anders, 2007). The stores can be classified into different formats, according to their size and the product assortment managed by each store. Three formats of stores are dominant in Germany: discounters, supermarkets and hypermarkets ${ }^{10}$. Discount stores account for $39 \%$ of German food retail revenues in 2014 (Jansik et al., 2014), a share that has been increasing steadily (Herrmann et al., 2009). Germany is the origin of the discount store concept (Cleeren et al., 2010). To be classified as a discount store, the discount principle is applied irrespective of the volume of sales (Herrmann et al., 2009). Discounters offer a limited number of SKUs; hence limited search costs for consumers. They assure low prices by offering very basic services to their customers (Cleeren et al., 2010; Herrmann et al., 2009; Loy et al., 2015; Morschett et al., 2006). Supermarkets account for $28 \%$ of retail food sales in Germany. They are defined in Herrmann et al., (2009, p. 2) as : “The smallest modern food-retailing store”. Supermarkets specialize exclusively in food and provide more services to their customers than the discounters (Loy et al., 2015) and their sales area size does not exceed $799 \mathrm{~m} 2$. Supermarkets offer a broader number of SKUs than the discounters, which can lead to higher search costs for the consumers. The national brands are also predominant in product assortments of

\footnotetext{
10 Other store formats include are small (large) consumer markets, with sales area of $800-1,499 \mathrm{~m}^{2}(1,500-$ $4,999 \mathrm{~m}^{2}$ ). Since we work with complete time series, the subsample does not include these types of stores.
} 
supermarkets. Hypermarkets account for $24 \%$ of food retail sales in Germany. To be classified as a hypermarket, a store should be at least 5,000 m2. Hypermarkets offer a broad variety of merchandise, with much higher number of SKUs than discounters. They supply both private labels and national brands. They offer considerable customer services, including salespeople to assist customers personally. They are usually organized into separate departments for displaying merchandise, e.g. dairy products, but with relatively high consumer search costs because of the large number of SKUs (Rondán et al., 2005; Gijsbrechts et al., 2008).

The seminal paper of Hoch et al.(1994), which links generating profits in retail industry and the adoption of EDLP versus HiLo, has generated a great interest to document these pricing strategies in details, both theoretically (Hellberg-Bahr et al., 2010; Kaltcheva et al., 2013) and empirically (Bolton \& Shankar, 2003; Ho, Tang, \& Bell, 1998; Lal \& Rao, 1997). Fassnacht \& El Husseini (2013) provide a literature review of pricing strategies and report on the current status of academic research in classifying the different pricing strategies.

A link between the positioning of each of the aforementioned different formats of stores described above and a specific marketing strategy has been documented in the literature (Gijsbrechts, Campo, and Nisol 2008, Cleeren et al. 2010). For instance, a link between the discount stores and EDLP has been found (González-Benito, et al., 2014, p. 118; Hoch et al., 1994, p. 16; Weber \& Anders, 2007). In contrast, supermarkets and hypermarkets tend to follow the HiLo strategy (Rondán Cataluña et al., 2005, p. 331; Weber \& Anders, 2007, p. 739). Sometimes retail chains, that employ the HiLo strategies, add discount stores that employ the EDLP strategy to their portfolio to compete with discounters (Cleeren et al., 2010).

To sum up, relatively few dairies sell their products to relatively few retailers in Germany, which creates a complex bilateral oligopoly situation with potential for non-competitive price determination. Since the food retail chains differ considerably in many aspects, including their structure and their pricing strategies, the question is whether or not this affects the price transmission from wholesale to retail prices. More specifically, what would be the expected effects of EDLP employed by discount stores in comparison HiLo employed by supermarkets and hypermarkets. The adoption of EDLP implies more of a focus on low price private labels, with limited search costs. These are typical characteristics of the discount stores. Thus, we 
expect to find less prevalence of asymmetries in VPT within retail chains that follow EDLP strategy than the retail chains that follow HiLo.

\subsection{Related literature on the factors that explain asymmetry in VPT}

\subsubsection{Studies of asymmetry in the VPT at the smallest possible scale}

Few papers have studied asymmetry in VPT using disaggregated retail price data. One reason for the scarcity of studies in the literature is perhaps the lack of data available for academic research. Even when the data are available, they cover a very limited number of chains (Nakamura, 2008), and sometimes just only a single chain is covered based on proprietary data with limited access. Without coverage across many store formats and chains, it is not feasible to analyze whether differences in the prevalence asymmetries in VPT is due to differences between store and chains.

In a seminal study, Peltzman tries to generalize the asymmetry phenomenon: "In two out of three markets, output prices rise faster than they fall" (Peltzman, 2000, p. 480). The data he analyses include prices from a large supermarket chain in the Chicago area. However, in trying to link asymmetry in VPT to the exercise of market power by retailers, he finds no strong patterns. More recently, Richards et al. (2014) argue that there must be alternative explanations for the pervasiveness of observing asymmetry in VPT.

Why might we expect that stores of different formats or belonging to different chains are more or less likely to display asymmetries in VPT? We hypothesize that there are four main factors associated with store format and chain that can influence the asymmetry of their VPT. These factors are price rigidity, double marginalization, consumer search costs, and pricing strategy. Additionally, the effects of the different formats of stores on findings of asymmetry in VPT cannot be easily separated from the aforementioned factors. We consider each of these factors in turn in the following.

There is a theoretical background to expect that price rigidity would influence VPT. Price rigidity can be explained by retail repricing or menu costs within a competitive framework (Levy, Bergen, Dutta, \& Venable, 1997). For instance, Azzam (1999) shows that the downward price rigidity in retail prices, which lead to asymmetry in VPT, is due to menu costs. Price rigidity is also consistent with the exercise of market power and Powers \& Powers (2001) show that prices do not change frequently in markets characterized by high retail concentration. Some evidence of this phenomenon has been found in the German food retail industry, and which was linked to the pricing strategies of the retailers (Herrmann et al., 
2005; Weber \& Anders, 2007). However, Powers \& Powers (2001) do not find a link between rigidity in prices and the asymmetry in the magnitude and in the frequency of price changes for California-Arizona lettuce. Sexton et al. (2003) graphically show how the strategic choice of some chains to hold constant or stabilize retail prices, and not to pass on changes in wholesale prices to attract and retain consumers, which affects retail price dynamics. Using scanner data and being interested in the nature of the relation between retail prices and costs, Eichenbaum et al. (2011) find that retail (reference) prices are systematically but imperfectly related to (reference) costs, which leads to asymmetries. They indirectly relate these findings to the duration of unchanged prices at the reference prices.

Double marginalization can affect both the speed and the nature of VPT. The introduction of a private labels by a food retail chain aims to foster vertical integration, to avoid additional middleman's costs (Hoch 1996), to reduce double marginalization (Mills, 1995), and circumvent the market power of competing national brand manufacturers (Hong and Li 2015; Li, Sexton, and Xia 2006). Private label circumvents the middleman's uncertainty surrounding an interpretation of cost changes in their environment that are behind the increases/decrease in their prices. An example would be the middleman's reaction to Governmental interventions to establish a floor on downstream prices and how it can lead to asymmetry in VPT (Aramyan and Kuiper 2009; Kinnucan and Forker 1987). The national brands are supposed to have control over the prices and do not transmit symmetrical changes in their costs to maintain high margins (Loy et al. 2015). Hong and Li (2015) employ scanner data of a single and multiple retail chains in the USA to investigate whether the effect of private labels enhances vertical integration by reducing double marginalization (vertical effect) or increases market power of the retail chains that employ them (horizontal effect). They show that the vertical effect associated with private labels dominates the horizontal effect. Loy et al. (2015) find higher prevalence of asymmetry in private labels than national brands, which is not in line the hypothesis that avoiding double marginalization would lead to less likelihood of asymmetries in VPT.

Richards, Gomez, and Lee (2014) study the asymmetries in VPT using panel data on prices for ready-to-eat breakfast cereal of the top ten (high volume) brands sold in the top five retail chains on the Los Angeles metropolitan market. They test traditional market power-based explanation of the findings of asymmetry in VPT against a more compelling explanation based on consumer search behavior. Their approach consists on allowing cost pass-through rates to depend on market power and consumer search cost proxies. They find that the cost 
pass-through rates are higher among more powerful retail chains and those that offer low search cost environment. Richards, Gomez, and Lee (2014, p 1066) conclude that: “market power causes retail prices to fall quickly and rise slowly, whereas consumer search causes retail prices to fall quickly and rise slowly”, results that are contrary to the conventional wisdom. Richards, Gomez, and Lee (2014) suggest some elements that are supposed to reduce consumer search costs such as limited merchandise assortment, low price dispersion, heavy price advertisement and more communication through social networks. Loy et al. (2015) employ data on 1,724 EANs to assess VPT between wholesale and retail prices for butter in Germany for the period 2005-2008. They test whether stores with higher consumer search costs are more likely to display asymmetries in VPT. They follow Richards, Gomez, and Lee (2014) and approximate consumer search costs by the number of SKU in each store. Loy et al. (2015) allow the cost pass-through rates to depend on the number of SKU in each store. They find that asymmetry in VPT for butter prices in Germany increases with an increase in consumer search costs, but the effect is rather small and ambiguous.

There are reasons to expect differences in the prevalence of asymmetry in VPT within and between the different formats of stores. Loy et al. (2015) find differences in the prevalence of asymmetry between the different formats of stores. However, these differences were not linked to other factors that might influence asymmetry in the VPT. For instance, consumer search costs are expected to be higher in the hypermarkets and supermarkets than in the discounters. If prices are rising and consumers are willing to bear store-switching costs to benefit from search within hypermarkets and supermarkets, then the VPT processes would depend on the response of these format of stores to the consumer's willingness to search. Moreover, discount stores exhibit a higher degree of rigid prices than other formats of stores in Germany (Weber and Anders 2007). Moreover, if hypermarkets and supermarkets mimic discount stores and display rigid prices, to avoid markup variation because they can, then price rigidity can affect the VPT processes.

To date, the effect of pricing strategy on price dispersion is well documented, but there is little literature on the implications of different pricing strategies on retail price dynamics. Loy et al. (2015, p. 442) suspect that pricing strategy influences the VPT process: "retail outlets can use single-product prices strategically, which may not only result in significant price dispersion, but also in different dynamic cost pass- through processes”. Owen \& Trzepacz (2002) compare two retail chains: one employs EDLP and the other uses the HiLo strategy, and provide evidence of a link between pricing strategy and the asymmetries in incidence and 
the magnitude of price changes. Owen \& Trzepacz (2002) conclude that the benefits of adopting a HiLo strategy are larger than the menu costs associated with it. However, Owen \& Trzepacz (2002) do not explicitly test for asymmetry in VPT, and they employ data with a very limited cross-sectional dimension (only two chains). Our data, which cover 37 different chains, that may be able to generate additional insights. Li et al. (2006) consider that retail market power manifests itself via the pricing strategies employed. They argue that in competitive retail markets, chains that adopt EDLP and do not react to price decreases in the wholesale prices would be undercut by chains who symmetrically transmit wholesale price changes. They consider EDLP as an extreme case, in which incomplete price transmission will occur, in particular when some chains hold prices constant for a specific product despite shifts in demand and / or supply at the wholesale level. In this scenario the price must adjust more widely for all the other chains in order for the market to clear. Moreover, some chains quite strictly dictate the prices to their store managers; other chains give the individual store managers more freedom. This leads to different degrees of control on pricing strategies that chains exercise over their stores (Konur \& Geunes, 2016).

The pricing strategy of a retailer is an unobservable variable, but we can approximate that with interaction between store format and other observable variable such as duration and consumer search costs. Hence, we expect the interaction between the duration and store format to influence the asymmetry in VPT, such as that for a given average duration of unchanged prices within the discount store, the supermarket and the hypermarket have more flexibility in adjusting their expected markup and margins, which can lead to asymmetries in the VPT. Moreover, consumer search costs may vary across store format, i.e. when the returns to search are high, consumers would not only search actively within a store, but also would search for formats of stores that offer low prices, or prefer stores that are known to use EDLP strategy. Thus, an interaction between the SKU and the different formats of store can help to explain the variation asymmetries in VPT.

In summary, a few studies have tested for asymmetries in vertical food price transmission to individual stores using scanner data. Those that have find that asymmetry is common but not homogenous. Some studies look at limited cross-sectional data for one or a small number of chains and they raise an additional point related to pricing strategy (Owen \& Trzepacz, 2002), that different chains and formats of store might display different degrees of asymmetries in VPT. Price strategies are usually not documented in the data, but they differ in many observable aspects, such as rigidity in prices implied and the formats of store that are likely to 
employ them. Other studies employed rich cross-sectional data and considered retailer's market power and consumer search costs (Loy et al., 2015; Richards et al., 2014) to explain asymmetries in VPT and that asymmetry might differ between private labels and national brands (Hong \& Li, 2015; Loy et al., 2015). To date, no study has systematically accounted for the hierarchical structure of the data in explaining the unobserved heterogeneity in asymmetries in VPT.

\subsubsection{Hypotheses}

Based on the literature reviewed above, the following hypotheses are subject for testing in this study. First, Eichenbaum et al. (2011, p. 235) suggest that: a " retailer chooses the duration of reference prices so as to limit markup variation" and "prices do not always change when the costs change". Hence, we expect that rigid prices will increase the prevalence of asymmetries in VPT. Second, the supply of private labels allows food retail chains to avoid double margination. Therefore, we expect to find fewer cases of asymmetry in VPT for products with private labels than for products with national brands. Third, the literature shows that there is an association between the increase in consumer search costs and an increase in the probability of asymmetries in VPT. Therefore, we hypothesize that higher consumer search costs will increase the prevalence of asymmetries in VPT. Fourth, we expect to find more asymmetries in VPT in supermarkets and hypermarkets than in discount stores. This is due to the established link in the literature between the discount stores and the EDLP strategy on the one hand, and between the HiLo strategy other formats of stores on the other hand. Fifth, we consider two aspects of pricing strategy that could influence VPT processes. First we hypothesize that rigid prices within hypermarket and supermarkets would lead to the increase in the likelihood of asymmetries in VPT. Second, since consumer search costs are high in hypermarkets and supermarkets, they are expected to employ their potential to divert from competitive single price equilibrium and display asymmetries in VPT. Sixth, we hypothesize that asymmetries in VPT depend on store membership in chain.

Due to the high competition in the food retail chain in Germany, most of the chains will display more or less similar pricing behavior, but there are chains that would deviate from this common behavior, and as stated in Loy et al. (2015, p. 442):” ... certain retail chains have some potential to divert from the competitive single-price equilibrium". We are particularly interested in investigating features of these chains, the format of store managed, their size, their location, the product assortment and their location. Moreover, depending on 
the flexibility applied by the chains to their stores, i.e. centralized of decentralized pricing decisions, differences between stores could be either considerable or limited, e.g. if the stores are centrally managed, then very little variation in price dynamics between the stores is expected.

\subsection{Data}

\subsubsection{Measuring asymmetry in vertical price transmission}

To test the hypotheses outlined above we estimate Asymmetric Vector Error Correction Models (AVECMs) for 1087-time series of prices at the retail level and a weekly weighted average national wholesale price for butter. We employ retail prices for 250-gram foilwrapped packages collected weekly starting from the first week of 2005 through the last week in 2010. Each retail price is first filtered to remove Temporary Sale Prices (TSP) that would otherwise bias the results of asymmetry tests (Tifaoui \& von Cramon-Taubadel, 2016).

The weighted average wholesale prices of butter in Germany were collected by the Southern German Butter and Cheese Exchange ${ }^{11}$ (SBKB) for the same period 2005-2010. In a Delphi study conducted by (Loy et al., 2015), the interviewed experts consider the weekly weighted average national wholesale price that is quoted by the SBKB to be the minimum opportunity cost for retailers in Germany. In such a case, the variation in price dynamics between the wholesale and the retail price of the different chains can be partially associated with the store/chain specific pricing strategy and product branding (Loy et al., 2015).

In each of the 1087 AVECMs we specify the retail price to be endogenous and the wholesale prices to be exogenous. This specification is based on Loy et al. (2015) who find Grangercausality tests to support this assumption for $90 \%$ of the butter prices. To estimate the AVECM, we employ a two stage procedure proposed by Engle \& Granger (1987) and Granger \& Lee (1989), and first applied to price transmission by von Cramon-Taubadel (1998). We find asymmetry in VPT in 26\% of the 1087 EANs included in this study.

Before investigating the factors explaining the $26 \%$ of the cases of asymmetries in VPT that we find in our data, understanding the structure of the data is necessary because it helps to determine which methods to use for data analysis.

${ }^{11}$ SBKB abrevaition for Süddeutsche Butter- und Käse-Börse 


\subsubsection{Data structure}

Figure 3.3 illustrates the structure of the data for two fictive chains: Chain $\mathrm{X}$ and Chain $\mathrm{Y}$, which may differ in many aspects, including their pricing and marketing strategies. The subsample of data that we use in this study covers 37 chains ${ }^{12}$. The chains names are also kept anonymous using identification codes, here we use " $\mathrm{X}$ " and " $\mathrm{Y}$ " for purpose of illustration.

\section{Figure 3.3 Hierarchical structure of the data}

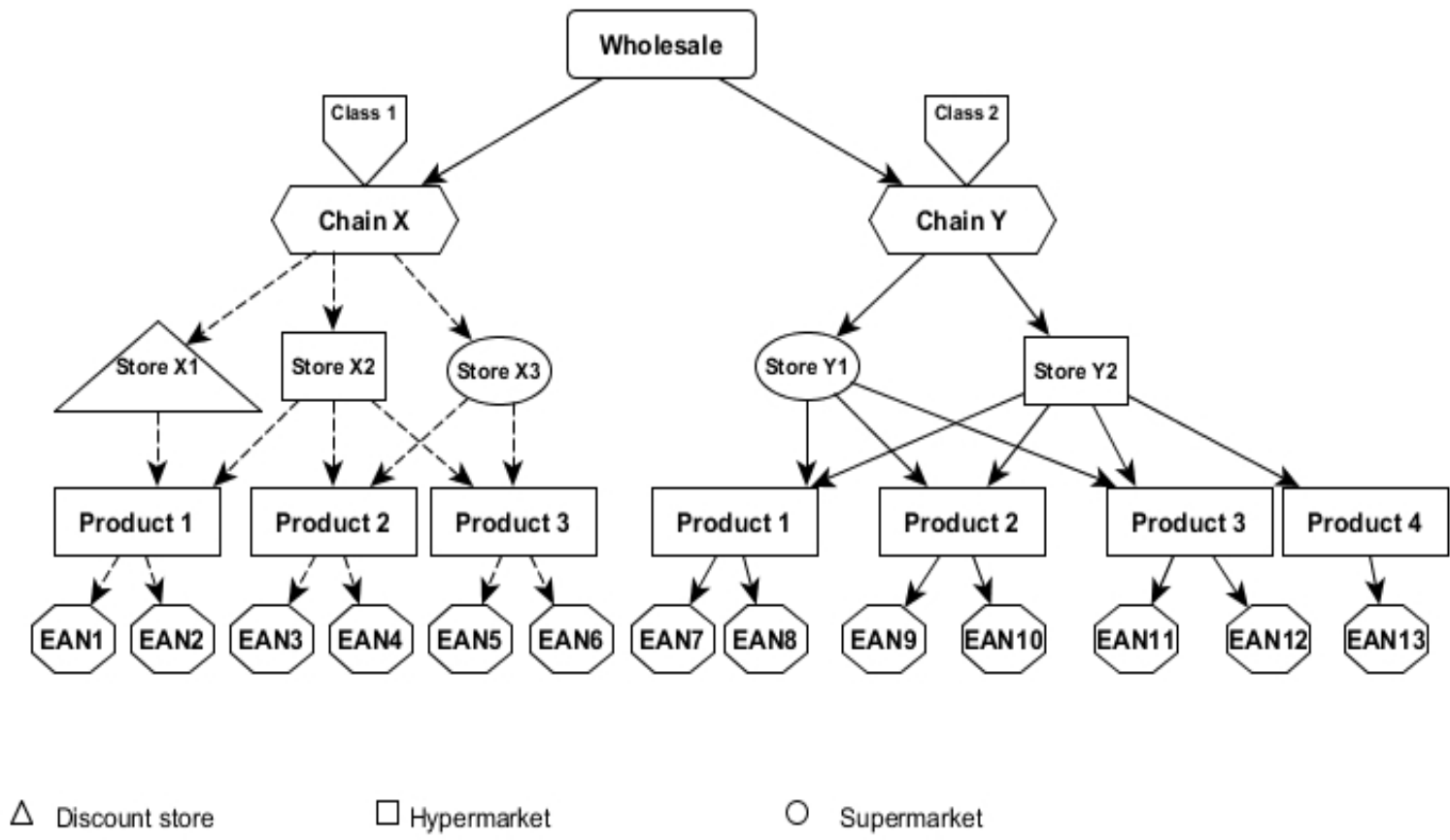

Source: Authors' schematization of the SIG data

The subsample covers 345 different stores, which are also identified by additional codes. The stores are nested into a chain and we know for instance that the stores X1, X2 and X3 belong to the Chain $\mathrm{X}$. The stores are classified into six different formats, and our subsample covers only three formats: discount stores, supermarkets and hypermarkets. It is not necessary that all of the stores in Chain $\mathrm{X}$ are of the same format, i.e. Chain $\mathrm{X}$ can have discounter store (triangle in Figure 3.3), hypermarket (square) and supermarket (ellipse) formats, or just only two formats as is with Chain Y in Figure 3.3. Other features of the store are also documented in the data. For instance, we know each store's size, its location and the number of products managed (SKU).

Moreover, introducing changes in prices does not depend solely on the store's manager. His/her decision might depend on the features of each product (e.g. national brand versus

\footnotetext{
12 The raw data purchased from the Symphony IRI Group GmbH cover 41 chains.
} 
private label). The data cover 56 products, which are sold in at least one of the 345 different stores. In addition, the data contain information on the characteristics of the 56 products, i.e. their prices, processor, brand, label, country of origin and the region where the product is commercialized in Germany.

Sometimes the exact same product (e.g. Product 1) is displayed in more than one store. Product 1 is identified with an EAN1 in Store X1, and with EAN7 in Store Y1. Sometimes a product can be found only in one store, e.g. Product 4 identified with EAN13. The total number of product-store combinations in our dataset (i.e. the number of EANs) is 1087. For Product 1, with the same features, the observation of asymmetry in VPT for EAN1 and/or EAN7 would depend on the store membership in a chain, e.g., symmetric pricing for EAN1 within the Chain X and asymmetry in VPT for EAN7 within Chain Y.

The cases of asymmetry in VPT may be aggregated at each of the four levels: product, store, chain, and class. This structure can lead to scaling effects, i.e. where aggregation or disaggregation at different levels of the hierarchy affect the statistical analysis of the factor explaining asymmetry in VPT. There are factors that explain asymmetry in VPT that are product specific and other factors that are chain specific. In order to avoid misleading conclusions, it is important then to opt for consistent models when explaining variation in the cases of asymmetry in VPT between the different EANs or the different EANs within the same chain.

To account for the store/chain effect, we could include in generalized linear models (GLMs) framework dummy variables for store/ chain. For instance, we could include 344 dummy variables to capture the unobserved heterogeneity between 345 different stores, but this is inconvenient because of the increasing number of parameters that we need to estimate, which could be inconsistent due to incidental parameter problems (Rabe-Hesketh \& Skrondal, 2012, p. 557).

An alternative is to employ a mixed model. Mixed models are well suited to model this particular structure of data presented in Figure 3.3 (Fahrmeir et al., 2013; Verbeke \& Molenberghs, 2000). Including random effects for each level of the hierarchy helps to account for unobserved heterogeneity between the EANs, to detect level specific effects and to induce correlation that could exist between the EANs (Rabe-Hesketh et al., 2005). Another argument that justifies including individual random effects is that we use average wholesale price at the national level as an approximation of the minimum opportunity cost in Germany; 
it could be the case that some chains could have access to lower wholesale prices by exercising negotiation power, but we do not observe in our data.

While the simplest mixed model comprises only two hierarchical levels, e.g. product effect, multilevel models with multiple nested and/or crossed hierarchical levels are better suited for the data structure in Figure 3.3. Multilevel models are an extension of mixed models applied to data structures with more than one grouping factors (Fahrmeir et al., 2013; Rabe-Hesketh \& Skrondal, 2012). The advantage that multilevel models have over mixed models is that they allow for the decomposition of the variability of finding asymmetry in VPT at different levels of the hierarchy, i.e. Class-Chain-Store-Product.

\subsubsection{Descriptive statistics of the factors that can explain asymmetry}

The response variable of interest is a binary variable that takes the value of one if we reject the null hypothesis of symmetry in the AVECMs, or zero when not rejected. Table 3.1 summarizes the descriptive statistics of some variables that might explain why we reject the hypothesis of symmetry in VPT for the 283 EANs.

Table 3.1 Descriptive statistics of the variables of interest

\begin{tabular}{lcccc}
\hline \multicolumn{1}{c}{ Variable Description } & $\begin{array}{c}\text { Number of } \\
\text { EAN }\end{array}$ & Symmetry & Asymmetry & Total \\
\hline Test for symmetry in VPT & $1087(100 \%)$ & $804(74 \%)$ & $283(26 \%)$ & $100 \%$ \\
\hline Brand & $75(7 \%)$ & $65(86.67 \%)$ & $10(13.33 \%)$ & $100 \%$ \\
Private labels & $1,012(93 \%)$ & $739(73.02 \%)$ & $273(26.98 \%)$ & $100 \%$ \\
National brand & & & \\
\hline Country of origin & $824(76 \%)$ & $575(69.78 \%)$ & $249(30.22 \%)$ & $100 \%$ \\
Germany & $239(22 \%)$ & $215(89.96 \%)$ & $24(10.04 \%)$ & $100 \%$ \\
Ireland & $24(2 \%)$ & $14(58.33 \%)$ & $10(41.67 \%)$ & $100 \%$ \\
Netherlands & & & & \\
\hline Region & $348(32 \%)$ & $259(74.43 \%)$ & $89(25.57 \%)$ & $100 \%$ \\
Central & $185(17 \%)$ & $151(81.62 \%)$ & $34(18.38 \%)$ & $100 \%$ \\
North & $249(23 \%)$ & $187(75.10 \%)$ & $62(24.90 \%)$ & $100 \%$ \\
West & $305(28 \%)$ & $207(67.87 \%)$ & $98(32.13 \%)$ & $100 \%$ \\
South & & & \\
\hline Store format & $183(17 \%)$ & $167(91 \%)$ & $16(9 \%)$ & $100 \%$ \\
Discounter & $91(8 \%)$ & $58(63.74 \%)$ & $33(36.26 \%)$ & $100 \%$ \\
Supermarket & $813(75 \%)$ & $579(71.22 \%)$ & $234(28.78 \%)$ & $100 \%$ \\
Hypermarket & & \multicolumn{3}{c}{ So $)$} \\
\hline
\end{tabular}

Source: Authors' calculations

Out of 1087 EANs, 93\% (1,012) of EANs carry a national brand. In addition to national brands, chains provide their customers with their own brand and 75 (7\%) EANs are identified as private labels in our data. The Fisher's exact test, Chi-square $(1)=6.74, \operatorname{Pr}=0.005$, indicates a statistical significant of the difference between the cases of asymmetry between the private labels (13.33\%) and the national brands (26.98\%). Most EANs are produced in 
Germany 824 (76\%), and the rest are imported from Ireland 239 (22\%) and the Netherlands 24 (2\%). The Netherlands EANs display relatively higher cases of asymmetry compared to the other countries and the differences are statistically significant.

The EANs can be found in four different regions in Germany: central 384 (32\%); north 185 (17\%), west 249 (23\%) and south 305 (28\%). There are differences between the four regions and there are relatively more cases of asymmetry in the south 98 (32.13\%), compared to the north 34 (18.38\%). This could be linked to the differences between the regions; the noncooperatives are based more in the south and the cooperatives operate mostly in the north. Moreover, discount stores account for 183 (17\%) of the 1087 unique EANs in the data, the supermarkets represent 91 (8\%), and the hypermarkets have 813 (75\%) unique EANs. As expected, there is a higher share of asymmetry cases in supermarkets (33 out of 91 EANs) and hypermarkets (234 out of 813 EANs), than in discount stores (16 out of 183 EANs).

In addition to factors described in Table 3.1, we consider price rigidity and the number of stock keeping units (SKU) to explain the findings of asymmetry in VPT. We follow Powers \& Powers (2001) and calculate the duration as the inverse of the frequency of price change for each of the 1087 EANs. Figure 3.4 illustrates the differences between the different formats of store in terms of SKU (Panel A) and duration of unchanged price (Panel B).

The duration measures how many weeks on average the prices for a given EAN remain unchanged. The mean duration for the subsample is 16 weeks and the median is 14 weeks, the range goes from 1.6 to 104 weeks. Simple correlation indicates that the duration is negatively associated with the findings of asymmetry in VPT. We also find a statistically significant difference in mean $(\mathrm{t}=-4.52, \mathrm{p}=0.000)$ between the EANs for which the hypothesis of symmetry is rejected (mean $=14.02$ and $\mathrm{SD}=0.73$ ) and the EANs for which we fail to reject the hypothesis of symmetry in VPT (mean=17.88 and SD=0.44).

We also find a significant difference between the different formats of stores and the duration of unchanged prices. The prices remain constant for several months with the discount stores and they tend to change more frequently with the supermarkets and hypermarkets. Moreover, the duration of unchanged prices can be linked to the pricing strategies explained above. By definition, the duration would be higher in the EDLP than in HiLo strategy. As expected, and illustrated in Panel B of Figure 3.4, the discount stores are characterized by a higher duration of unchanged prices compared to the supermarkets and hypermarkets, on average. This is perhaps due to the established link between the EDLP pricing strategy and discount stores. 
Figure 3.4 also indicates that employing interactions between the variables' duration and format of store can help to explain asymmetry in VPT.

Figure 3.4 Stock keeping units and duration per store format
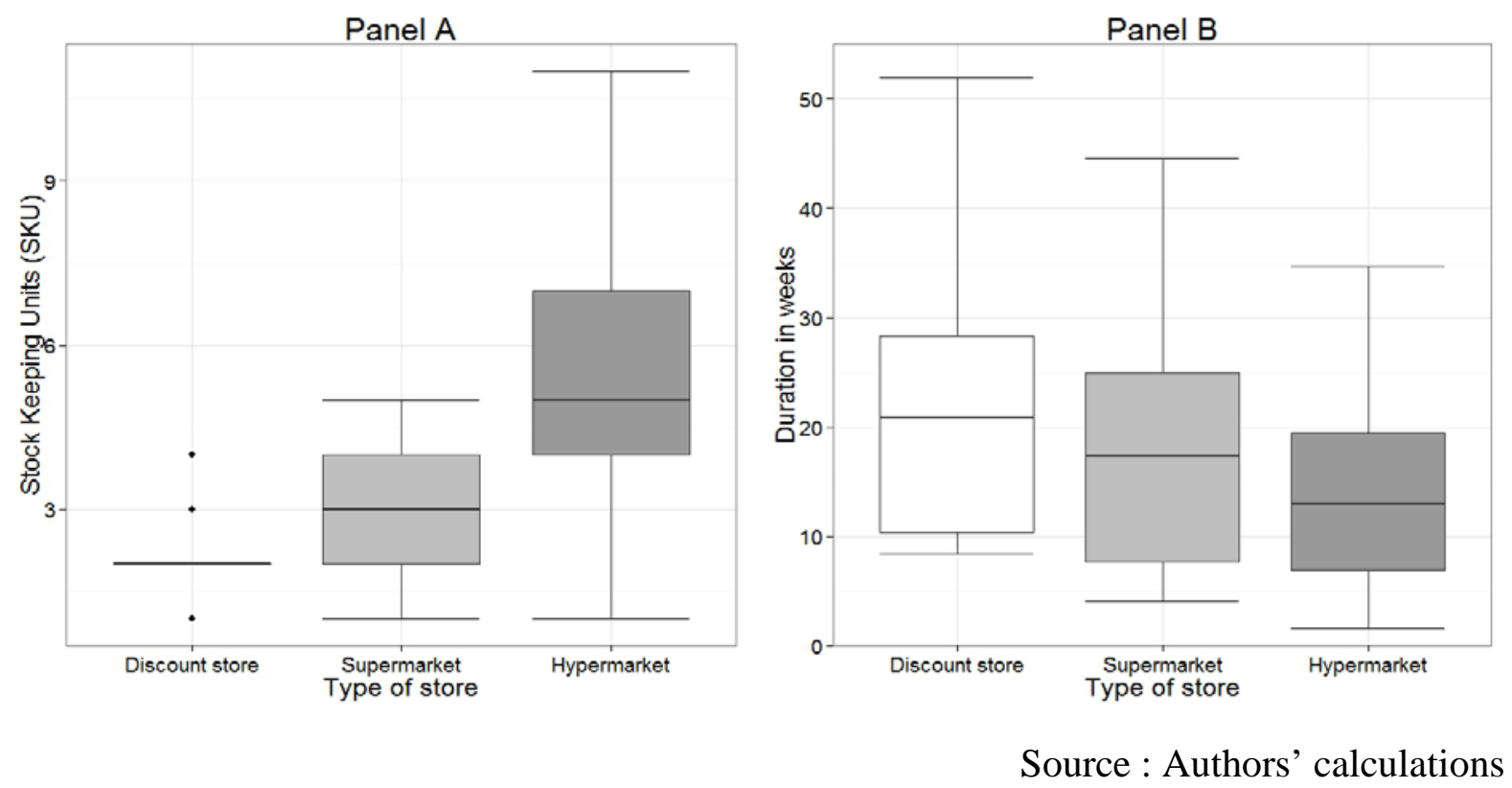

On average, there are four SKU per store, one SKU being the minimum and eleven SKU the maximum. As is expected, a discount store has on average 2 SKU, with a low standard deviation ( $\mathrm{SD}=0.86$ ), followed by supermarkets with an average number of $3 \mathrm{SKU}$ and $\mathrm{SD}=1.26$, and the hypermarkets have the most $\mathrm{SKU}$, with an average of $5 \mathrm{SKU}$, with $\mathrm{SD}=2.80$.

\subsection{Methods}

\subsubsection{Latent data formulation of the findings of asymmetry in VPT}

Suppose that a retail manager decides to change the price of an EAN as a reaction to a change in the average wholesale prices quoted by the SBKB. If the manager responds in the same manner to a wholesale price increase as he/she reacts to a wholesale price decrease, then the VPT is symmetric. In contrast, if the reaction to a wholesale price increase differs from the reaction to a wholesale price decrease, VPT is then asymmetric. However, the retail manager is not able to observe the reaction of other competing retailers that face the same choice problem. Let us consider the latent utility $U$ behind the decision of changing prices made by the chain's/ store's manager. We can assign utilities $U_{i S}$ and $U_{i A}$ to the symmetric and asymmetric reactions, respectively. The manager choses the alternative that maximize his/her 
utility, i.e., $U_{i s}>U_{i A}$ if the reaction is symmetric $y_{i}=A$ symmetry $y_{i}=0$ and $U_{i s} \leq U_{i A}$. If the reaction is asymmetric $y_{i}=$ Asymmetry $_{i}=1$.

We want to investigate what factors are behind this choice. Nevertheless, we do not observe the latent utilities behind each decision. What we are able to observe, is the result of the decisions after assessing VPT from the SBKB wholesale price to the retail price for each $\mathrm{EAN}_{i}, i=1, \ldots, 1087$, using time series analyses. We also observe a number of explanatory variables $x_{i 1}, \ldots, x_{i k}$ (explained in Table 3.1) that may influence the choice made by the manager. Assuming that the unobserved utilities can be additively decomposed and follow a linear model, we obtain: $U_{i A}=x_{i}^{\prime} \tilde{\beta}_{A}+\tilde{\varepsilon}_{i A}$ and $U_{i S}=x_{i}^{\prime} \tilde{\beta}_{S}+\tilde{\varepsilon}_{i S}$. with $x_{i}=\left(1, x_{i 1}, \ldots, x_{i k}\right)^{\prime}$. The unknown coefficient vectors $\tilde{\beta}_{A}$ and $\tilde{\beta}_{S}$ determine the effect of the explanatory variables on the utilities defined above. The errors $\tilde{\varepsilon}_{i A}$ and $\tilde{\varepsilon}_{i S}$ include the effects of the unobserved variables, such as the pricing strategy of the chains, e.g. EDLP. The difference in the utility is as follows:

$$
\tilde{y}_{i}=U_{i A}-U_{i S}=x_{i}^{\prime}\left(\tilde{\beta}_{A}-\tilde{\beta}_{S}\right)+\tilde{\varepsilon}_{i A}-\tilde{\varepsilon}_{i S}=X_{i}^{\prime} \beta+\epsilon_{i}
$$

The connection to the observed decision is now given by $y_{i}=1$ if $\tilde{y}_{i}=U_{i A}-U_{i s} \geq 0$ and $y_{i}=0$ if $\tilde{y}_{i}=U_{i A}-U_{i s}<0$.

\subsubsection{Model specification}

Assume that all the retail chains in our data are managed by the identical managers, each with the same flexibility in terms of introducing price changes to all the EANs, $i=1, \ldots, 1087$. In this case, a complete pooling, whereby we ignore completely store membership in chains, would be appropriate. In this case, we could use a single pooled generalized linear model (GLM) to fit the data. In a GLM framework we estimate the effects of a linear combination of covariates eta $\left(\eta_{i}=\beta_{0}+\beta_{1} x_{i 1}+\cdots+\beta_{k} x_{i k}\right)$ on the conditional expectation of a response $E(y \mid \eta)$, where $y$ are independent Bernoulli random variables with probability $\pi$. In our case the conditional probability $\pi_{i}=\operatorname{Pr}\left(y_{i}=1\right)$ represents the probability that VPT for a given EAN, $i=1, \ldots, 1087$ is asymmetric. The probabilities $\pi_{i}$ are linked to the $\eta_{i}$ via a response function $h($.$) , which is smooth and strictly increasing such as: h():. R \rightarrow(0,1)$ and $\pi_{i}=$ $h\left(\eta_{i}\right)$. A common choice for $h($.$) is the logistic response function where \pi=h(\eta)=$ $\operatorname{logit}^{-1}(\eta)=\frac{\exp (\eta)}{1+\exp (\eta)}$. The likelihood that we maximize conditional to vector of coefficient $\beta=\left(\beta_{0}, \ldots, \beta_{k}\right)^{\prime}$ and data $x_{i}=\left(1, x_{i 1}, \ldots, x_{i k}\right)^{\prime}$ is given in equations (6) 


$$
\operatorname{Pr}(y \mid \beta, x)=\prod_{i=1}^{1087}\left\{\begin{array}{c}
\operatorname{logit}^{-1}\left(x_{i} \beta\right) \text { if } y_{i}=1, \quad \text { VPT is asymmetric } \\
1-\operatorname{logit}^{-1}\left(x_{i} \beta\right) \text { if } y_{i}=0, \quad \text { VPT si symmetric }
\end{array}\right.
$$

or equivalently as expressed in equation (7):

$$
\operatorname{Pr}(y \mid \beta, x)=\prod_{i=1}^{1087}\left(\operatorname{logit}^{-1}\left(x_{i} \beta\right)\right)^{y_{i}}\left(1-\operatorname{logit}^{-1}\left(X_{i} \beta\right)\right)^{1-y_{i}}
$$

We use this pooled GLM specification as a benchmark, despite the obvious drawback that it treats the 1087 EANs as if they were all displayed in identical stores. Two alternatives to pooled estimation are possible. First, one could estimate without pooling or with partial pooling. A no pooling approach would be to estimate equation (7) separately for each product, store, chain and class in our data. However, this is not suitable since some chains in our sample have only one store and display only one EAN. Furthermore, this would only account for one dimension of the data hierarchy at a time. Partial pooling or multilevel modeling is a compromise between the complete pooling and the no pooling cases (Gelman \& Hill, 2007). In comparison to the pooled GLM, in multilevel modeling applied to the logistic regression, additional parameters are affiliated to the classes, to chains, to stores, and to products as batches and a probability distribution is assigned to each batch (Gelman \& Hill, 2007). In other words, error terms that correspond to different sources of variation in the data and represent random effects, are added to the GLM model, which otherwise includes solely fixed effects $(\beta)$ parameters. The result is referred to as a Generalized Linear Mixed Model (GLMM).

GLMMs extend the GLM, which include only fixed effects parameters ( $\beta$ ), by adding random effects $\gamma$ parameters on the linear predictor $\eta: \eta_{i j}=x_{i j}^{\prime} \beta+u_{i j}^{\prime} \gamma_{i}$. The random effects $\gamma$ are assumed to have a multivariate normal distribution, with zero mean and $\operatorname{var}(\gamma)=Q$, i.e. with $\gamma \sim N(0, Q)$. The conditional mean $E\left(y_{i j} \mid \gamma_{i}\right)$ of the response is also linked to the linear predictor $\eta$ through the response function $\operatorname{logit}^{-1}(\eta)=\left(1+e^{-\eta}\right)^{-1}$.

Moreover, given random effects $\gamma_{i}$, the responses $y_{i j}$ are conditionally independent and their distribution is of exponential family form, i.e. $y_{i j} \mid \theta_{i j}, \phi \sim f($.$) , where f($.$) is a member of the$ exponential family. This is expressed as follows:

$$
\log \left(f\left(y_{i j} \mid \theta_{i j}, \phi\right)\right)=\frac{y_{i j} \theta_{i j}-b\left(\theta_{i j}\right)}{\phi}+c\left(y_{i j}, \phi\right)
$$


In equation (8), $b($.$) depends only on \theta, c($.$) depend on y$ and $\phi$. The parameter $\theta_{i j}$ is the canonical parameter and $\phi$ is a common dispersion parameter independent of $i$ (Fahrmeir et al., 2013, p. 304).

The probability of finding asymmetry in VPT, conditioned on the random effects, is formulated as follows:

$$
\pi_{i j}=\mathrm{E}\left(y_{i j} \mid \beta, \gamma\right)=\operatorname{Pr}\left(y_{i j}=1 \mid x_{i j}^{\prime}, \beta_{i}, u_{i j}^{\prime}, \gamma_{i}\right)=\operatorname{logit}^{-1}\left(\eta_{i j}=x_{i j}^{\prime} \beta+u_{i j}^{\prime} \gamma_{i}\right)
$$

The $u_{i j}$ contain variables which are unique to each level, and usually it is a sub-vector of $x_{i j}$. Moreover, the choice of $u_{i j} \equiv 1$ in equation (9), i.e. $\eta_{i j}=\beta_{0}+\beta_{1} x_{i j 1}+\cdots+\beta_{k} x_{i j k}+\gamma_{0 i}$ defines the random intercept model (Fahrmeir et al., 2013, p. 390), where $\gamma_{0 i}$ contains random deviations from the fixed intercept $\beta_{0}$ associated to EAN. We specify a simple random intercept model for our data, where we include random effects $\gamma_{p}, \gamma_{s}, \gamma_{c}, \gamma_{l}$ for product, store, chain and class respectively as expressed in equation (10):

$$
\operatorname{Pr}\left(y_{i p s c l}=1\right)=\operatorname{logit}^{-1}\left(\beta^{0}+\sum_{m}^{M} \beta^{m} \text { covariate }_{m[i]}+\gamma_{p[i]}+\gamma_{s[i]}+\gamma_{c[i]}+\gamma_{l[i]}\right)
$$

The distributions of the random effect $\gamma_{p} \gamma_{s} \gamma_{c} \gamma_{l}$ are given:

$$
\begin{aligned}
& \gamma_{p} \sim N\left(\mu_{p}, \sigma_{p}^{2}\right) \ldots \ldots \ldots \text { for } p=1, \ldots \ldots \ldots, 56 \text { products } \\
& \gamma_{s} \sim N\left(\mu_{s}, \sigma_{s}^{2}\right) \ldots \ldots \ldots \text { for } s=1, \ldots \ldots \ldots, 345 \text { stores } \\
& \gamma_{c} \sim N\left(\mu_{c}, \sigma_{c}^{2}\right) \ldots \ldots \ldots \text { for } c=1, \ldots \ldots \ldots, 37 \text { chains } \\
& \gamma_{l} \sim N\left(\mu_{l}, \sigma_{l}^{2}\right) \ldots \ldots \ldots \text { for } l=1, \ldots \ldots \ldots, 6 \text { for classes }
\end{aligned}
$$

The random intercepts capture the deviation in the conditional probability of asymmetry in VPT that is associated to each level of the data hierarchy. If the data structure has no influence on the asymmetries in VPT, i.e. no random effects, then the model in equation (10) reverts to the pooled GLM model in equation (7).

\subsubsection{Model estimation}

To obtain the unconditional maximum likelihood estimates for the $\beta$ and the $\gamma$ from equation (10) one must integrate likelihoods over all possible values for the random effects, i.e. random effects “integrate out”(Rodriguez \& Goldman, 1995, 2001). This complicates the use of the standard maximum likelihood estimation (Rabe-Hesketh \& Skrondal, 2012, p. 537). Moreover, Fahrmeir et al.( 2013, p. 394) point out that since the conditional likelihood is in general non-Gaussian and the relationship between the $E\left(y_{i j} \mid \gamma_{i}\right)$ and $\eta_{i j}$ is nonlinear in 
GLMM, important parts of the likelihood cannot be carried out analytically, but rather numerically or with suitable approximations.

\subsubsection{Frequentist estimation of the GLMMs}

In the literature, different ways are suggested to approximate the likelihood to estimate GLMMs parameters in equation (10) using a frequentist approach. These include: the pseudo (marginal) and penalized quasi-likelihood (PQL) approximation (Breslow \& Clayton, 1993; Schall, 1991; Wolfinger \& O'connell, 1993); and an improved version of the PQL approximation (Goldstein \& Rasbash, 1996; Rodriguez \& Goldman, 2001); Laplace approximation (Breslow, 2004; Raudenbush et al., 2000); and Gauss-Hermite quadrature (GHQ) approximation (Pinheiro \& Chao, 2006) and adaptive quadrature (AGHQ) (RabeHesketh et al., 2005).

The PQL approximation does not compute true likelihood (Bolker et al., 2009; Rabe-Hesketh et al., 2005) and it should not be used for inference (Pinheiro \& Chao, 2006; Rabe-Hesketh et al., 2005). Further, this approximation works poorly with dichotomous data with small cluster sizes (Breslow, 2004) and leads to biased estimates in the case of large variance in random effects (Browne \& Draper, 2006; Rodriguez \& Goldman, 1995, 2001). Laplace approximation is more accurate than the PQL (Bolker et al., 2009; Rabe-Hesketh et al., 2005). It allows for the calculation of the true GLMM likelihood; hence maximum likelihood based inference is possible, and the Laplace approximation reduces the bias compared to the PQL. An even better approximation is GHQ, which works well with moderate cluster size data (Rabe-Hesketh et al., 2005), but it becomes complicated and slow with more than two or three random effects (Bolker et al., 2009) and the estimates become biased with large cluster sizes.

\subsubsection{Bayesian estimation of the GLMMs}

Markov chain Monte Carlo (MCMC) methods (Gilks et al., 1996) in a Bayesian framework is also used in the GLMMs literature to estimate equation (10). Unlike the PQL, Laplace approximation and (A)GHQ, the MCMC method extends easily to include complex multilevel structures and multiple (more than three) random effects (Gilks et al., 1996). Moreover, the use of the MCMC algorithm to approximate the likelihood for the GLMMs does not require integration over random effects using approximation, but it rather generates random samples from distributions of potential parameter values for fixed and random effects. These distributions are classified into prior and posterior distributions. MCMC 
incorporates prior information based on the previous knowledge about both fixed and random effects, or just specifies non-informative priors in the case of lacking information. After including the data or observation model, and updating the priors, the inference is based on characteristics from the posterior distribution, such as mean, the variance or quantiles, or the posterior density itself (Fahrmeir et al., 2013).

In summary, the use of the MCMC algorithm in a Bayesian framework to infer GLMMs offers several advantages over the frequentist approach. Perhaps the most important advantage is stated in Bolker et al. (2009, p. 133): “Markov Chain Monte Carlo (MCMC) provides confidence intervals on GLMM parameters, and hence tests for whether those parameters could plausibly equal zero, in a way that naturally averages over uncertainty in both fixed and random-effects parameters avoiding many of the difficult approximations used in frequentist hypothesis testing." Therefore, to estimate the model in equation (10) we have chosen to use a full Bayesian approach. ${ }^{13}$

All the parameters from equation (10) need a prior distribution. The response variable is binary and it cannot be over dispersed and $\phi=1$, therefore there is no need to specify a prior for $\phi$ (Fahrmeir et al., 2013, p. 397). In the case of the fixed effects, we chose to assign an (informative) prior normal distribution for $\beta \sim N\left(\mu_{\beta}, \sigma_{\beta}^{2}\right)$, with hyper-parameters $\left(\mu_{\beta}, \sigma_{\beta}\right)$; they are estimated from the data. As a rule of thumb, the range of uncertainty of the prior distribution should be wider than the range of the reasonable values of the fixed effects parameters of interest, e.g., $\mu_{\beta}=0$ and $\sigma_{\beta}$ being very small (Gelman \& Hill, 2007).

Moreover, the levels of hierarchy in multilevel modeling are treated as prior information in Bayesian inference; hence they are also assigned a prior distribution with hyper-parameters (Gelman \& Hill, 2007). For easy interpretation, we set the prior information of hyperparameters $\left(\mu_{p}, \mu_{s}, \mu_{c}, \mu_{l}\right)$ to zero so that the random effects are i.i.d with normal distributions: $\gamma \sim N(0, Q)$. For convenience, and following (Fahrmeir et al. 2013, p. 397), we assume a priori independent diagonal elements of the covariance matrix $Q$ i.e. $Q=$ $\operatorname{diag}\left(\tau_{p}^{2}, \tau_{s}^{2}, \tau_{c}^{2}, \tau_{l}^{2}\right)$

The posterior results depend on the choice of prior distribution. The inverse gamma is mostly used as a prior hyper-parameter for variance parameters in the literature, but this choice is criticized by Gelman (2006). He suggests to use the uniform distribution. In particular, when

\footnotetext{
${ }^{13}$ There is also an empirical Bayesian approach that is not different in philosophy from the frequentist methods.
} 
the variance components are near zero, Gelman \& Hill, (2007, p. 346) argue that the inversegamma is not the best choice as a prior for the variance parameters. Fahrmeir et al. (2013, p. 387) suggest to check for sensitivity of the results by comparing different choices of inverse gamma parameters. We follow Gelman (2006) and use the uniform distribution as a prior for each of the precision parameters: $\tau_{p}^{2}, \tau_{s}^{2}, \tau_{c}^{2}, \tau_{l}^{2}$.

Based on the assumption outlined above, both on the prior and the observation model, and after using the data and applying the Bayes' rule, we derive the posterior distribution as follows:

$$
\operatorname{Pr}\left(\beta, \gamma_{1}, \ldots \gamma_{m}, Q \mid y\right) \propto \prod_{i=1}^{m} \prod_{j=1}^{n i} \operatorname{Pr}\left(y_{i j} \mid \beta, \gamma_{i}\right) \operatorname{Pr}(\beta) \prod_{i=1}^{m} \operatorname{Pr}\left(\gamma_{i} \mid Q\right) \operatorname{Pr}(Q)
$$

The full conditionals are given as follows:

$$
\begin{gathered}
\operatorname{Pr}(\beta \mid .) \propto \prod_{i}^{m} \prod_{j}^{n_{i}} \operatorname{Pr}\left(y_{i j} \mid \beta, \gamma_{i}\right) \operatorname{Pr}(\beta) \\
\operatorname{Pr}\left(\gamma_{i} \mid .\right) \propto \prod_{j}^{n_{i}} \operatorname{Pr}\left(y_{i j} \mid \beta, \gamma_{i}\right) \operatorname{Pr}\left(\gamma_{i} \mid Q\right), i=1, \ldots, m \\
\operatorname{Pr}\left(\tau_{r}^{2} \mid .\right) \propto \prod_{i}^{m} \operatorname{Pr}\left(\gamma_{i r} \mid r_{r}^{2}\right) \operatorname{Pr}\left(\tau^{2}\right), r=1, \ldots, q
\end{gathered}
$$

Since the full conditionals for $\beta$ and $\gamma$ are not available in a known analytical form, Fahrmeir et al. (2013) suggest to use the Metropolis-Hastings algorithm with an MCMC ${ }^{14}$ approach to draw random numbers from these full conditionals. The drawing of random numbers is based on generating (three) Markov Chains with sufficient number of iterations (we use 100,000), so that the transition kernel converges to the posterior of interest. In order to avoid estimates to dependent on guesswork, we specify 2000 iterations to be discarded as burn out in each phase to reduce the influence of the intial values of the Markov Chains. The convergence and correlation are also important elements to assess the quality of the MCMC algorithm. The convergence is assessed with $\hat{R}$, which is calculated as the square root of the variance of the mixture of all (three) the chains, divided by the average within chain variance. Usually, $\hat{R}<1.1$ for all parameters is a good indicator of convergence and that the (three) Markov

${ }^{14}$ We employ WinBugs software with R2WinBUGS R interface proposed in Sturtz, Ligges, \& Gelman (2005). 
Chains have mixed well (Gelman \& Hill, 2007). We use an autocorrelation function (AFC) of the (three) Markov Chains, which need to converge to zero after only a few lags. We also carry out thinning, where only the $100^{\text {th }}$ random number is saved for posterior analysis, such as that the remaining random numbers in the thinned sample are uncorrelated.

We base our choice in model selection on the deviance information criterion (DIC) proposed in Spiegelhalter et al. (2002), which is calculated as a sum of two quantities, the unstandardized deviance: $D(\theta)=-2 \log (\operatorname{Pr}(y \mid \theta))$, and the effective number of parameters in the model: $p_{D}=\overline{D(\theta)}-D(\bar{\theta})$, as the difference between the average posterior deviance and the deviance evaluated at $\bar{\theta}=\frac{1}{T} \sum_{t=1}^{T} \theta^{(t)}$, where $\mathrm{T}$ is the number of iteration and $\theta$ is the unknown vector of parameters, such as: $\quad D I C=\overline{D(\theta)}+p_{D}=2 \overline{D(\theta)}-D(\bar{\theta})=$ $2\left(\frac{1}{T} \sum_{t=1}^{T} D\left(\theta^{(t)}\right)\right)-D(\bar{\theta})$

Moreover, we follow Nakagawa \& Schielzeth (2013) and calculate pseudo-R-squared for GLMMs. We calculate both the marginal R-squared $R_{G L M M(m)}^{2}=\frac{\sigma_{f e}^{2}}{\sigma_{f e}^{2}+\sum_{l}^{u} \sigma_{l}^{2}+\sigma_{e}^{2}+\frac{\pi^{2}}{3}}$ to assess the contribution of the fixed effect to the explained variances and the conditional R-squared: $R_{G L M M(c)}^{2}=\frac{\sigma_{f e}^{2}+\sum_{l}^{u} \sigma_{l}^{2}}{\sigma_{f e}^{2}+\sum_{l}^{u} \sigma_{l}^{2}+\sigma_{e}^{2}+\frac{\pi^{2}}{3}}$ in order to assess the contribution of each random effect to the explained variance in model estimated from equation (10).

\subsection{Results and discussion}

\subsubsection{Estimation results}

Table 3.2 summarizes the estimation results from the GLMs and the GLMMs. The fixed effects, i.e. the logit coefficients from GLMs, are displayed in the second column of Table 3.2. The marginal R-squared ( $R_{G L M M(m)}^{2}$ ) indicates that the fixed effects explain $24.7 \%$ of the variance in the prevalence of asymmetries in VPT.

On average the probability of finding asymmetry is lower with the increase of duration of unchanged prices. The fitted probability of asymmetry in VPT for the EAN with the lowest duration (1.64 weeks) is 34\%, ceteris paribus. This fitted probability is only $2 \%$ for the EAN with highest duration of unchanged prices (104 weeks). From the marginal effects, the third column of Table 3.2, an increase of one week in duration implies a decrease of $3.5 \%$ in the probability of asymmetry in VPT; thus cannot support the first hypothesis of this study. 
We do not find a systematic difference between the EANs with a national brand and EANs with a private label in our dataset; therefore, the second hypothesis is not verified. This could be explained by the limited middleman activity in the dairy sector in Germany as outlined above. Moreover, the double marginalization is not an issue since the dairies often deal directly with the retailers in Germany (Friedrich, 2010; Loy et al., 2015). 
Table 3.2 Factors that explain the asymmetry in VPT using GLMs and GLMMs

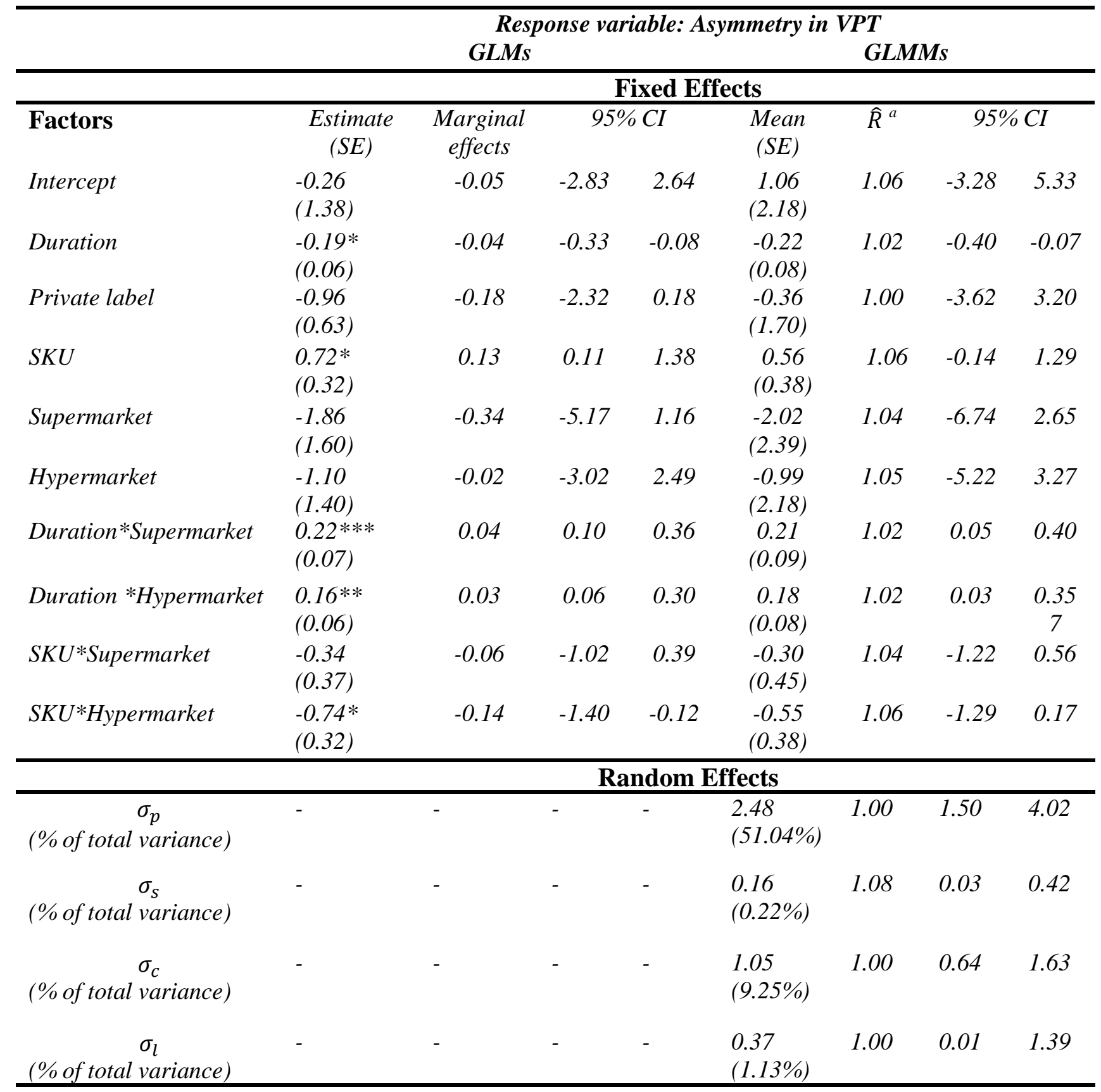

(\% of total variance)

\section{Explained Variance}

\begin{tabular}{lll}
\hline \multicolumn{1}{c}{$R_{\text {GLMM }(m)}^{2}$} & $24.71 \%$ & $10.95 \%$ \\
\hline \multicolumn{1}{c}{$R_{G L M M(c)}^{2}$} & $24.71 \%$ & $72.61 \%$ \\
\hline Number of & Null deviance $=1246.6 ;$ & Deviance $=942.8$ \\
observations :1087 & Residual deviance=1184.3; & $p D=72.4$ \\
& AIC=1204.3 & DIC $=1015.2$ \\
\hline '***' denotes significance at 1\%, '**'at 5\% and '*'at 10\%." &
\end{tabular}

'***' denotes significance at $1 \%$, '**'at $5 \%$ and '*'at $10 \%$.

${ }^{a} \hat{R}$ : indicator of convergence, as a rule of thumb: $\hat{R}<1.1$ means convergence (Gelman \& Hill, 2007)

Source: Authors' calculations

The coefficient associated with consumer search costs (SKU) is positive and significantly different from zero, which suggests that consumer search costs do explain asymmetry in the 
VPT. An increase of one stock keeping unit implies an increase of $13.2 \%$ in the likelihood of asymmetry in VPT. Therefore, we verify the third hypothesis. This result is in line with Richards et al.(2014), who provide some evidence for cereal bars in the USA.

Furthermore, we do not find that supermarkets and hypermarkets employ more asymmetries in VPT than the discount stores. Therefore, the fourth hypothesis is not verified. However, the interactions between the formats of store and duration are significant. They reveal that when prices are kept unchanged for one (additional) week within the supermarkets and the hypermarkets, to limit markup variation, the results lead to an increase of $4 \%$ and $3 \%$ in asymmetry in VPT, respectively. This, provides initial evidence that allows us to verify the fifth hypothesis.

We also find that the interaction between the format of store and number of SKU can explain the differences in asymmetries in VPT. More specifically, differences are found between the discount stores and the hypermarkets. An increase of one unit in the number of SKU within the hypermarkets implies a decrease in the probability of finding asymmetry in VPT of 13.6\%. Hypermarkets are supposed to change their prices more often due to the HiLo strategy, and consumers expect a benefit from their search. Thus, when hypermarkets reduce prices only enough to cause consumers not to search for new prices within the discount stores (EDLP), and if in addition the hypermarkets use butter as a loss leader to attract consumers to the store (Loy et al., 2015), this could lead to the decrease in asymmetry of VPT. This result provides additional evidence that allows the verification the fifth hypothesis.

The random effects are displayed in the bottom of the third column of Table 3.2. The conditional R-squared $\left(R_{G L M M(c)}^{2}\right)$ indicates that the together with the fixed effects the random effects explain $72.61 \%$ of the variance in the prevalence of asymmetries in VPT. In all cases, the $\hat{R}<1.1$ is fulfilled, which means that the condition of convergence for the Markov Chains is met. For further details on the quality of the convergence in the MCMC see Figure A (Annex), where the mixtures of the three Markov Chains and the check for au-correlation using and the ACF plots are displayed.

The variance of the random effects associated with factor product is large ( $\left.\sigma_{p}^{2}=6.130\right)$. This means that $51.04 \%$ of the explained variance in the prevalence of asymmetries in VPT is product specific. This is what we expect, because the exact same product is subject to different pricing strategies in different stores and chains. The variance of the random effects associated with store is small $\left(\sigma_{s}^{2}=0.027\right)$. The differences between stores explain only 
$0.22 \%$ of the variance in the occurrence of asymmetries in VPT, which means that the differences between the 345 stores have little influence on the asymmetry in VPT. This is perhaps due to the limited flexibility the stores managers have in determining prices. The differences between the chains are rather large, where the estimated variance of the random effects associated to the chain is $\sigma_{c}^{2}=1.110$. The differences between the retail chains explain $9.25 \%$ of the variance in the occurrence of asymmetries in VPT. This suggests centralized management of price indication across the stores. Last but not least, we find small differences between the different classes of chains, where the variance of the random effects associated with facto Class is $\sigma_{l}^{2}=0.154$, which explain $1.13 \%$ of the explained variance.

Figure 3.5 illustrates the effect of duration, ceteris paribus, on the fitted probabilities of asymmetry in VPT for the 37 chains. Obviously, many chains deviate from the solid brown line, which represents the mean model fitted with the GLMMs. Above all, we highlight two chains (Chain $A$ in dashed blue line and Chain $C$ in solid blue line) whose intercept deviates one and two standard deviations respectively below the mean intercept of GLMMs; and two chains (Chain $B$ in dashed red line and Chain $D$ in solid blue line) whose intercept deviate one and two standard deviations above the mean intercept of the GLMMs. This provides additional evidence to validate our sixth hypothesis: that there are indeed certain retail chains that have some potential to divert from the mean intercept. More evidence on the other factors can be found in annex (see Figure A 3.2).

Figure 3.5 The fitted probabilities of asymmetry in VPT as a function of duration for different chains

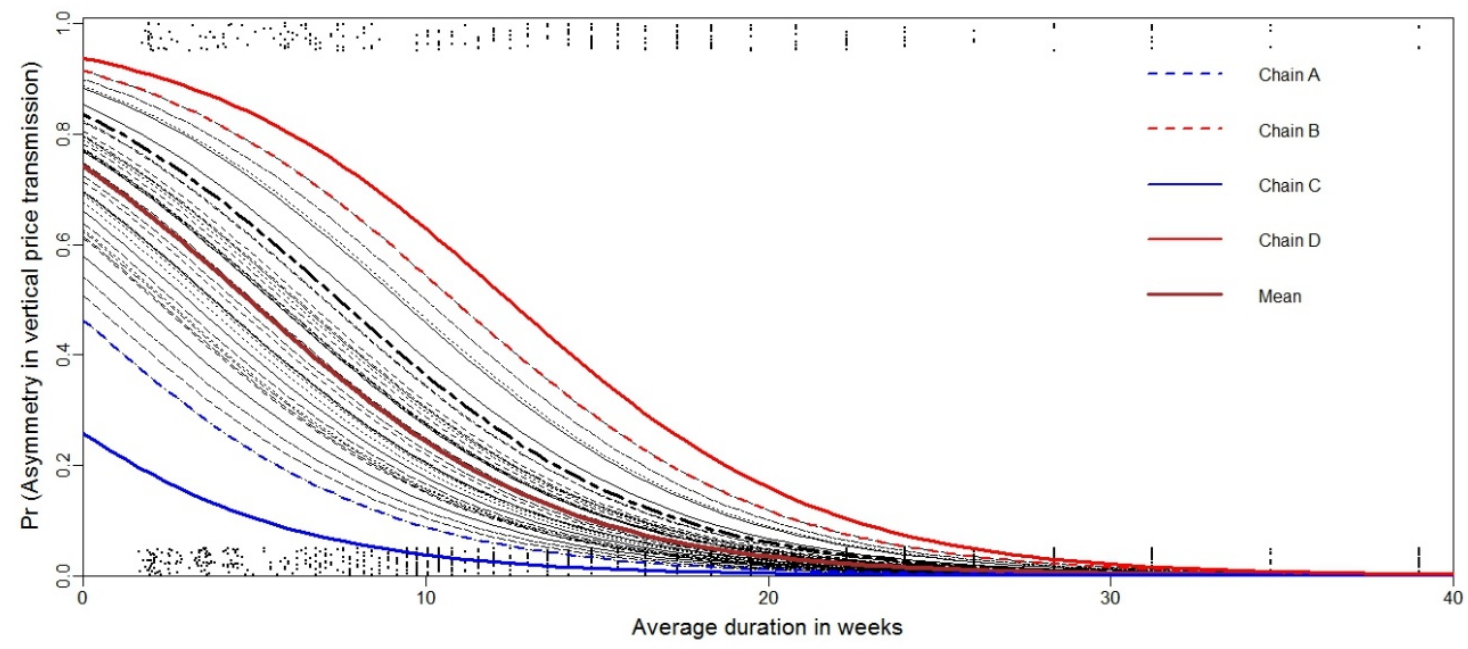

Source: Authors' calculations 


\subsubsection{Features of the chains that are distributed in the tails}

Figure 3.6 illustrates, with the same four examples of chains (Chain A, Chain B, Chain C, and Chain D) highlighted in Figure 3.5, which estimated intercepts are in the tails of the distribution of $\gamma_{c}$. The features of these four chains are of particular interest, because it casts light on the discrepancies that we find in the price dynamics between the 1087 EANs. Table 3.3 presents the features of the chains that contribute to the decrease or the increase in the probability of finding asymmetry in VPT.

\section{Figure 3.6 Kernel density of random effects associated with the factor chain}

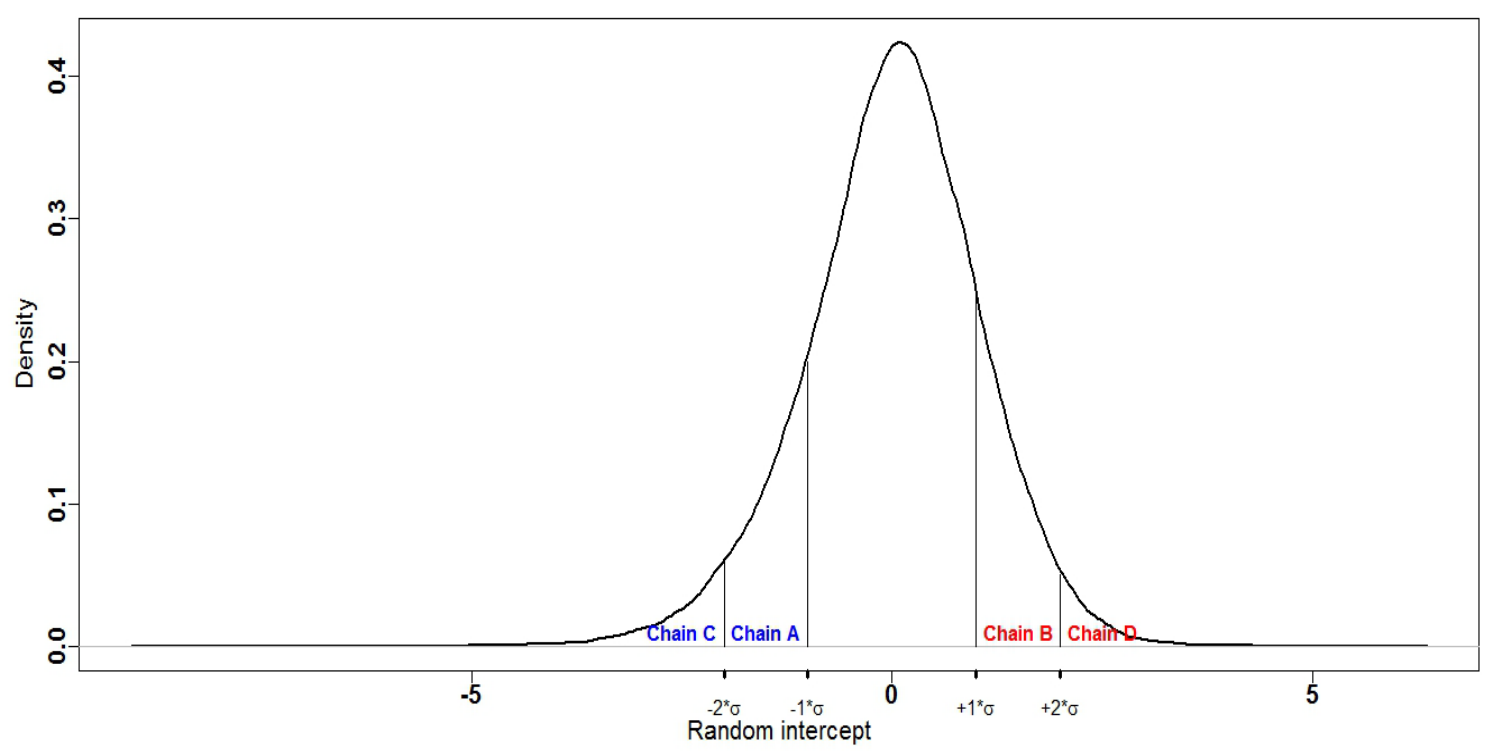

Source: Authors’ calculations

In Figure 3.6, the intercept for Chain $A$ is likely to lie between one and two standard deviations below the mean intercept, indicating that stores in Chain $A$ are less likely to display asymmetries in VPT. VPT is found to be symmetric in $90 \%$ of the EANs sold by the stores that belong to this chain. Chain A manages a relatively large number of stores (26) and products (13). Within Chain A, the average duration of 24 weeks, which is higher than the average duration of 16 weeks in the data. The average number of 4 SKUs is equal to the average in the subsample. Regarding the format of store, $18 \%$ are discount stores, $16 \%$ supermarkets and 64\% hypermarkets. The intercept for Chain $C$ is likely to lie under two standard deviations below the mean intercept, indicating that it is very unlikely to find asymmetry in VPT for this chain. VPT is symmetric for $100 \%$ of the EANs sold by the stores that belong to this chain. Chain $C$ manages a small number of stores (9), but has almost the same number of products (12) as Chain A. The average duration (31) and average number of 
SKU (7) are higher in Chain $C$ than Chain $A$. The format stores that belong to Chain $C$ are mostly hypermarkets (93\%).

The intercept for Chain B is likely to lie between one and two standard deviations above the mean intercept, indicating that the stores in Chain B are more likely to display asymmetries in VPT. VPT is found to asymmetric in $88 \%$ of the EANs sold by the stores that belong to this chain. Chain B manages mostly supermarkets (88\%) and it does not have discount stores. In comparison to Chain A, Chain B manages fewer numbers of stores (4) and products (4).

Table 3.3 Features of the chains that are distributed in the tails of the posterior distribution of the random effects

\begin{tabular}{|c|c|c|c|c|c|c|c|c|c|}
\hline Chain & $\overline{\text { Class }}$ & $\overline{E A N}$ & $\overline{S K U}$ & Duration & $\begin{array}{l}\text { Number } \\
\text { of } \\
\text { stores }\end{array}$ & Format of store & $\begin{array}{l}\text { Number } \\
\text { of } \\
\text { products }\end{array}$ & Region & $\overline{V P T}$ \\
\hline$A$ & Class 1 & 65 & 4 & 24 & 26 & $\begin{array}{l}\text { 18\% Discount stores } \\
\text { 16\% Supermarkets } \\
64 \% \text { Hypermarkets }\end{array}$ & 13 & $\begin{array}{l}\text { All } \\
\text { regions, } \\
\text { but South }\end{array}$ & $\begin{array}{l}90 \% \\
\text { Symmetric }\end{array}$ \\
\hline $\bar{C}$ & Class 1 & 45 & 7 & 31 & 9 & $\begin{array}{l}\text { 7\% Supermarkets } \\
\text { 93\% Hypermarkets }\end{array}$ & 12 & $\begin{array}{l}\text { All } \\
\text { regions, } \\
\text { but South }\end{array}$ & $\begin{array}{l}100 \% \\
\text { Symmetric }\end{array}$ \\
\hline $\bar{B}$ & Class 1 & 8 & 2 & 21 & 4 & $\begin{array}{l}88 \% \text { Supermarkets } \\
12 \% \text { Hypermarkets }\end{array}$ & 4 & South & $\begin{array}{l}88 \% \\
\text { Asymmetric }\end{array}$ \\
\hline$D$ & Class 1 & 30 & 4 & 23 & 11 & $\begin{array}{l}\text { 13\% Supermarket } \\
87 \% \text { Hypermarket }\end{array}$ & 9 & South & $\begin{array}{l}66 \% \\
\text { Asymmetric }\end{array}$ \\
\hline
\end{tabular}

$\%$ relative to EANs in each chain, not to the total sample

Source: Authors' calculations

Since the distribution of $\gamma_{c}$ is slightly left-skewed, the choice for Chain $D$ was not easy. The intercept for Chain $D$ is likely to lie two standard deviations above the mean intercept. The Chain D is a special case though. VPT is asymmetric in $66 \%$ of the EANs sold by the stores that belong to this chain. The results from checking for patterns that would explain why asymmetries in VPT are important within Chain $D$ are not conclusive.

Moreover, the region seems to influence the finding of asymmetry VPT, because all stores that belong to Chain B and Chain D are located in the southern part of Germany. This can be explained by the fact that geographically the dairy industry is concentrated in two major areas: the Bavarians dairies, mostly private companies located in southern Germany, and cooperatives-based dairies located in the northwestern regions of Germany (Jansik et al., 2014). A link between the non-cooperatives dairies and the finding of asymmetries in VPT has been found for the case of butter (Loy et al., 2015). We also notice that Chain $B$ and 
Chain D do not include discount stores, whereas discount stores are present in Chain A. This means that the difference between the formats of store in explaining the finding of asymmetry in VPT are rather mixed. 


\subsection{Conclusion}

In theory, asymmetry in vertical price transmission (VPT) is explained with reference to an individual economic agent: farmer, manufacturer, wholesaler, or retailer. Yet typically, price aggregated data are used in empirical studies of VPT. Retail chains differ in several aspects though, and more importantly in their pricing strategies, which might lead to variations in price dynamics. In this study, we investigate why some chains/stores display more asymmetries in VPT and others less for the same product defined by a European Article Number. In a first step, we assess the nature of the price dynamics, i.e. symmetric or asymmetric VPT at the individual retail store, from wholesale to retail prices for 56 welldefined and homogeneous 250-gram foil-wrapped packages of butter in Germany over a 312week period using scanner data. In a second step, we link the variations in price dynamics to some factors and indicators of pricing strategy that might help to explain asymmetric VPT patterns. We also employ indicators of well-defined pricing strategies (EDLP and HiLo), such as price rigidity and consumer search costs, combined with the format of stores that are likely to employ them to explain the prevalence of asymmetry in VPT.

Our results complement the findings of Loy et al.(2015) in that we explicitly take the hierarchically structured data and separate out the effects of the product, store and chain on the variation in the price dynamics. We show that asymmetry in VPT is systematically related to store membership in a retail chain. We also cast light on some differences between the retail chains that employ asymmetries in VPT from those who employ symmetries in VPT. We do not find important differences at the store level, which is explained by the limited flexibility left to store managers in price setting. We do not no find systematic differences between the private labels compared to the national brands; a result which is not in line with Hong \& Li (2015).

The implications resulting from our research may help both retailers and dairies to reduce asymmetries in VPT. First, we can determine that double marginalization is not much of an issue, since it does not necessarily lead to asymmetries in VPT. Second, rigid prices and consumer search costs affect VPT processes; therefore, dairies and retailers who are interested in improving market integration and avoid asymmetries in VPT might consider reducing consumer search costs and allow prices to fluctuate to reflect the changes in the wholesale prices. Third, rather than treating all retail chains the same, we show that there are some retail chains that contribute to the enhancement of passing along costs. Finally, we 
document some indicators of retail chain pricing strategies that reduce asymmetries in VPT, which may be informative for dairies. 


\subsection{References}

Anania, G., \& Nisticò, R. (2014). Price dispersion and seller heterogeneity in retail food markets. Food Policy, 44, 190-201.

Aramyan, L. H., \& Kuiper, M. (2009). Analyzing price transmission in agri-food supply chains: an overview. Measuring Business Excellence, 13(3), 3-12.

Azzam, A. M. (1999). Asymmetry and Rigidity in Farm-Retail Price Transmission. American Journal of Agricultural Economics, 81(3), 525-533.

Bolker, B. M., Brooks, M. E., Clark, C. J., Geange, S. W., Poulsen, J. R., Stevens, M. H. H., \& White, J.-S. S. (2009). Generalized linear mixed models: a practical guide for ecology and evolution. Trends in Ecology \& Evolution, 24(3), 127-35.

Bolton, R. N., \& Shankar, V. (2003). An empirically derived taxonomy of retailer pricing and promotion strategies. Journal of Retailing, 79(4), 213-224.

Breslow, N. E. (2004). Whither PQL? In D. Y. Lin \& P. J. Heagerty (Eds.), Proceedings of the Second Seattle Symposium in Biostatistics (Vol. 179, pp. 1-22). New York, NY: Springer New York.

Breslow, N. E., \& Clayton, D. G. (1993). Approximate Inference in Generalized Linear Mixed Models. Journal of the American Statistical Association, 88(421), 9-25.

Browne, W. J., \& Draper, D. (2006). A comparison of Bayesian and likelihood-based methods for fitting multilevel models. Bayesian Analysis, 1(3), 473-514.

BVE. (2014). Marktanteile der führenden Unternehmen im Lebensmittelhandel in Deutschland im Jahr 2014.

Cleeren, K., Verboven, F., Dekimpe, M. G., \& Gielens, K. (2010). Intra- and Interformat Competition Among Discounters and Supermarkets. Marketing Science, 29(3), 456-473.

Eichenbaum, M., Jaimovich, N., \& Rebelo, S. (2011). Reference Prices, Costs, and Nominal Rigidities. American Economic Review, 101(1), 234-262.

Engle, R. F., \& Granger, C. W. J. (1987). Co-Integration and Error Correction: Representation, Estimation, and Testing. Econometrica, 55(2), 251-276.

Everwand, W. C., Ingenbleek, P. T. M., \& Backus, G. B. C. (2007). From commodity to customer value : the transition from a production-oriented to a market-oriented European dairy industry.

Fahrmeir, L., Kneib, T., Lang, S., \& Marx, B. (2013). Regression Models. In Regression (pp. 389-397). Springer.

Fassnacht, M., \& El Husseini, S. (2013). EDLP versus Hi-Lo pricing strategies in retailing-a state of the art article. Journal of Business Economics, 83(3), 259-289.

Frey, G., \& Manera, M. (2007). ECONOMETRIC MODELS OF ASYMMETRIC PRICE TRANSMISSION. Journal of Economic Surveys, 21(2), 349-415.

Friedrich, C. (2010). Milchverarbeitung und -vermarktung in Deutschland - eine deskriptive Analyse der Wertschöpfungskette.

Gelman, A. (2006). Prior distributions for variance parameters in hierarchical models (comment on article by Browne and Draper). Bayesian Analysis, 1(3), 515-534.

Gelman, A., \& Hill, J. (2007). Data analysis using regression and multilevel/hierarchical models (pp. 235-434). Cambridge University Press.

Gijsbrechts, E., Campo, K., \& Nisol, P. (2008). Beyond promotion-based store switching: Antecedents and patterns of systematic multiple-store shopping. International Journal of Research in Marketing, 25(1), 5-21.

Gilks, W. R., Richardson, S., \& Spiegelhalter, D. J. (1996). Introducing Markov Chain Monte Carlo. In Markov Chain Monte Carlo in Practice (pp. 1-19). London: Chapman and Hall.

Goldstein, H., \& Rasbash, J. (1996). Improved Approximations for Multilevel Models with 
Binary Responses. Journal of the Royal Statistical Society. Series A (Statistics in Society), 159(3), 505-513.

González-Benito, Ó., Martos-Partal, M., \& Fustinoni-Venturini, M. (2014). Retailers' Price Positioning and the Motivational Profiling of Store-Brand Shoppers: The Case of Spain. Psychology \& Marketing, 31(2), 115-125.

Granger, C. W. J., \& Lee, T. H. (1989). Investigation of production, sales and inventory relationships using multicointegration and non-symmetric error correction models. Journal of Applied Econometrics, 4(S1), S145-S159.

Hellberg-Bahr, A., Pfeuffer, M., Steffen, N., Brümmer, B., \& Spiller, A. (2010, September 1). Preisbildungssysteme in der Milchwirtschaft. Ein Überblick über die Supply Chain Milch.

Herrmann, R., Moeser, A., \& Weber, S. A. (2005). Price Rigidity in the German GroceryRetailing Sector: Scanner-Data Evidence on Magnitude and Causes. Journal of Agricultural \& Food Industrial Organization, 3(1).

Herrmann, R., Möser, A., \& Weber, S. A. (2009). Grocery retailing in Germany: Situation, development and pricing strategies.

Ho, T.-H., Tang, C. S., \& Bell, D. R. (1998). Rational Shopping Behavior and the Option Value of Variable Pricing. Management Science, 44(12-Part-2), S145-S160.

Hoch, S. J. (1996). How Should National Brands Think about Private Labels? Sloan Management Review, 37(2), 89-102.

Hoch, S. J., Drèze, X., \& Purk, M. E. (1994). EDLP, Hi-Lo, and margin arithmetic. Journal of Marketing, 58(4), 16.

Hong, G. H., \& Li, N. (2015). Market structure and cost pass-through in retail. Review of Economics and Statistics.

Jansik, C., Irz, X., \& Kuosmanen, N. (2014). Competitiveness of Northern European dairy chains. Helsinki, Finland: Vammalan Kirjapaino Oy.

Jürgens, K., Poppinga, O., \& Wohlgemuth, M. (2013). What is the cost of producing milk? Calculatiuons of the milk production costs in Germany for the years 2002-2012.

Kaltcheva, V. D., Winsor, R. D., Patino, A., \& Shapiro, S. (2013). Impact of promotions on shopper price comparisons. Journal of Business Research, 66(7), 809-815.

Kinnucan, H. W., \& Forker, O. D. (1987). Asymmetry in Farm-Retail Price Transmission for Major Dairy Products. American Journal of Agricultural Economics, 69(2), 285.

Konur, D., \& Geunes, J. (2016). Supplier wholesale pricing for a retail chain: Implications of centralized vs. decentralized retailing and procurement under quantity competition. Omega.

Lal, R., \& Rao, R. (1997). Supermarket Competition: The Case of Every Day Low Pricing. Marketing Science, 16(1), 60-80.

Lebensmittel Zeitung (LZ). (2014). Revenue of the leading dairy companies in Germany in 2014 (in million euros).

Levy, D., Bergen, M., Dutta, S., \& Venable, R. (1997). The Magnitude of Menu Costs: Direct Evidence From Large U. S. Supermarket Chains. The Quarterly Journal of Economics, 112(3), 791-825.

Li, L., Sexton, R. J., \& Xia, T. (2006). Food Retailers’ Pricing and Marketing Strategies, with Implications for Producers. Agricultural and Resource Economics Review, 35(2).

Loy, J.-P. J.-P., Holm, T., Steinhagen, C., \& Glauben, T. (2015). Cost pass-through in differentiated product markets: a disaggregated study for milk and butter. European Review of Agricultural Economics, 42(3), 441-471.

McNeil, A. J., \& Wendin, J. P. (2007). Bayesian inference for generalized linear mixed models of portfolio credit risk. Journal of Empirical Finance, 14(2), 131-149.

Meyer, J., \& Cramon-Taubadel, S. (2004). Asymmetric Price Transmission: A Survey. 
Journal of Agricultural Economics, 55(3), 581-611.

Mills, D. E. (1995). Why Retailers Sell Private Labels. Journal of Economics Management Strategy, 4(3), 509-528.

Morschett, D., Swoboda, B., \& Schramm-Klein, H. (2006). Competitive strategies in retailing - an investigation of the applicability of Porter's framework for food retailers. Journal of Retailing and Consumer Services, 13(4), 275-287.

Nakagawa, S., \& Schielzeth, H. (2013). A general and simple method for obtaining R 2 from generalized linear mixed-effects models. Methods in Ecology and Evolution, 4(2), 133142.

Nakamura, E. (2008). Pass-Through in Retail and Wholesale. American Economic Review, 98(2), 430-437.

Owen, A., \& Trzepacz, D. (2002). Menu costs, firm strategy, and price rigidity. Economics Letters, 76(3), 345-349.

Peltzman, S. (2000). Prices Rise Faster than They Fall. Journal of Political Economy, 108(3), 466-502.

Pinheiro, J. C., \& Chao, E. C. (2006). Efficient Laplacian and Adaptive Gaussian Quadrature Algorithms for Multilevel Generalized Linear Mixed Models. Journal of Computational and Graphical Statistics, 15(1), 58-81.

Powers, E. T., \& Powers, N. J. (2001). No Title. Review of Industrial Organization, 18(4), 397-416.

Rabe-Hesketh, S., \& Skrondal, A. (2012). Multilevel and Longitudinal Modeling Using Stata Volume II: Categorical Responses, Counts, and Survival (Third Edit). College Station, Texas: Stata Press.

Rabe-Hesketh, S., Skrondal, A., \& Pickles, A. (2005). Maximum likelihood estimation of limited and discrete dependent variable models with nested random effects. Journal of Econometrics, 128(2), 301-323.

Raudenbush, S. W., Yang, M.-L., \& Yosef, M. (2000). Maximum Likelihood for Generalized Linear Models with Nested Random Effects via High-Order, Multivariate Laplace Approximation. Journal of Computational and Graphical Statistics, 9(1), 141-157.

Richards, T. J., Gomez, M. I., \& Lee, J. (2014). Pass-Through and Consumer Search: An Empirical Analysis. American Journal of Agricultural Economics, 96(4), 1049-1069.

Rodriguez, G., \& Goldman, N. (1995). An Assessment of Estimation Procedures for Multilevel Models with Binary Responses. Journal of the Royal Statistical Society. Series A (Statistics in Society), 158(1), 73-89.

Rodriguez, G., \& Goldman, N. (2001). Improved Estimation Procedures for Multilevel Models with Binary Response: A Case-Study. Journal of the Royal Statistical Society. Series A (Statistics in Society), 164(2), 339-355.

Rondán Cataluña, F. J., Sánchez Franco, M. J., \& Villarejo Ramos, A. F. (2005). Are hypermarket prices different from discount store prices? Journal of Product \& Brand Management, 14(5), 330-337.

SBKB. (2011). Weekly wholesale prices. Süddeutsche Butter- und Käse-Börse e.V. Kempten (Allgäu).

Schall, R. (1991). Estimation in generalized linear models with random effects. Biometrika, 78(4), 719-727.

Sexton, R. J., Zhang, M., \& Chalfant, J. (2003). Grocery retailer behavior in the procurement and sale of perishable fresh produce commodities. USDA Economic Research Sevice.

SIG (Symphony IRI Group GmbH). (2011). Retail Scanner Data.

Spiegelhalter, D. J., Best, N. G., Carlin, B. P., \& van der Linde, A. (2002). Bayesian measures of model complexity and fit. Journal of the Royal Statistical Society: Series B (Statistical Methodology), 64(4), 583-639. 
Sturtz, S., Ligges, U., \& Gelman, A. E. (2005). R2WinBUGS: A Package for Running WinBUGS from R. Journal of Statistical Software, 12(3), 1-16.

Tappata, M. (2009). Rockets and feathers: Understanding asymmetric pricing. The RAND Journal of Economics, 40(4), 673-687.

Tifaoui, S., \& von Cramon-Taubadel, S. (2016). Temporary Sales Prices and Asymmetric Price Transmission. Agribusiness, n/a-n/a.

Vavra, P., \& Goodwin, B. K. (2005). Analysis of price transmission along the food chain (No. 3). France.

Verbeke, G., \& Molenberghs, G. (2000). Linear mixed models for longitudinal data. Springer series in statistics.

von Cramon-Taubadel, S. (1998). Estimating asymmetric price transmission with the error correction representation: An application to the German pork market. European Review of Agricultural Economics, 25(1), 1-18.

Weber, S. A., \& Anders, S. M. (2007). Price rigidity and market power in German retailing. Managerial and Decision Economics, 28(7), 737-749.

Wolfinger, R., \& O’connell, M. (1993). Generalized linear mixed models a pseudo-likelihood approach. Journal of Statistical Computation and Simulation, 48(3-4), 233-243.

Yang, H., \& Ye, L. (2008). Search with learning: understanding asymmetric price adjustments. The RAND Journal of Economics, 39(2), 547-564.

Yuan, H., \& Han, S. (2011). The Effects of Consumers' Price Expectations on Sellers' Dynamic Pricing Strategies. Journal of Marketing Research, 48(1), 48-61. 
3.9. Annex

Figure A 3.1 Sampling path of the variance of the random effects associated with the product, store, chain and class

Sampling path Sigma product

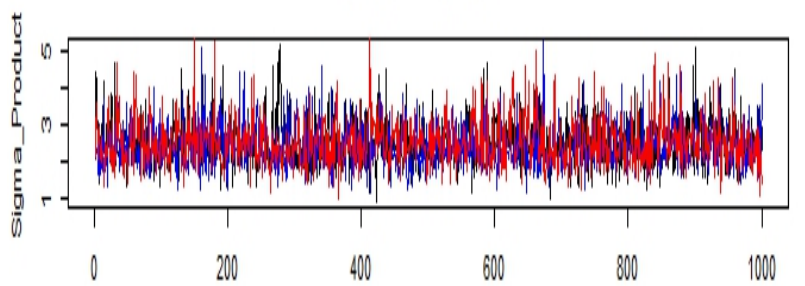

terations

Sampling path Sigma_store

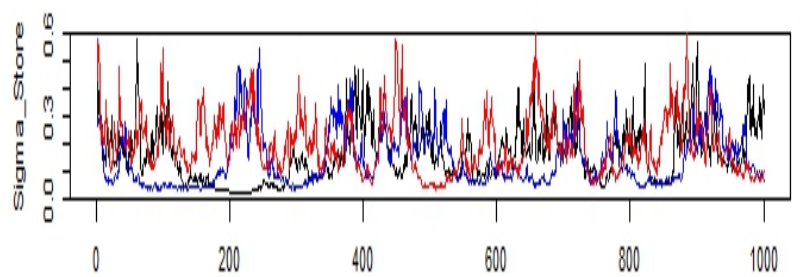

Herations

Sampling path Sigma_chain

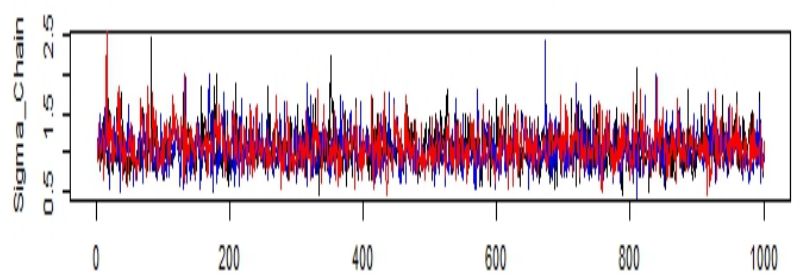

Herations

Sampling path Sigma_class

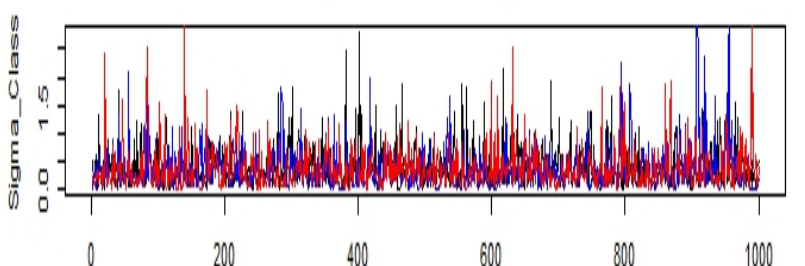

Herations
ACF for Markoo Chains Sigma_product

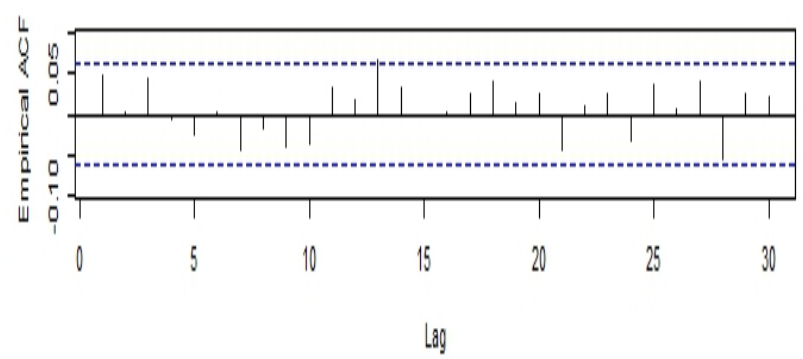

ACF for Markov Chains Sigma store

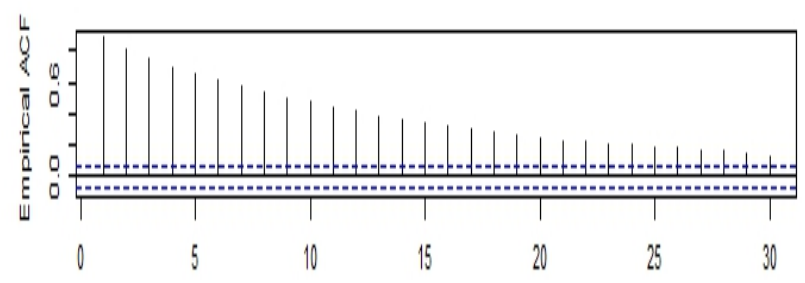

Log

ACF for Markov Chainn Sigma _hain

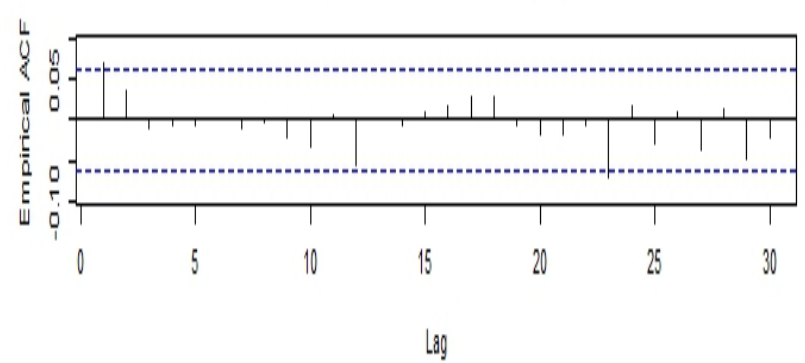

ACF for Markou Chains Sigma _lass

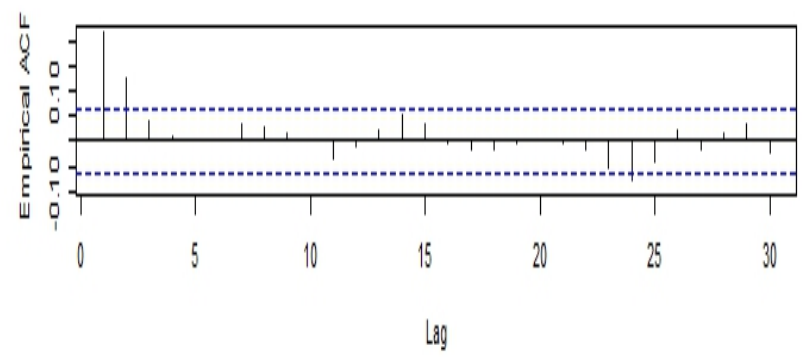

Source: Authors' calculations 
Figure A 3.2 The fitted probabilities of asymmetry in VPT as a function of duration for different class, stores and products
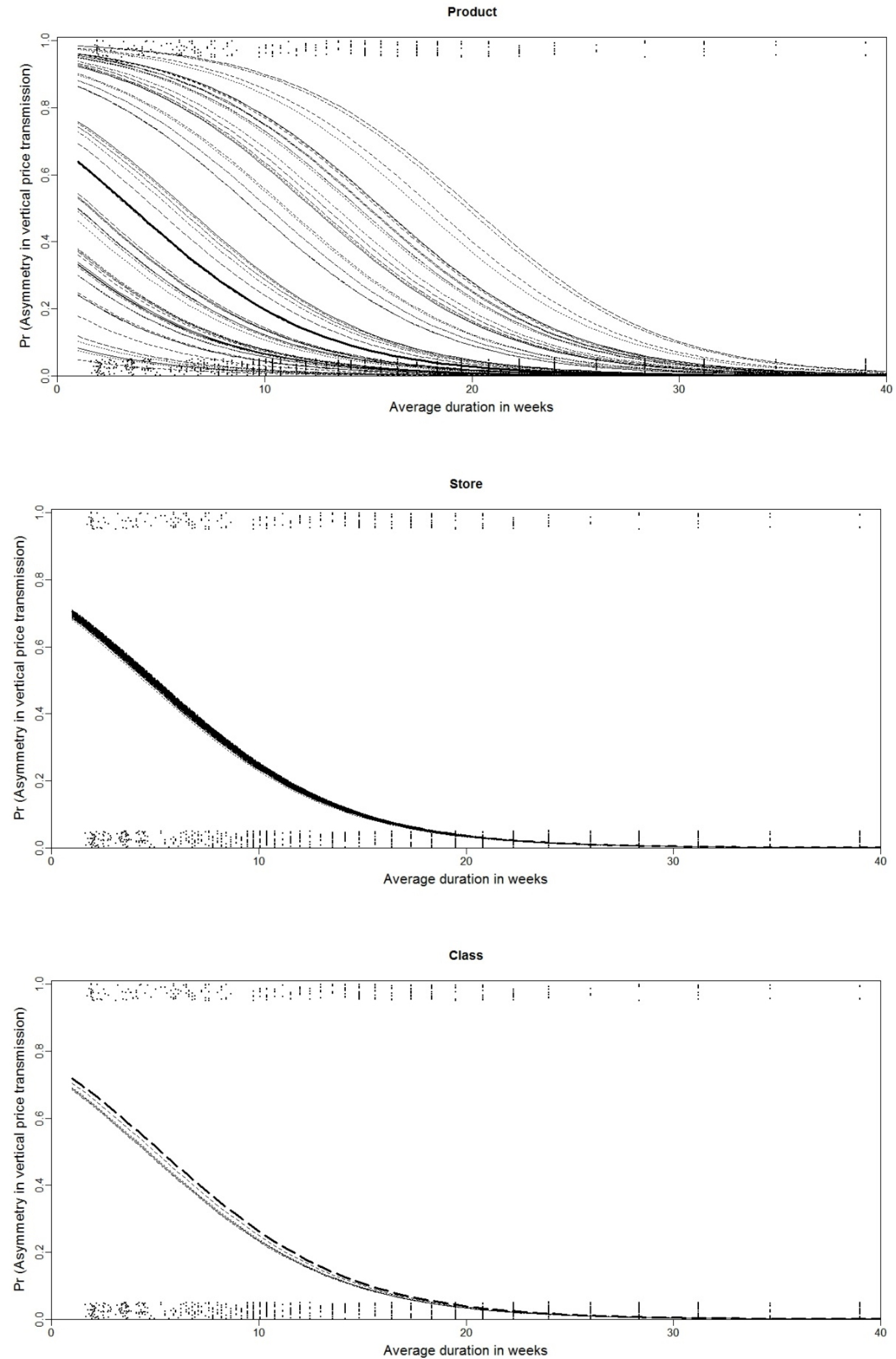

Source: Authors’ calculations 


\title{
4. Vertical price transmission at the individual store level
}

\begin{abstract}
In this study, we model retailers' dichotomous choice of changing retail prices against displaying rigid prices at the retail store level as a function of time and state dependent variables. As state dependent variables, we consider the level of wholesale prices and the reference price, i.e. price of competing retail chains for the same product. We use the elapsed time from the last price change to assess time dependence on retail chains' pricing decisions. To capture the differences that might exist between retail chains' pricing decisions, we employ mixed models. To specify, the marketing margins have both fixed and random effects on the probability of changing retail prices. As a case study, we use scanner data from the German dairy market. We hypothesize that an increase (a decrease) in marketing margins (reference prices) would lead to a decrease (an increase) in the likelihood of introducing a new price change. We also expect that retail chains that are sensitive to changes in their marketing margins will more frequently adjust their prices than the retail chains that are insensitive to their marketing margins. Our findings indicate that retail chains react to the wholesale prices with temporary sales price (TSP). To changes of competing retail prices, retail chains react with changing their regular prices. Moreover, we find a relationship between retailer's sensitivity to changes in their marketing margins and the frequency of changing their regular prices. We also find that it is more likely to change new prices than changing old prices; thus a result that is at odds with the conventional theories of costly price adjustment.
\end{abstract}

Keywords: marketing margin, state dependence, time dependence, generalized linear mixed models. 


\subsection{Introduction}

The study of vertical price transmission (or marketing margins) aims to measure how changes in prices at one market level of a value chain are transmitted to another level of the same value chain (Schwartz \& Schertz Willet, 1994). The marketing margin and the factors that may influence it have generated an abundant literature. Only few areas of agricultural economics have received as much public attention as marketing margins (Wohlgenant, 2001). This is because marketing margins have important implications for consumers' welfare. Yet, retail prices and marketing margins can be influenced by a myriad of factors, including -but not limited to - changes in retail sector prices and upstream suppliers such as wholesalers (Wohlgenant, 2001).

Previous empirical applications of VPT employ only one pair of time series of weighted averages on retail prices in a country or a region, with likely no change in market conditions over time (Loy et al, 2015), or very limited cross-sectional data (see Peltzman, 2000). Using aggregated retail prices to measure VPT implies that all market participants respond to the exact same change in margins and have identical conjectures about the responses of the other participants (Hassouneh et al, 2012). However, this is a strong assumption. At the disaggregated level, different chains follow different pricing strategies, e.g. Every Day Low Price (EDLP) and High-Low (HiLo). The differences between the pricing strategies of the retail chains could explain price dispersion (Loy et al., 2015). However, pricing strategies alone are not sufficient to explain the differences in sensitivity of retail chains toward their marketing margins.

Most of the available literature on VPT use aggregated price data. Deriving conclusions from these studies to explain the individual economic agent behavior, e.g. individual retail store, can be misleading (von Cramon-Taubadel et al. 2006). A more compelling alternative is the VPT assessment at the level of the individual economic agent. Two difficulties are encountered regarding the empirical applications of VPT at the disaggregated level: data availability and appropriate methods. Academic research has recently started to use disaggregated scanner data to assess VPT. This has helped to overcome the first difficultly. However, the latter is not yet well investigated. So far, most of the available literature on VPT use Vector Error Correction Models (VECMs), and non-linear variants of the VECMs. It has only been recently that researchers have started to employ panel data methods to investigate price dynamics at the disaggregated level (Empen, 2014; Holm, 2013; Hong \& Li, 2015; Loy et al., 2015; Richards et al., 2014). To assess price dynamics, previous studies have used first 
differences $\left(\Delta P_{t}=P_{t}-P_{t-1}\right)$ of prices. However, assessing price dynamics with first difference in prices leads to information loss and zero inflated data. This is because retail prices at the store level are sticky. We also use panel data. However, we depart from the previous studies in avoiding the use of first differences to assess price dynamics. This contribution consists in analyzing dichotomous choices between introducing frequent changes in retail prices or displaying rigid prices. As a case study we investigate homogenous products (250-gram foil-wrapped butter) throughout the same period of time (2005-2010), in the same country (Germany).

Retail prices are rigid at the microeconomic level (Kehoe \& Midrigan, 2015). A literature review on the theoretical models in Weiss (1993) and in Taylor (1999) and more recently in Gautier (2009), show that there is no consensus on the theories behind the price adjustments at the microeconomic level. Blinder (1994) for instance identifies twelve different theories, and discusses them in detail. In general, there are two main competing families that try to explain how a price changes at the microeconomic level: time dependent (Calvo) models and state dependent (menu cost) models. More recently, Eichenbaum et al. (2011) challenge both the Calvo model and menu cost models in explaining some important and recurrent features of price data at the microeconomic level. More specifically, how reference prices adjust to reference costs.

The study of price changes at the microeconomic level can also be considered for its intrinsic value, (Loy \& Weiss, 2002). How this intrinsic value can shed light on how prices are determined and transmitted at the smallest possible scale is the main subject of this study. More specifically: how do retail chains adjust their prices at the individual store level as a response to shocks in wholesale prices? How do retail chains react to shocks in prices of a similar product sold by other competing retail chains? Moreover, since price changes imply repricing costs, to what extent can costs be determined at the time of adjusting the prices. We consider a time dependent factor by introducing elapsed time from the last price change to approximate the effect of accumulated shocks on the likelihood of introducing new price changes.

With this study, we contribute to the literature in several ways. First, to the best of our knowledge this is the first study that attempts to extend the intrinsic value of changing price to research areas such as VPT. We depart from previous studies in linking the patterns of changing retail prices to marketing margins (vertical price transmission). As a case study, we 
use scanner data from the German dairy market. Second, a particularity of this study, compared to the previous studies, is that we explicitly check for the sensitivity of retail chains to their marketing margins. We also check how this sensitivity is connected to the frequency of changing retail prices. More specifically, we model the heterogeneity in price setting and sensitivity to marketing margins within and between retail chains. This has been possible with the use of mixed models, where the marketing margins are modelled to have both fixed and random effects.

The rest of the study is organized as follows. In Section 4.2, we describe situations of retail chains' reactions in the cases of squeezed or stretched marketing margins. Then, we derive scenarios that could explain price setting at the individual retail store. In Section 4.3, we review the related literature on theories that have been proposed so far to explain price setting at the smallest possible scale. In Section 4.4, we present some features of the data and describe the methods that we employ. In Section 4.5, we present and discuss our results. In Section 4.6, we conclude.

\subsection{Background}

In a pioneer study, Gardner (1975) analytically derives a relationship between retail and farm gate prices. Gardner's model assumes perfect competition and constant returns to scale. The retail margin reflects marketing costs. However, perfect competition is not always maintained (Lloyd et al, 2006). There is evidence of imperfect competition in many European countries (McCorriston, 2002), including the German retail food sector (Herrmann et al., 2005; Weber \& Anders, 2007). McCorriston et al. (2001, 1998) and Lloyd et al. (2006) relax the perfect competition assumption in Gardner's model and extend it to situations of oligopoly power and non-constant returns to scale.

Let us consider a typical time series of prices from our data. The solid black line from Figure 4.1 depicts a typical price series for a 250-gram foil-wrapped package of butter sold at a randomly selected store on a weekly basis for the period 2005-2010. The dashed line is a time series of regular prices for the same item filtered from temporary sales prices (TSP). The solid grey line represents the simple average of all filtered prices series in our data set for the same period. The dashed black line represents the wholesale prices for the same period.

Given the level of the marketing margin, i.e. the difference between the retail prices and the wholesale prices, two scenarios are plausible. The first scenario represents the case where the wholesale prices increase; thus the marketing margin is squeezed. Hence, there is a tension 
between the need to change prices or to display rigid prices because of the adjustment costs. Therefore, the retail chain faces a dichotomous choice. The second scenario is opposite to the first one; the wholesale prices decrease. The tension of changing retail prices is not the result of the marketing margins, which are obviously stretched, but is rather the result of the changes in the prices of other competing retail chains. More specifically, the reference prices of others for the same product are decreasing; therefore, there is a need to adjust retail prices again.

\section{Figure 4.1 Factors that may explain changes in prices at the smallest possible scale}

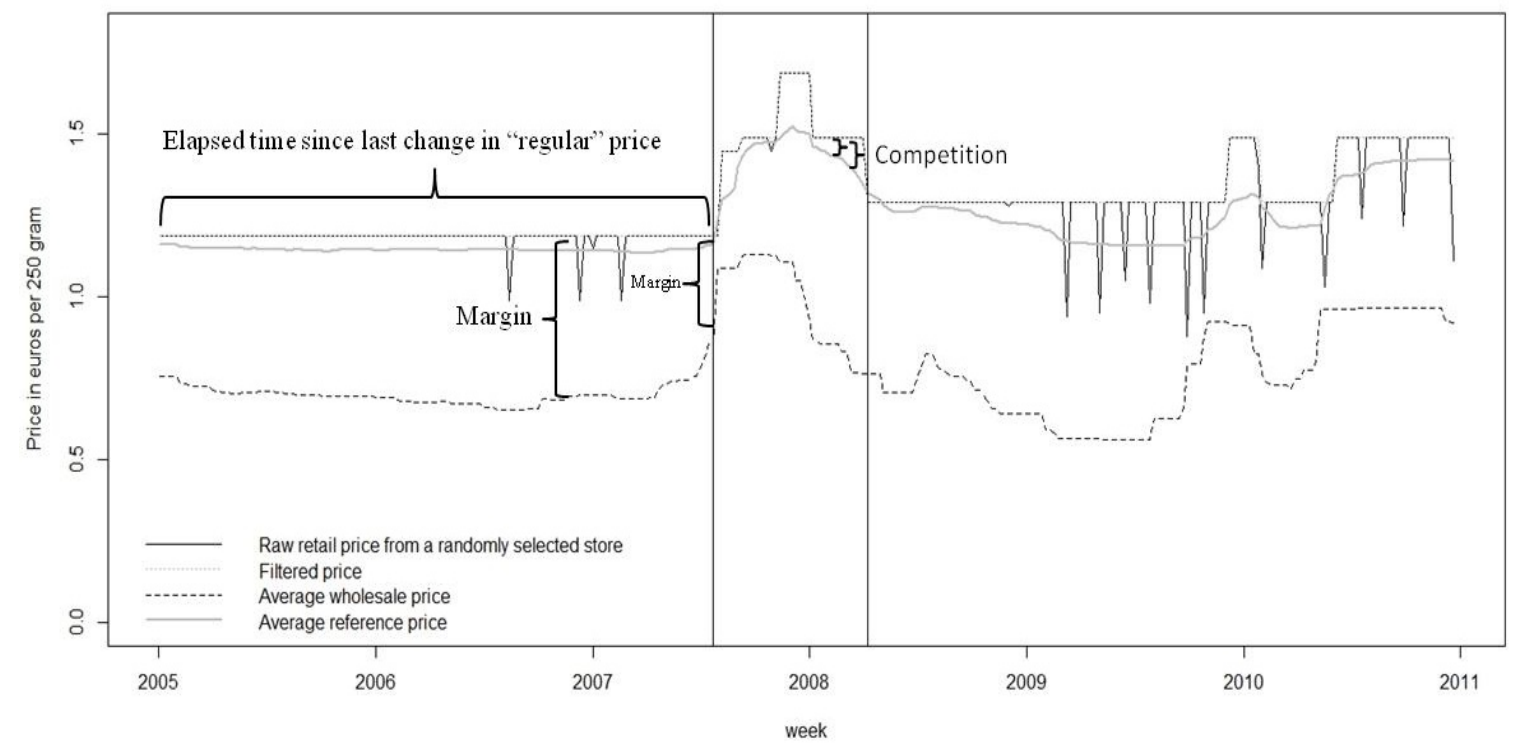

Source: Authors' schematization

Figure 4.1 illustrates a randomly selected time series of prices from our data. To check whether the two scenarios above described hold for the 1,087 different time series included in our dataset, we plot a histogram of the weekly differences between the filtered retail prices and the wholesale prices, and between the filtered retail prices and the reference prices. The results are displayed in Figure 4.2. The left panel from Figure 4.2 indicates that most of the observations are above the wholesale prices (below zero). The observations that are below wholesale prices can be explained by the fact that, when wholesale prices increase, the retail prices need some period of time to adjust to their regular prices; therefore, the average wholesale prices could exceed the retail prices for some weeks. The right panel from Figure 4.2, shows that there are more observations that are below zero than in the left panel. This can be explained by the fact that some retail chains choose to set prices below the average reference prices, e.g. if they follow an EDLP pricing strategy. Some retail chains may also 
wait to accumulate shocks in their costs and make changes in prices that cover re-pricing costs.

Figure 4.2 Histogram margins to wholesale and reference prices
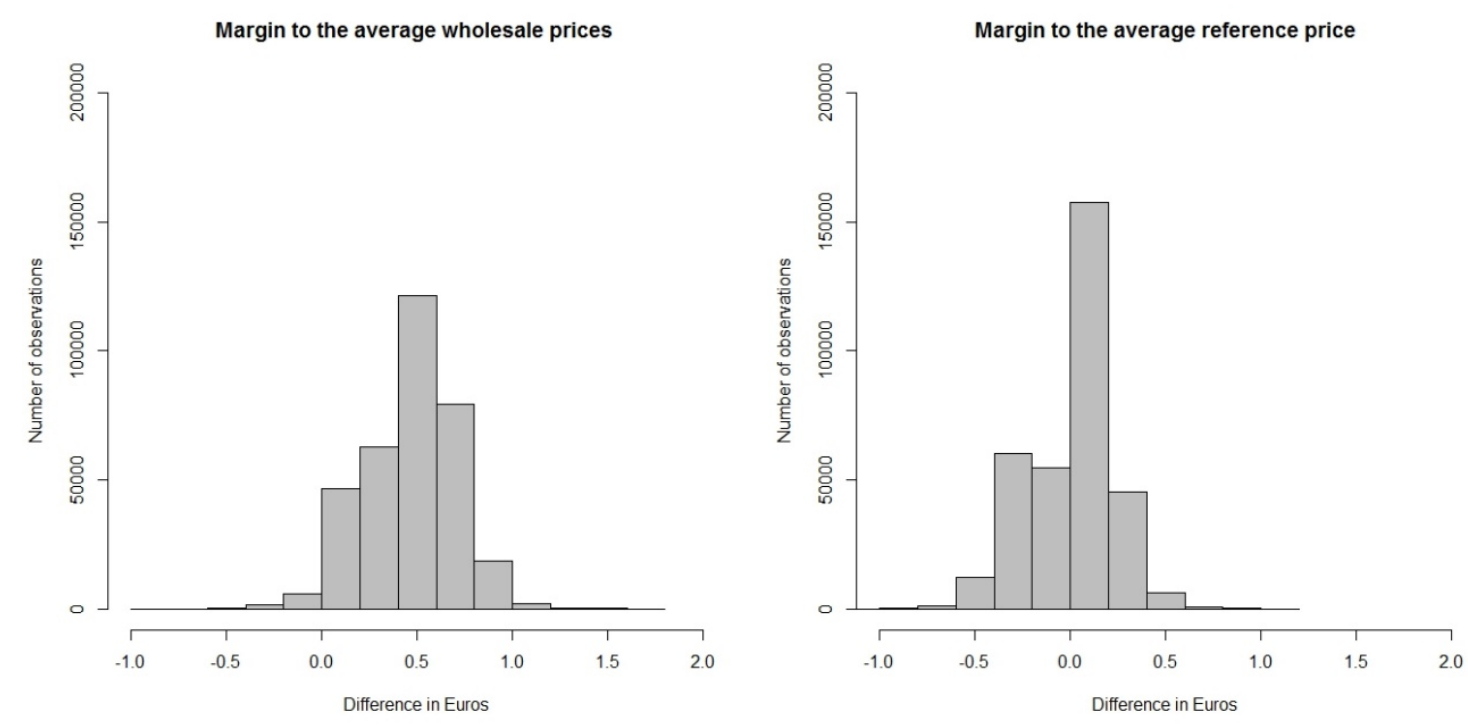

Source: Authors’ calculations

Despite that the analysis of evolution of marketing margins and vertical price transmission are closely related subjects; they are not necessarily identical (Vavra \& Goodwin, 2005). To what extent and with which speed are the changes in wholesale prices transmitted to the retail level are the kinds of questions that are answered with a VPT study. In addition to the evolution of the margins over time, a VPT framework considers costs, which helps in assessing the nature and the level of efficiency along the value chain. This is equivalent to measuring the effect of the changes in margins between the raw (filtered) retail price and the wholesale price on the odds of introducing a price change at the raw (filtered) retail price. Obviously, price adjustments would also depend on other factors that are much more complex than considering just these two factors. However, it is a simplification that could contribute to the understanding of the pricing behavior of retail chains at the smallest possible scale

In this study we aim to answer the following three questions. First, how changes in wholesale prices (changes in marketing margins) affect the changes in retail prices at the smallest possible scale? Second, are the retailers that have recently adjusted their nominal (regular) price likely to adjust their prices again? In this study we employ elapsed time from the last price change to determine the time dependence in price setting. Third, are there many other factors that may influence the changes in a retailer's regular prices? We mainly consider the level of prices of other competitors selling the same product. Other factors such as the 
differences between the private labels and national brand; the differences between different store formats; and the heterogeneity between the retail chains are also considered.

To answer these questions, we consider that changes in retail prices are driven by factors that are related to the external and internal environments of each retail chain. Therefore, several determinants on four different dimensions can be considered. First, the external environment is determined by the level of the wholesale prices and the level of competition of other retail chains. Second, the internal environment is determined by the management of each store, which can be centralized or decentralized. Third, the different format of store, and their pricing strategy, e.g., EDLP and HiLo are also two factors related to the internal environment of the retail chain. Fourth, the chains are different in several aspects; thus heterogeneity may exist in their way of reacting to idiosyncratic shocks from the external environment. Hence, the probability of a change in price $\operatorname{Pr}\left(\Delta\right.$ Price $\left._{i t} \neq 0\right)$ for an EAN $i=1, \ldots, 1087$ at a given week $t=1, \ldots, 312$ is expressed in equation (13):

$$
\operatorname{Pr}\left(\Delta \text { Price }_{i t} \neq 0\right)=f(\text { State dependence, } \text { Time dependence, Control variables, }
$$

Unobseved heterogeneity)

By unobserved heterogeneity in equation (13), we refer to differences between retail chains in their price setting and their sensitivity to time and state dependent factors, e.g. marketing margins.

Figure 4.3 provides a simple schematic of a fictive retail Chain $\mathrm{X}$, which has discount stores, supermarkets, and hypermarkets in its portfolio. Depending on the store format, a retail chain may choose between flexible price setting, e.g. product 1 and product 2, or rigid price setting, e.g. product 3. Exogenous shocks could originate from the external environment, e.g. changes in the retail margin due to increase in wholesale prices or a decrease in demand because of the decrease in prices of a competing retail chain. Our data cover 37 different retail chains. 
Figure 4.3 Simple schematic of price setting at chain level

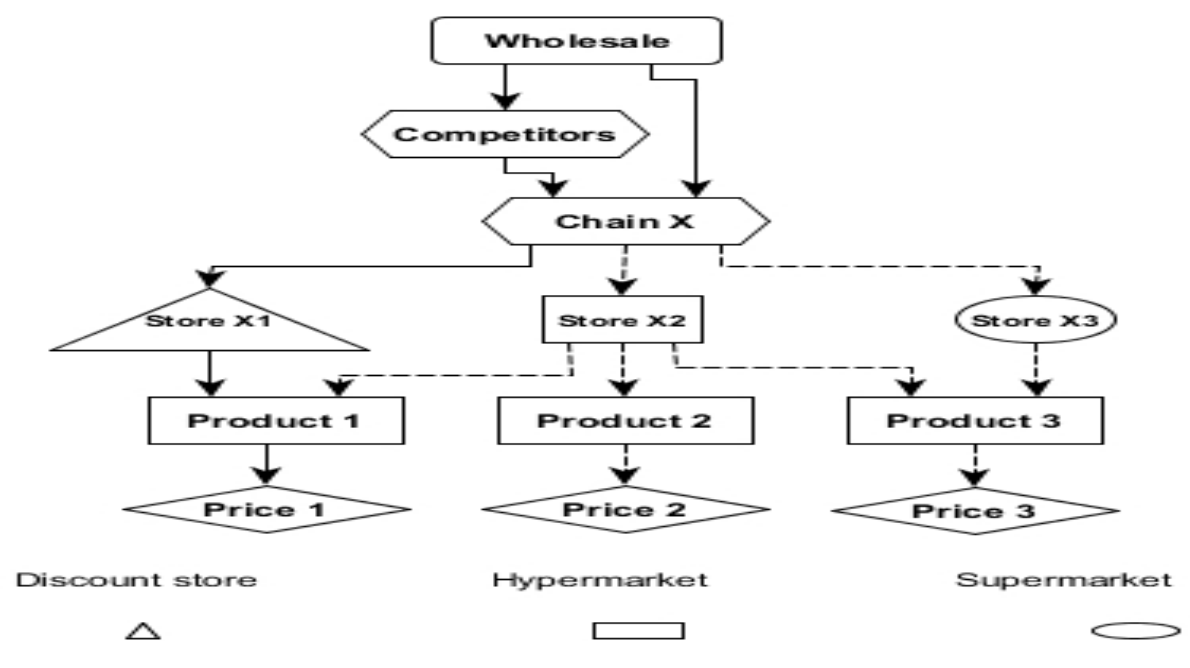

Source: Authors’ schematization

\subsection{Related literature on the different theories of price setting}

According to Kehoe \& Midrigan (2015, p. 35) :"prices are sticky after all”. This is the main conclusion of a recent study on rigid prices at the microeconomic level. Many studies try to come up with a reasonable theoretical explanation for price rigidity at the microeconomic level. Taylor (1999) review the literature on the different proposed theories to explain rigid prices at the microeconomics level. These theories are usually grouped into three main categories: the flexible pricing in Neo-Keynesian economics, the time dependent models or better known as the Calvo models, and state dependent models, which are also known as menu cost models. The time dependent and state dependent theories are the two main families that are discussed most in the literature (Eichenbaum et al., 2011; Gautier, 2009). Weiss (1993) conducts a literature review on models that explain price rigidity in the 1980s and 1990s. Gautier (2009) extends the literature review to include both recent theoretical and empirical developments in the literature. In what follows we present briefly each family of theoretical models and their empirical verification in the literature. Because of the huge number of papers that have been published, we limit ourselves to review the most cited papers, e.g. Cecchetti (1986), and the studies conducted in the agro-food sector.

\subsubsection{Time dependent (Calvo) models and their empirical test}

Time dependent models assume that only a few firms can adjust their prices at a given period of time. Taylor (1980) and Calvo (1983) propose models where prices are not only predetermined, but remain unchanged for several periods of time. One of the main reasons for which firms adopt time dependent models is the existence of explicit contracts. If changes in prices are determined according to a time dependent rule, then the question is whether 
changes in prices are staggered or synchronized. Ball \& Cecchetti (1988) argue that firms work in an uncertain environment and information on competitors' reactions to market shocks are collected with delay. Thus, a firm prefers to set its prices shortly after other firms set their prices. Therefore, we consider the elapsed time from the last change in price to assess time dependence in price setting in our data.

Lach \& Tsiddon $(1992,1996)$ study meat and wine and show that the time dependent rules are not empirically verified. However, their method is criticized. They use a test that does not follow a standard distribution (Chakrabarti \& Scholnick, 2005). Fisher \& Konieczny (2000) propose a test, with a $\chi^{2}$ distribution to check for the hypotheses proposed in Calvo's model. Many studies use Fisher and Konieczny's approach to test for staggering prices for different products and sectors. For instance, Loy \& Weiss (2002, 2004) provide evidence of price synchronization within retail chains and between products in the case of the food retail sector in Germany. However, Loy \& Weiss (2004) argue that common shocks explain only some synchronization of prices and other strategic motives and state dependent factor might be important.

Conducting surveys is another approach used in the literature to determine whether firms follow a time dependent rule. Surveys have been conducted in different countries. Blinder (1991) and Blinder et al. (1998) find that $40 \%$ of firms follow a time dependent model in the USA. Fabiani et al. (2006) survey 11,000 firms in the Euro zone and find that around onethird of firms follow time dependent pricing rules. The proportion of firms that follow a time dependent rule is even higher in the UK with 79\% (Hall et al., 2000).

\subsubsection{State dependent (menu cost) models and their empirical verification}

To cite only a few, Sheshinski \& Weiss (1977, 1979, 1983); Danziger (1983, 1984) and Dotsey et al (1999) are among theoretical studies that belong to this second class of models. In a survey of 11,000 firms, Fabiani et al. (2006) find that two-thirds of firms follow state dependence models in the Euro zone.

Since firms face costs every time they change their prices, they prefer to wait for some period of time to accumulate shocks before changing their prices. Two main components of costs are distinguishable: fixed and variable costs. Regarding the fixed costs, Levy et al. (1997) and Dutta et al. (1999) find that menu costs account for between $27 \%$ and $35 \%$ of net profit margins in the USA retail market. Rotemberg (2005) argues that menu costs are not necessarily fixed. They depend either on the magnitude or the frequency of the price change (Konieczny, 1993). Moreover, changing prices very often can create customer anger 
(Rotemberg, 2005). This argument was also mentioned in many surveys of companies. For instance $55.3 \%$ of surveyed firms in Canada mention avoiding frequent price changes to circumvent disturbing customer relations (Amirault et al., 2005).

There are also empirical studies that try to bring theoretical menu cost models into practice. Two approaches are used in the literature: reduced form and structural models. Using reduced form approach, Cecchetti (1986) examines the determinants of the frequency of price adjustments in the case of magazines in Canada. Cecchetti (1986) shows that higher inflation leads to more frequent price adjustments and real cost of nominal price change varies with the frequency of adjustment and size of real price change. Willis (2006) argues that the methods employed in Cecchetti's model suffer from misspecification and proposes a model to obtain more consistent estimates. Willis (2006) confirms state dependence in price setting in the case of magazines, but he finds that the argument for the cost of price adjustment weak. In the same vein, Baudry et al. (2005) show that inflation influences the increase in price, but not a price decrease. Fougère et al. (2007) show that inflation positively influences the duration of unchanged prices in $45 \%$ of the products included in their study. Schenkelberg (2013) shows that in a low inflation environment, e.g. Germany, state dependent factors such as input costs are more important determinants of adjusting prices than the inflation rate. We follow Schenkelberg's (2013) suggestion and focus on including other factors other than inflation rates, such as the level of reference prices, the wholesale prices and the temporary sales prices.

Another variant to test for hypotheses of state dependence in prices is to employ semistructural models. The common starting point is the $(\mathrm{S}, \mathrm{s})$ model with either deterministic inflation rates (Sheshinski \& Weiss, 1977) or stochastic inflation rates (Danziger, 1983, 1984; Sheshinski \& Weiss, 1983). Sheshinski et al.(1981) provide empirical tests of semi-structural model with data on instant coffee and noodles in Israel over the period 1965-1978. Ratfai (2006) implements a semi-structural model and uses prices of processed meat products in Hungary. Ratfai (2006) approximates the optimal price based on wholesale prices of processed meat. Even though the semi-structural models are important and very informative, the scope of this study is not building a structural model. We use a reduced form variant and the novelty of this study is the use of mixed models.

In summary, the choice between the Calvo and the menu cost models is still the subject of discussion (Kehoe \& Midrigan, 2015). Blinder (1991) argues that it is not easy to evaluate 
adjustment costs of prices, which makes the empirical verification of the menu cost model hard, or even impossible. Furthermore, the difficulty of accessing disaggregated prices made early studies focus on the theoretical explanation of sticky prices. The early empirical studies focused on a specific product or a sector. More recently as data have become available at the disaggregated level, studies attempt to verify the hypotheses of the theoretical models. For instance, influential papers include Bils \& Klenow (2004), Nakamura \& Steinsson (2008) and (Eichenbaum et al., 2011) for the USA, and Dhyne et al. (2006) for the euro zone. For Germany, a recent study by Schenkelberg (2013) shows that Calvo models are not sufficient to explain price adjustment processes in German retail businesses. Moreover, Campbell \& Eden (2014) try to assess time and state dependence of retail chains' pricing decisions in the USA. Campbell \& Eden (2014) find evidence of both state and time dependence in price setting. More specifically, they find that the probability of nominal price adjustment declines with increasing time from the last price change. In addition, the probability of a nominal adjustment increases when a chain's price diverges from the reference price of other retail chains. We follow the modeling strategies in Schenkelberg (2013) and Campbell \& Eden (2014) and extend their approach to consider heterogeneity in retail chains in terms of their sensitivity to their marketing margins.

\subsubsection{The role of data structure}

Nakamura (2008) investigates how the pass-through patterns from the wholesale to retailer level vary across $(100)$ products, $(7,000)$ stores and (33) chains in (50) cities in the USA. Nakamura (2008) employs variance decomposition to link the frequency of price change to product, store and chain, by including random effects associated with each level. Nakamura (2008) finds the variability between the 33 chains is the most important factor in explaining $65 \%$ of the variation in prices, followed by products (17\%) and stores (16 \%). In the same vein, Nakamura et al. (2011) use variance decomposition to explain cross-sectional variation in price dynamics for coffee, cold cereals and soft drinks in the USA. For a given homogenous product, Nakamura et al. (2011) find more variation in pricing dynamics across retail chains than across stores within the same chain. They also find that the characteristics of the chains explain a larger proportion of the variation in retail price dynamics than the characteristics of the stores. They recommend focusing on extending the number of chains in the data collection and with a focus on representative stores for each chain. In this study we follow Nakamura's et al. (2011) suggestions and focus more on the differences between the 
retail chains than the differences between the stores. We also account for the data structure in order to derive consistent modelling for the dichotomous choices in pricing decisions.

\subsubsection{Hypotheses}

The following hypotheses are subject for testing in this study. First, we hypothesize that high retail margin would lead to a decrease in the likelihood of introducing a price change. Second, we hypothesize that the increase in the difference between a chain's price and the average price for the same item at other competing retail chains increases the probability of a price change. Third, we expect that an increase in the elapsed time from the last price change would lead to an increase in the likelihood of introducing new changes in retail prices. Fourth, we expect that retail chains that are sensitive to the changes in their marketing margins will adjust their prices more frequently than the chains that are insensitive to marketing margins.

\subsection{Data and methods}

\subsubsection{Data}

Our dataset is composed of weekly panel data purchased from Symphony IRI Group GmbH (2011) containing scanner retail prices. The dataset covers 37 different retail chains and 345 different retail stores in Germany. It contains 333,144 observations on prices and quantities of 56 products. The period covered is from the first week of 2005 until the last week of 2010. Products are identified at a highly disaggregated barcode level. Since the same product may be sold in more than one retail store, the identification of each product at each store is made by the European Article Number (EAN). There are 1,087 different EANs, from which 1,012 EANs are national brands and 75 EANs are private labels. Moreover, discount stores account for $183(17 \%)$ of the 1087 unique EANs in the data, the supermarkets represent 91 (8\%), and the hypermarkets have 813 (75\%) unique EANs.

The weekly prices are calculated by dividing the average unit revenues on quantities sold each week for a given EAN at a given store. In this way, the calculation of prices in each week may result in small price changes in the data (Eichenbaum et al., 2014; Lloyd et al., 2014). With the use of both raw and filtered retail prices using an algorithm proposed in Chahrour (2011), we are able to assess the effect of sales and the small changes on the overall results. The weekly observations also allow the accurate calculation of elapsed time from the last price change and the corresponding reference prices set by other retail chains (Campbell \& Eden, 2014). 
The wholesale prices for the same product and same period of 2005-2010 are collected by the Butter and Cheese Exchange (SBKB), located in Kempten, Germany. These prices represent the average opportunity cost for the retailers to acquire a 250-gram foil-wrapped package of butter in Germany (Loy et al., 2015).

\subsubsection{Descriptive statistics}

In Table 4.1, the frequency of price change of raw retail prices (23.3\%) is higher than the frequency of price changes when the TSP are filtered out (3.4\%). Surprisingly, there are no remarkable differences between price increases $11.8 \%(1.7 \%)$ and price decreases $11.5 \%$ $(1.7 \%)$ for raw (filtered) retail prices. The average retail margin in the case of raw retail prices is 45 eurocents per 250 grams of butter. Filtering out the TSP leads to higher marketing margins than the raw retail prices, with an average margin of 47 eurocents per 250 grams of butter. Moreover, the average difference between the raw retail prices and the reference prices is 19 eurocents. On average, the prices remain unchanged for 16 weeks in the case of raw retail prices and 38 weeks in the case of filtered retail prices.

Table 4.1 Summary statistics for some variables of interest

\begin{tabular}{|c|c|c|}
\hline Variable & Raw retail prices & Filtered retail prices \\
\hline Price increase & 39,125 (11.8\%) & $5,803(1.7 \%)$ \\
\hline No change & $260,079(76.7 \%)$ & 327,606 (96.6\%) \\
\hline Price decrease & 39,940 (11.5\%) & $5,735(1.7 \%)$ \\
\hline Average margin & 45 & 47 \\
\hline Reference Price & 19 & 0.1 \\
\hline Elapsed Time & 16 & 38 \\
\hline Total number & of 339,144 & 339,144 \\
\hline
\end{tabular}

\subsubsection{Decomposition of price variation into regular price and sales}

To what extent do regular price periods and sales periods account for price adjustment in our data? We follow Lloyd et al. (2014) and estimate regressions in which the deviation in an EAN's price about its mean $p_{i t}=P_{i t}-\bar{P}_{l}$ is regressed on two dummy variables, one dummy that captures changes in the regular price and another dummy that account for TSP.

$$
\begin{aligned}
& p_{i t}=\beta_{1} \text { regular }_{i t}+\varepsilon_{i t} \\
& p_{i t}=\beta_{2} \text { sales }_{i t}+\varepsilon_{i t} \\
& p_{i t}=\beta_{1} \text { regular }_{i t}+\beta_{2} \text { sale }_{i t}+\varepsilon_{i t}
\end{aligned}
$$

The interest is not on the coefficients $\left(\beta_{1}, \beta_{2}\right)$ from the regressions in equations $(14,15$, and16), but rather on the coefficient of determination and the contribution of each dummy 
variable to the explained variance (Lloyd et al., 2014). The results of the regressions are displayed in Table 4.2.

Table 4.2 Contribution of regular prices and sales in price variation

\begin{tabular}{lllll}
\hline & Filtered price & Sales & Total & Residuals \\
\hline Price & $\mathbf{2 7 . 0 9 \%}$ & $\mathbf{6 5 . 7 0 \%}$ & $\mathbf{9 2 . 8 0 \%}$ & $\mathbf{7 . 2 0 \%}$ \\
\hline${ }^{\mathrm{a}}$ Note there are EANs where sales account for zero variation in prices and in others EAN sales account for \\
\hline
\end{tabular}

Despite occupying only $15.30 \%$ of price changes in our dataset, sales account for $65.70 \%$ of price variation in our data, whereas the changes in regular prices account only for $27.09 \%$. These results are not in line with Lloyd et al. (2014) who find that price adjustment is evenly split between sales (43\%) and regular price changes (44\%) for several categories of agro-food products in the UK.

The results presented in Table 4.2 are averages of the 1087 regressions from equations (14, 15, and16). The contribution of regular price' spells and sales to price variation varies across chains. Figure 4.4 reports the breakdown by chain. The contribution of sales to price variation ranges from $22 \%$ in the case of Chain $27^{15}$ to $93.5 \%$ in the case of Chain 23, whereas the contribution of regular price change to price variation ranges from $1 \%$ in the case of Chain 30 to $87 \%$ in the case of Chain 8 . This provides initial evidence that allows us to verify the fourth hypothesis of this study.

Figure 4.4 Contribution of regular price changes and sales in price variation by retail chain

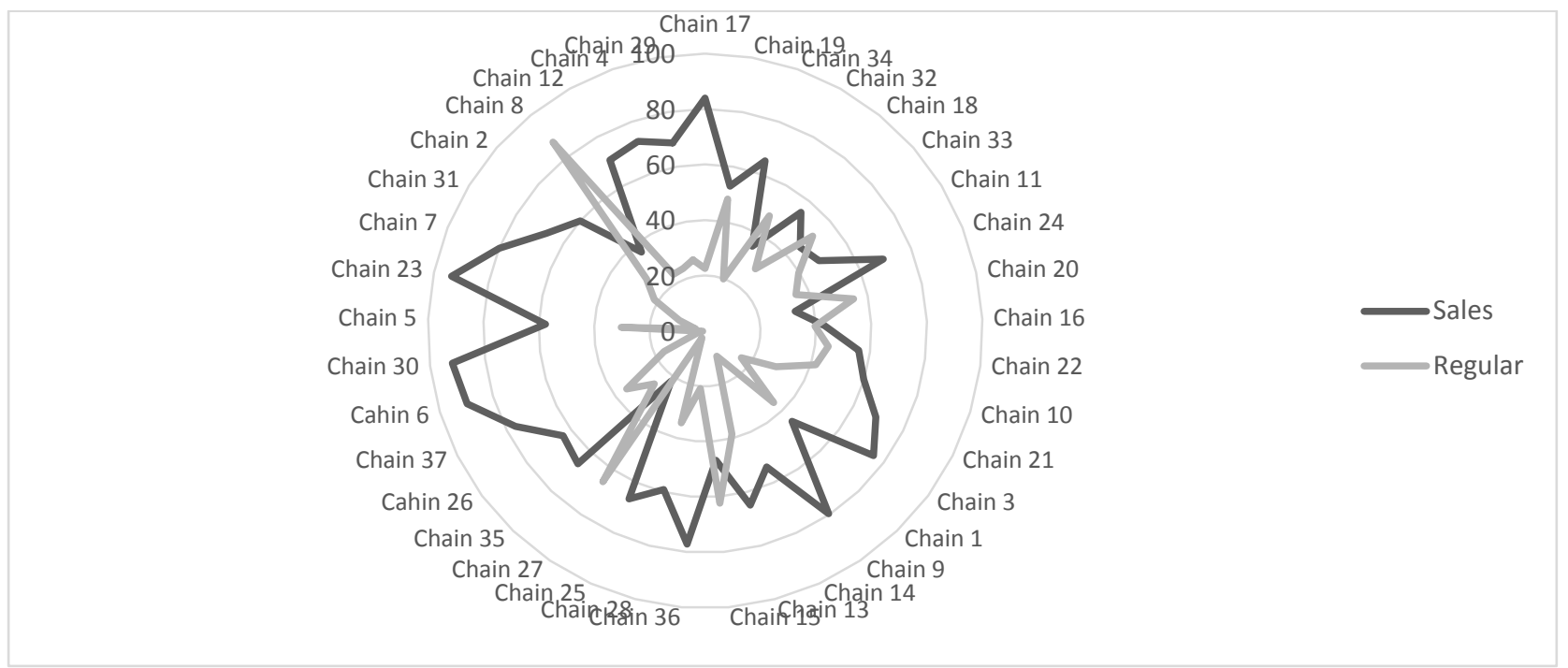

Source: Authors’ calculation

${ }^{15}$ The chains are labelled from 1 to 37 only for illustration purpose. 


\subsubsection{Variance decomposition}

We follow Nakamura et al. (2011) and undertake variance decomposition of price variation across product, store and chain. The procedure consists of a random intercepts model as expressed in equation (17). The frequency of price change for each EANs is regressed on random intercepts for product, store and chain:

$$
f_{i p s c}=\xi_{i p}+\xi_{i s}+\xi_{i c}+\varepsilon_{i p s c}
$$

In equation (17), $f_{\text {ipsc }}, i=1,1087$, denotes the frequency of price change, including or excluding TSP. The $\xi_{i p}, \xi_{i s}, \xi_{i c}$, and $\varepsilon_{i p s c}$ are random intercepts, which are assumed to be identically, independently, and normally distributed. The component $\xi_{i p} \sim N\left(0, \tau_{p}^{2}\right)$ is common to a given product sold in different stores. The component $\xi_{i s} \sim N\left(0, \tau_{s}^{2}\right)$ is common to all stores selling the same product. The component $\xi_{i c} \sim N\left(0, \tau_{c}^{2}\right)$ is common to all stores in a given retail chain. The component $\varepsilon_{i p s c} \sim N\left(0, \tau_{\varepsilon}^{2}\right)$, the residual, captures the remaining variation in the frequency of price change.

Table 4.3 displays the results of two regressions using equation (17) of raw and filtered retail prices. The percentages in Table 4.3 are based on the contribution of each level on the conditional $\mathrm{R}$ squared: $R_{G L M M(c)}^{2}=\frac{\tau_{f e}^{2}+\tau_{p}^{2}+\tau_{s}^{2}+\tau_{c}^{2}}{\tau_{f e}^{2}+\tau_{p}^{2}+\tau_{s}^{2}+\tau_{c}^{2}+\tau_{\varepsilon}^{2}}$, as implemented in Nakagawa \& Schielzeth (2013). The component $\tau_{f e}^{2}$ denotes the variance of the fixed effects, which is zero because equation (17) does not include fixed effects. The results show that most of the price variation is captured at the chain level, with 51.43\% (33.95\%) for raw (filtered) retail prices. The product level accounts for 26.50\% (24.93\%) in raw (filtered) retail price variation. Only $2.5 \%(5.30 \%)$ of raw (filtered) retail prices variation is common to stores. These results are in line with Nakamura et al. (2011) who find that stores do not account for much of the variation in the prices.

Table 4.3 Variance decomposition of frequency of price change including and excluding sales

\begin{tabular}{lrrrrr}
\hline & Product & Store & Chain & Residuals & Conditional \\
& $\xi_{i p}$ & $\xi_{\text {is }}$ & $\xi_{\text {ic }}$ & $\varepsilon_{\text {ipsc }}$ & $R_{G L M M(c)}^{2}$ \\
\hline Raw prices & $\mathbf{2 6 . 5 0 \%}$ & $2.58 \%$ & $\mathbf{5 1 . 4 3 \%}$ & $19.47 \%$ & 0.80 \\
Filtered prices & $24.93 \%$ & $5.30 \%$ & $33.95 \%$ & $35.80 \%$ & 0.64 \\
\hline
\end{tabular}




\subsubsection{Methods}

\subsubsection{Model specification}

In order to model retailers' dichotomous choice of changing retail prices against displaying rigid prices, we need to construct the choices. The response variable is therefore a binary variable recording any price change for any given EANs, $i$, between week $t$ and week $t-1$. Moreover, we assume that no price change has been introduced at the first week of 2005 and therefore the first observation is set to zero, such as expressed in equation (18):

$$
y_{i t}=\left\{\begin{array}{l}
0, \text { for } t=1 \\
1, \quad \text { if } \text { Price }_{i, t}^{\text {retail }}-\text { Price }_{i, t-1}^{\text {retail }}=\Delta \text { Price }_{i t}^{\text {retail }} \neq 0, \text { for } t=2, \ldots, 312 \\
0, \quad \text { if Price }{ }_{i, t}^{\text {retail }}-\text { Price }_{i, t-1}^{\text {retail }}=\Delta \text { Price }_{i t}^{\text {retail }}=0, \text { for } t=2, \ldots, 312
\end{array}\right.
$$

The response variable consist of 312 observations for each of the 1087 EANs included in our dataset, i.e., a balanced panel of 339,144 observations.

Let us consider changes in retail prices for a randomly selected product " $P 1$ " that is sold in 42 different stores within Chain A and in 4 stores within Chain B. Chain A and Chain B were selected because their contributions of the regular price to the price variation are similar in the two chains, i.e. $22 \%$ in the case of Chain $A$ and $20 \%$ in the case of Chain $B^{16}$. Figure 4.5 shows the fitted probabilities of introducing regular price change against the retail margin to the wholesale prices using the generalized linear model proposed in McCullagh and Nelder (1989).

\footnotetext{
${ }^{16}$ The chain A is labelled Chain 17 and Chain B is labelled Chain 34
} 
Figure 4.5 Fitted probabilities of regular price change for same product between stores within the same chain
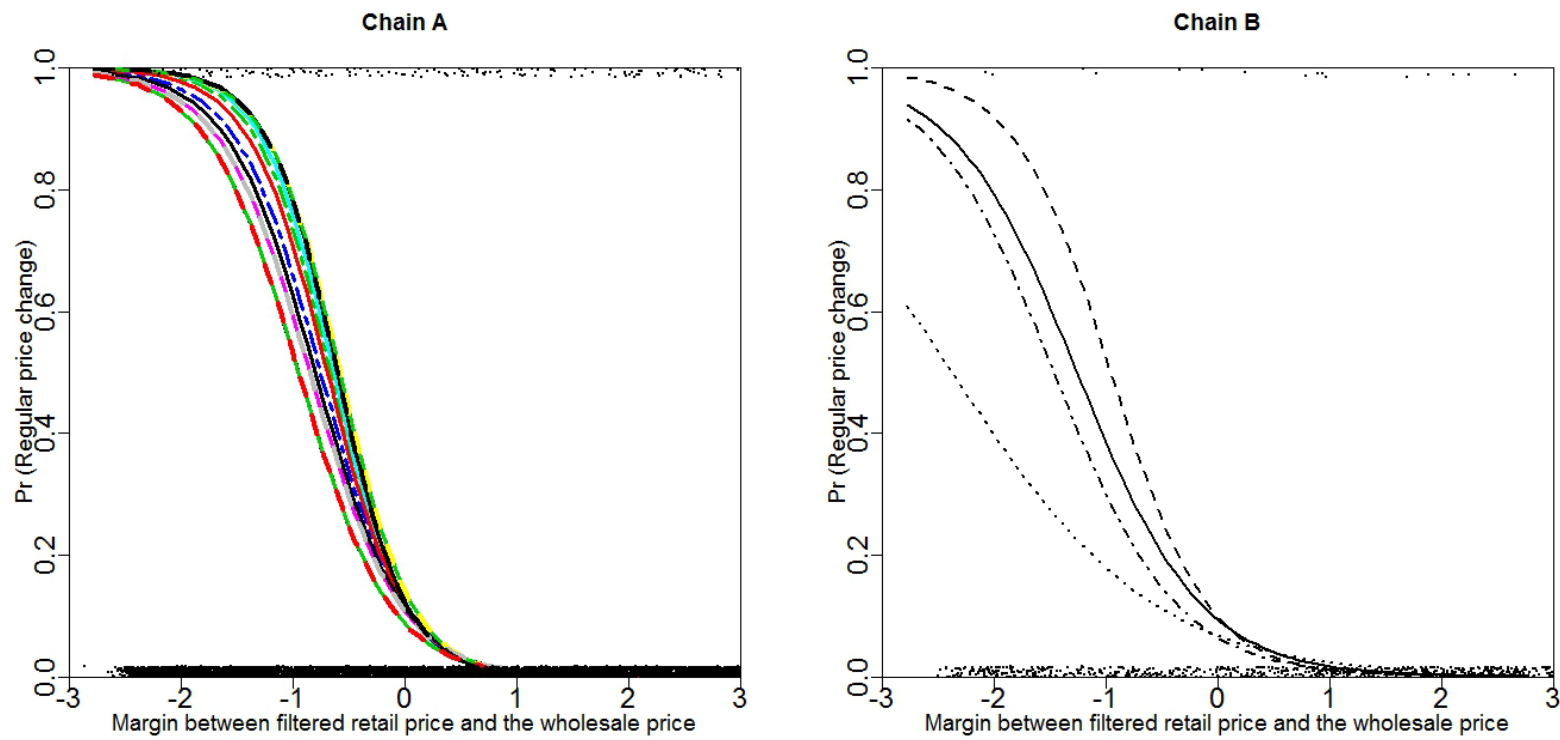

Source: Authors’ calculations

The probabilities of changing the regular prices appear synchronized within Chain A, i.e., many curves overlap. Moreover, the curves start at different intercepts and intercross, indicating differences between the slopes for each curve, which is clearer in the case of Chain $B$ than in Chain A. This indicates differences in terms of sensitivity of chains in terms of their marketing margins. In order to capture these differences, we include random effects for each EAN and each chain.

Moreover, data have a specific structure that we consider at the time of modelling the probabilities of price changes $\left(y_{i t}\right)$. Each level (products, store, and chain) contains additional information that we capture by adding random intercepts and slopes. For instance, the sensitivity to marketing margin for a given EAN varies between chains and within the same chain and between the different retail chains. The probability of changing prices for each EAN is as expressed in equation (19):

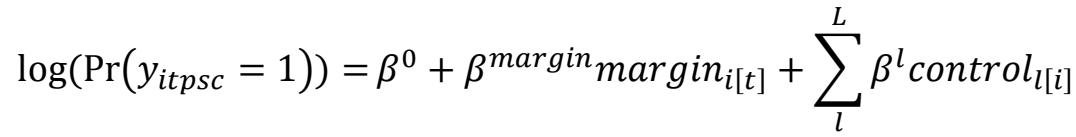

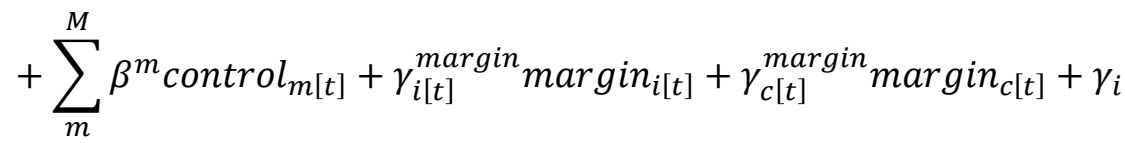

$$
\begin{aligned}
& +\gamma_{p}+\gamma_{s}+\gamma_{c}
\end{aligned}
$$

A generalized linear mixed models approach (GLMMs) is well suited to model price changes as expressed in equation (19). Given the random effects 
$\gamma=\left(\gamma_{i}^{\prime}, \gamma_{p}^{\prime}, \gamma_{s}^{\prime}, \gamma_{c}^{\prime}, \gamma_{i}^{\text {margin' }^{\prime}}, \gamma_{c}^{\text {margin' }^{\prime}}\right)$ and the data, the responses $y_{i}$ are conditionally independent and their conditional mean is linked to the linear predictor $\left(\eta_{i}\right)$ via a response function $h$ such as $\mu_{i}=E\left(y_{i} \mid \gamma\right)=h\left(\eta_{i}\right)$. The conditional density of $y_{i}$ belongs to an exponential family (Fahrmeir et al., 2013), which can be expressed as follows:

$$
\log \left(f\left(y_{i} \mid \beta, \gamma\right)\right)=\frac{y_{i} \theta_{i}-b\left(\theta_{i}\right)}{\phi}+c\left(y_{i}, \phi\right)
$$

In equation (20), $b($.$) depends only on \theta$, and $c($.$) depends on y$ and $\phi$. The parameter $\theta_{i}$ is the canonical parameter and $\phi$ is a common dispersion parameter independent of $i$ (Fahrmeir et al., 2013, p. 304).

In equation (19) the control $l_{l[i]}$ are time invariant covariates, such as format of store (discount stores, supermarket and hypermarket), or whether the product has a private label or national brand. The control $_{m[t]}$ denotes time variant covariates such as TSP. The parameters $\beta^{0}, \beta^{\text {margin }}, \beta^{l}$, and $\beta^{m}$ are fixed effects. $\beta^{0}, \beta^{\text {margin }}$ represent the mean intercept and the mean slope of the retail margin respectively. To capture the deviations from the mean intercept $\beta^{0}$, we add four random intercepts $\gamma_{i}, \gamma_{p}, \gamma_{s}, \gamma_{c}$, at the level of EAN, product, store and chain to the linear predictor $\eta$. To capture the deviations from the mean slope of marketing margin $\beta^{\text {margin }}$, we add two components to the linear predictor: $\gamma_{i}^{\text {margin }}$ and $\gamma_{c}^{\text {margin }}$. The first component $\gamma_{i}^{\text {margin }}$ captures the deviations from $\beta^{\text {margin }}$ for each EAN. The second component $\gamma_{c}^{\text {margin }}$ captures the deviation from the average slope $\beta^{\text {margin }}$ for each chain. In addition, random intercepts and random slopes are assumed to be identically, independently, and normally distributed. The distributions are expressed as follows:

$$
\begin{array}{r}
\gamma_{i} \sim N\left(0, \sigma_{i}^{2}\right) \ldots \ldots \ldots \text { for } i=1, \ldots \ldots \ldots, 1087 \text { EANs } \\
\gamma_{p} \sim N\left(0, \sigma_{p}^{2}\right) \ldots \ldots \ldots \text { for } p=1, \ldots \ldots \ldots, 56 \text { products } \\
\gamma_{s} \sim N\left(0, \sigma_{s}^{2}\right) \ldots \ldots \ldots \text { for } s=1, \ldots \ldots \ldots 345 \text { stores } \\
\gamma_{c} \sim N\left(0, \sigma_{c}^{2}\right) \ldots \ldots \ldots \text { for } c=1, \ldots \ldots \ldots, 37 \text { chains } \\
\gamma_{i}^{\text {margin }} \sim N\left(0, \sigma_{i[\text { margin }]}^{2}\right), \ldots \ldots \ldots, \text { for } i=1, \ldots \ldots \ldots 1087 \text { EANs } \\
\gamma_{c}^{\text {margin }} \sim N\left(0, \sigma_{c[\text { margin }]}^{2}\right), \ldots \ldots \ldots, \text { for } c=1, \ldots \ldots \ldots, 37 \text { chains }
\end{array}
$$

The probability of changing retail price for an EAN at week $t$, conditional to the random effects $\gamma$, is formulated as follows: 


$$
\pi_{i t}=\mathrm{E}\left(y_{i t} \mid \beta, \gamma\right)=\operatorname{Pr}\left(y_{i t}=1 \mid x_{i t}^{\prime}, \beta_{i}, u_{i t}^{\prime}, \gamma_{i}\right)=\log ^{-1}{ }^{-1}\left(\eta_{i t}=x_{i t}^{\prime} \beta+u_{i t}^{\prime} \gamma_{i}\right)
$$

The $u_{i t}$ contain variables which are unique to each level, and usually it is a sub-vector of $x_{i t}$. Moreover, the choice of $u_{i t} \equiv 1$ in equation (21) defines the random intercept model (Fahrmeir et al., 2013, p. 390).

\subsubsection{Model estimation and model selection}

Different methods have been suggested in the literature to approximate the likelihood to estimate the GLMMs parameters in equation (19), including the pseudo (marginal) and penalized quasi-likelihood (PQL) approximation (Breslow \& Clayton, 1993; Schall, 1991; Wolfinger \& O'connell, 1993), and an improved version of the PQL approximation (Goldstein \& Rasbash, 1996; Rodriguez \& Goldman, 2001), Laplace approximation (Breslow, 2004; Raudenbush et al., 2000) and Gauss-Hermite quadrature (GHQ) approximation (Pinheiro \& Chao, 2006) and adaptive quadrature (AGHQ) (Rabe-Hesketh et al., 2005).

The PQL approximation suffers from not computing true likelihood (Bolker et al., 2009; Rabe-Hesketh et al., 2005), and it should not be used for inference (Pinheiro \& Chao, 2006; Rabe-Hesketh et al., 2005). Further, this approximation works poorly with dichotomous data with small cluster sizes (Breslow, 2004) and leads to biased estimates in case of large variance of random effects (Browne \& Draper, 2006; Rodriguez \& Goldman, 1995, 2001). Laplace approximation is more accurate than the PQL (Bolker et al., 2009; Rabe-Hesketh et al., 2005), it allows the calculation of the true GLMM likelihood, hence the maximum likelihood based inference is possible, and reduces the bias compared to the PQL. To estimate the model in equation (19) we employ Laplace approximation ${ }^{17}$. The AGHQ works well with moderate cluster size (Rabe-Hesketh et al., 2005), but it becomes complicated and slow with more than two random coefficients (Bolker et al., 2009) and the estimates become biased with large cluster sizes.

Our model selection is based on the pseudo-R-squared implemented in Nakagawa \& Schielzeth (2013) in the case of random intercept models and extended to the case of random slopes in Johnson \& O’Hara (2014). To assess the contribution of the fixed effect to the explained variances we calculate the marginal pseudo R-squared $R_{G L M M(m)}^{2}=\frac{\sigma_{f e}^{2}}{\sigma_{f e}^{2}+\sum_{l=1}^{u} \sigma_{l}^{2}+\sigma_{e}^{2}+\frac{\pi^{2}}{3}}$. The conditional pseudo R-squared:

\footnotetext{
${ }^{17}$ we use the function glmer function implemented in Ime4 package in $\mathrm{R}$
} 
$R_{G L M M(c)}^{2}=\frac{\sigma_{f e}^{2}+\sum_{l}^{u} \sigma_{l}^{2}}{\sigma_{f e}^{2}+\sum_{l}^{u} \sigma_{l}^{2}+\sigma_{e}^{2}+\frac{\pi^{2}}{3}}$, allows us to measure of the contribution of each random effect to the explained variance.

\subsection{Results and discussion}

We follow a stepwise procedure, which consists of sequentially adding elements to equation (19). That is, the baseline model contains $\beta^{0}$ and $\gamma_{i}$. The decision of keeping an element in the regression is based on its significant contribution to the $R_{G L M M(c)}^{2}$. Using raw retail prices, the baseline model results in $R_{G L M M(c)}^{2}=0.24$. Adding $\gamma_{p}$ improves $R_{G L M M(c)}^{2}$ from to 0.24 to 0.25 . Adding $\gamma_{s}$ does not lead to a significant increase in $R_{G L M M(c)}^{2}$; thus we drop it from the model. Adding $\gamma_{c}$ also does not improve $R_{G L M M(c)}^{2}$. Since it is not recommended to add random slope without the random intercept (Fahrmeir et al., 2013, p. 402), we keep $\gamma_{c}$ in the model.

\subsubsection{Estimation results}

The final estimation results after model selection are displayed in Table 4.4. The second column of Table 4.4 displays estimation results from equation (19) using raw retail prices. Based on the $\mathrm{R}_{\mathrm{GLMM}(\mathrm{m})}^{2}$, the fixed effects contribute with $35 \%$ to the explained variance.

All coefficient of time varying variables are significant, except the coefficient of reference price. The main fixed effect is as expected TSP. From the marginal effects, TSP increase the likelihood of price change by 31\%. We have shown in section 4.4.1.2 that TSP contribute with $65.70 \%$ to the raw retail price variation in our data. As expected, marketing margin negatively influences the probability of changing retail prices. From the marginal effects, an increase of one eurocent, per 250-gram of butter, in the margin implies a decrease in the likelihood of changing prices by $4 \%$. This provides initial evidence to verify the first hypothesis of this study.

The coefficient of elapsed time is positive and significant. Therefore, the elapsed time from the last price change positively influence the probability of introducing changes in price. The marginal effects indicate that an increase in elapsed time of one unit implies an increase in the probability of changing raw retail prices by $12 \%$. This provides initial evidence to verify the third hypothesis of this study. We do not find that the reference prices set by other competing retail chains influence the probability of changing raw retail prices; thus, we cannot verify the second hypothesis of the study in the case of raw retail prices. 
The coefficient of the dummy variable indicating private label is not significant; thus we do not find a difference between private labels and national brands. The other two time invariant variables are statistically significant. Raw retail prices change more frequently in supermarkets and hypermarkets than in discount stores. Moving from discount store to supermarket and hypermarket leads to an increase in the likelihood of changing retail prices by $27 \%$ and $30 \%$, respectively.

Together with the fixed effects, the random effects contribute 55\% to the explained variance. The random intercepts associated with EAN, product, and chain contribute 3\%, 2\%, and 3\% to the explained variance respectively. The random slope associated with the margin contributes $6 \%$ to the explained variance at the EAN level, and with $6.5 \%$ at the chain level.

The estimation results with filtered retail prices are displayed in the third column of Table 4.4. Based on the $R_{G L M M(m)}^{2}$, the fixed effects contribute $65.91 \%$ to the explained variance in price change. The retail margin is insignificant; thus the marketing margin does not explain the changes in the regular prices. The main fixed effect is the elapsed time from the last price change. From the marginal effects, an increase of one unit in the elapsed time from the last price change implies an increase in the likelihood of price change by $17 \%$. This provides supplementary evidence to verify the third hypothesis of this study.

The reference prices of other competing retail chains influence the probability of changing a chain's regular prices. From the marginal effects, an increase in the reference prices by 1 eurocent would lead to an increase in the likelihood of changing regular prices by $0.4 \%$. This provide some evidence to verify the second hypothesis of this study.

Moreover, we do not find differences between private labels and national brands. We also do not find differences between changes in the regular prices within the supermarkets and hypermarkets compared to the discount store.

The random effects contribute very little $(0.1 \%)$ to the explained variance in changes of regular prices. This very small contribution to the explained variance is due to the differences between the retail chains. 
Table 4.4 Estimation results of random intercepts and random slope models

\begin{tabular}{|c|c|c|c|c|c|c|c|c|}
\hline & \multicolumn{4}{|c|}{ Raw retail prices } & \multicolumn{4}{|c|}{ Filtered retail prices } \\
\hline & \multicolumn{8}{|c|}{ Fixed Effects } \\
\hline Factor & $\begin{array}{l}\text { Estimate } \\
\left(\mathrm{ME}^{\mathrm{a}}\right)\end{array}$ & $\mathrm{SE}^{\mathrm{b}}$ & $\mathrm{L}-\mathrm{CI}$ & U-CI & $\begin{array}{l}\text { Estimate } \\
\text { (ME) }\end{array}$ & $\mathrm{SE}$ & $\overline{\mathrm{L}-\mathrm{CI}}$ & $\overline{\mathrm{U}-\mathrm{CI}}$ \\
\hline Intercept & $\begin{array}{l}-3.04 * * * \\
-\end{array}$ & 0.14 & -3.32 & -2.76 & $\begin{array}{l}-9.90 * * * \\
-\end{array}$ & 0.15 & -10.21 & -9.60 \\
\hline Margin & $\begin{array}{l}-0.47 * * \\
(-0.04)\end{array}$ & 0.15 & -0.77 & -0.16 & $\begin{array}{l}-0.19 \\
(-0.0034)\end{array}$ & 0.12 & -0.42 & 0.05 \\
\hline Elapsed time & $\begin{array}{l}1.48^{* * * *} \\
(0.12)\end{array}$ & 0.01 & 1.44 & 1.51 & $\begin{array}{l}9.96 * * * \\
(0.1709)\end{array}$ & 0.14 & 9.69 & 10.24 \\
\hline $\begin{array}{l}\text { Reference } \\
\text { price }\end{array}$ & $\begin{array}{l}0.008 \\
(0.10)\end{array}$ & 0.10 & -0.11 & 0.30 & $\begin{array}{l}0.24^{*} \\
(0.0042)\end{array}$ & 0.12 & 0.005 & 0.48 \\
\hline Private label & $\begin{array}{l}-0.03 \\
(-0.35)\end{array}$ & 0.24 & -0.82 & 0.13 & $\begin{array}{l}0.01 \\
(0.0003)\end{array}$ & 0.06 & -0.10 & 0.14 \\
\hline TSP & $\begin{array}{l}3.63^{* * *} \\
(0.31)\end{array}$ & 0.01 & 3.60 & 3.67 & - & - & - & - \\
\hline Supermarket & $\begin{array}{l}0.023^{*} \\
(0.27)\end{array}$ & 0.10 & 0.06 & 0.49 & $\begin{array}{l}0.008 \\
(0.0002)\end{array}$ & 0.06 & -0.12 & 0.14 \\
\hline Hypermarket & $\begin{array}{l}0.025^{* *} \\
(0.30)\end{array}$ & 0.10 & 0.10 & 0.51 & $\begin{array}{l}0.02 \\
(0.0004)\end{array}$ & 0.04 & -0.06 & 0.12 \\
\hline \multirow{3}{*}{$R_{G L M M(m)}^{2}$} & \multicolumn{4}{|c|}{0.35} & \multicolumn{4}{|c|}{0.65} \\
\hline & \multicolumn{8}{|c|}{ Random Effects } \\
\hline & \multicolumn{2}{|l|}{ Estimate } & \multicolumn{2}{|c|}{$\begin{array}{l}\text { Explained } \\
\text { variance }\end{array}$} & Estimate & \multicolumn{3}{|c|}{$\begin{array}{l}\text { Explained } \\
\text { Variance }\end{array}$} \\
\hline$\sigma_{i}^{2}$ & 0.22 & & $3 \%$ & & $3.02 \mathrm{e}^{-15}$ & \multicolumn{3}{|c|}{$2.22 \mathrm{e}-{ }^{14} \%$} \\
\hline$\sigma_{p}^{2}$ & 0.15 & & $2 \%$ & & 0.00 & \multicolumn{3}{|c|}{$0 \%$} \\
\hline$\sigma_{c}^{2}$ & 0.21 & & $3 \%$ & & $3.26 \mathrm{e}^{-05}$ & \multicolumn{3}{|c|}{$0.0003 \%$} \\
\hline$\sigma_{i[\text { margin }]}^{2}$ & 0.43 & & $6 \%$ & & $1.47 \mathrm{e}^{-12}$ & \multicolumn{3}{|c|}{$1.51^{\mathrm{e}-11}$} \\
\hline$\sigma_{c[\text { margin }]}^{2}$ & 0.48 & & $6.5 \%$ & & 0.001 & \multicolumn{3}{|c|}{$0.01 \%$} \\
\hline$R_{G L M M(c)}^{2}$ & \multicolumn{4}{|c|}{0.55} & \multicolumn{4}{|c|}{0.66} \\
\hline $\begin{array}{l}\text { Number of } \\
\text { observations }\end{array}$ & \multicolumn{4}{|c|}{339,144} & \multicolumn{4}{|c|}{339,144} \\
\hline Deviance & \multicolumn{4}{|c|}{$204,400.5$} & \multicolumn{4}{|c|}{$33,353.3$} \\
\hline $\begin{array}{l}\text { Degrees of } \\
\text { freedom }\end{array}$ & \multicolumn{4}{|c|}{339,129} & \multicolumn{4}{|c|}{339,130} \\
\hline $\begin{array}{l}\text { Log- } \\
\text { Likelihood }\end{array}$ & \multicolumn{4}{|c|}{$-102,200.3$} & \multicolumn{4}{|c|}{$-16,676.7$} \\
\hline AIC & \multicolumn{4}{|c|}{204430.5} & \multicolumn{4}{|c|}{33381.3} \\
\hline \multicolumn{9}{|c|}{ Significance: ‘***’1\%; ‘**’5\%; ‘*’ $10 \%$} \\
\hline
\end{tabular}




\subsubsection{Discussion}

Figure 4.6 illustrates the overall reaction by retail chains to changes in the wholesale prices. The left panel of Figure 4.6 displays the fitted probabilities against the marketing margin in the case of raw retail prices. On average, when retail margins are close to zero or negative, there is a high probability (17\%) of changing retail price. This probability decreases to $7 \%$ when the marketing margins are high, i.e. above 100 eurocents. This provides supplementary evidence to verify the first hypothesis of this study. Our first scenario described in Given the level of the marketing margin, i.e. the difference between the retail prices and the wholesale prices, two scenarios are plausible. The first scenario represents the case where the wholesale prices increase; thus the marketing margin is squeezed. Hence, there is a tension between the need to change prices or to display rigid prices because of the adjustment costs. Therefore, the retail chain faces a dichotomous choice. The second scenario is opposite to the first one; the wholesale prices decrease. The tension of changing retail prices is not the result of the marketing margins, which are obviously stretched, but is rather the result of the changes in the prices of other competing retail chains. More specifically, the reference prices of others for the same product are decreasing; therefore, there is a need to adjust retail prices again.

\section{Figure 4.6 Fitted probability of price change against the marketing margin}
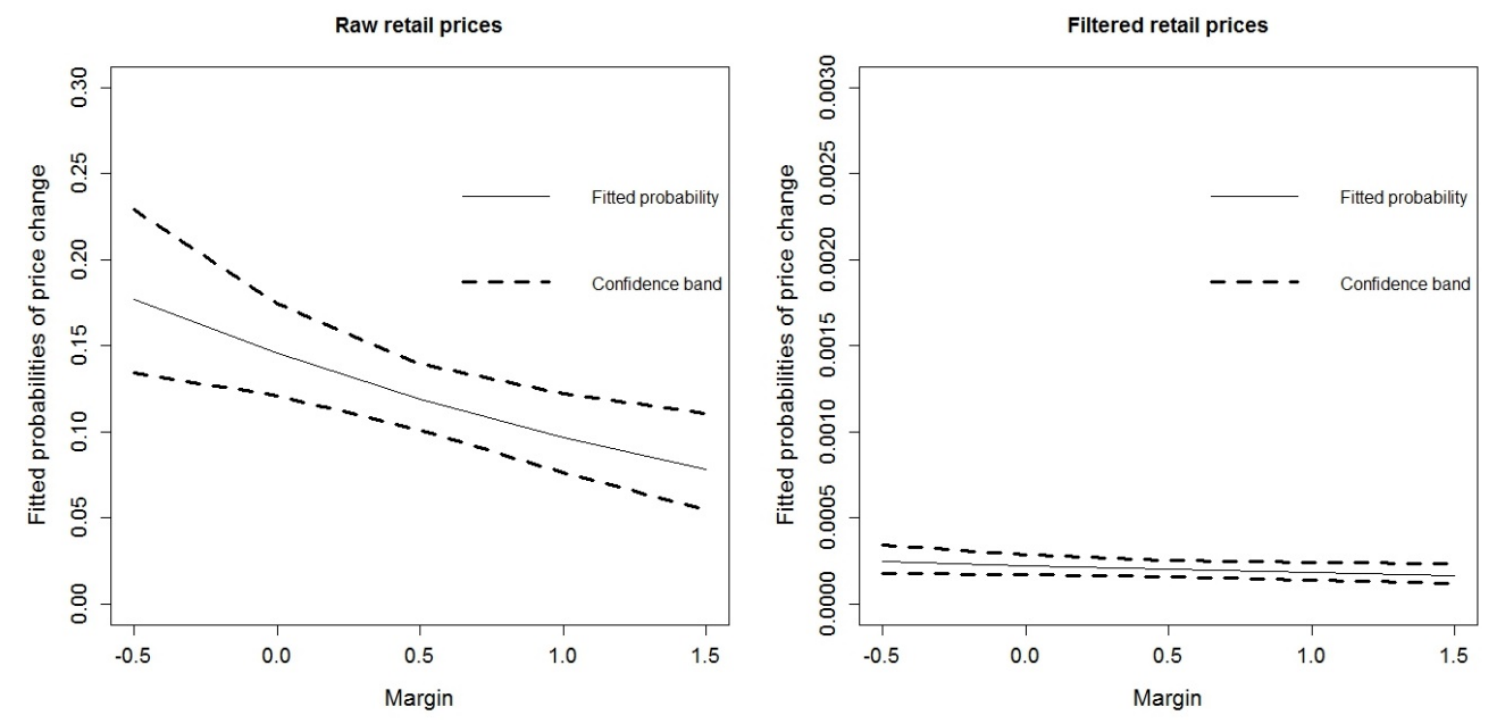

Source: Authors’ calculations

Figure 4.1 holds only for raw retail prices though. The marketing margins, ceteris paribus, are not sufficient to explain changes in regular retail prices. The right panel from Figure 4.6 shows that, when the TSP are filtered out, the fitted probabilities become very small, and the 
marketing margins do not explain the changes in retail prices. Therefore, we consider that retail chains react to changes in the wholesale prices by introducing small changes in price. The overall picture of the influence of the other factors, such as the elapsed time from the last price change, reference prices, and differences between store format can be found in the annex (see Figure A-4.1).

The sensitivity of retail chains to changes in their marketing margins is captured by random effects parameter $\gamma_{c}$ and $\gamma_{c}^{\text {margin }}$. Figure 4.7 reports the breakdown by chain of the effect of the marketing margin on the probability of changing raw retail prices. Negative deviation of $\gamma_{c}^{\text {margin }}$ from $\beta^{\text {margin }}$ means high sensitivity to retail margins. Positive deviation means low sensitivity to retail marketing margins.

Figure 4.7 Sensitivity to retail marketing margin and frequency of changing retail prices by retail chain

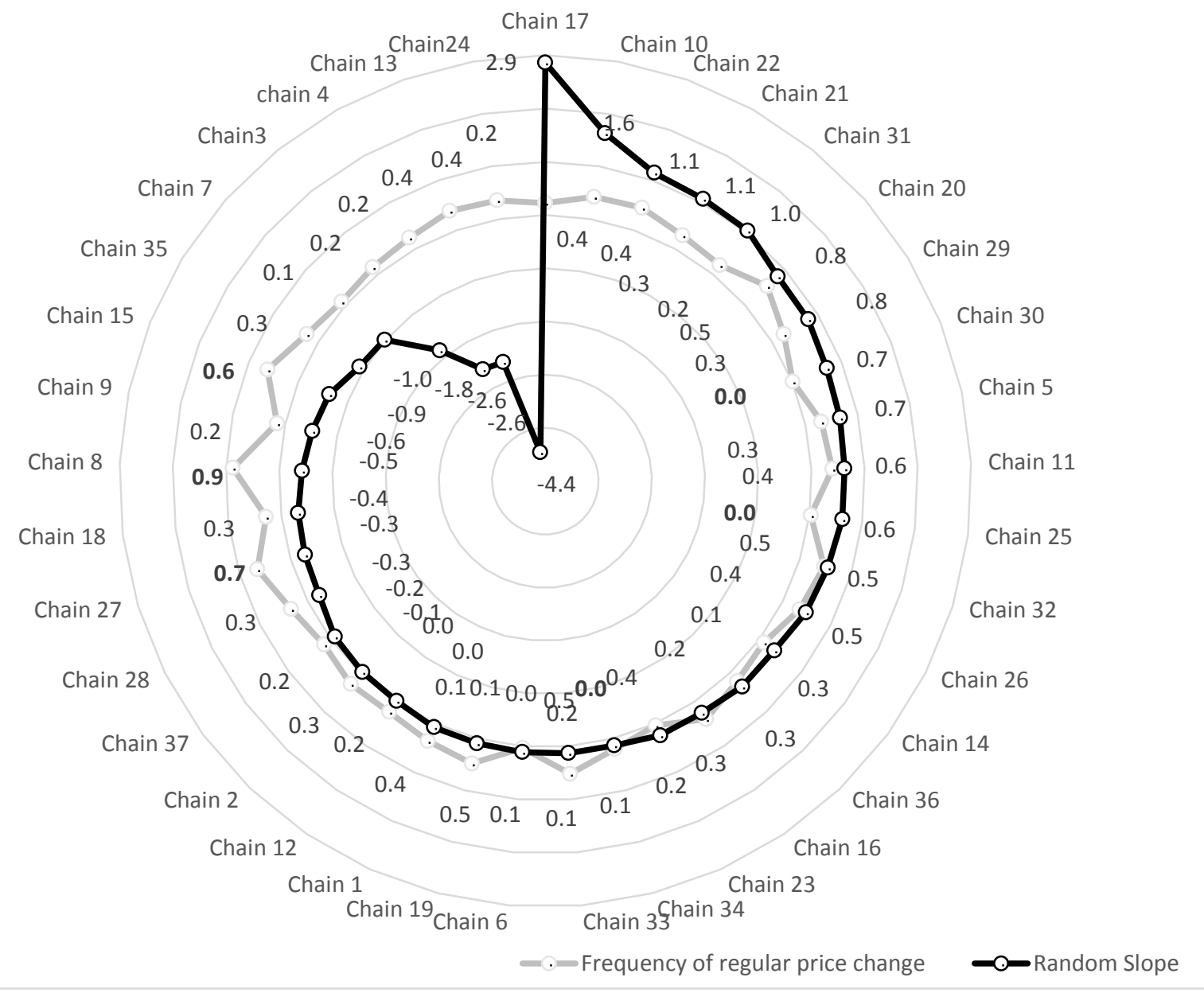

Source: Authors' calculation 
In Figure 4.7, we plot the sensitivity of retail chains alongside frequency of price changes due to regular prices as presented in Figure 4.4. The results show that there is an association between the two measures. From a visual inspection it can be seen that both high sensitivity and high frequency in changing regular prices lie on the left hand of the plot. The right half of the same plot mainly features those retail chains that manifest low sensitivity and low frequency rates of changing regular retail prices. Note however that there are outliers that do not allow for the generalization of these findings; thus the fourth hypothesis holds only for some retail chains. For instance, frequency of changing regular price is the lowest (1\%) in the case of Chain $30^{18}$. This is translated into low sensitivity to changes in marketing margins. More specifically, the deviation from the average slope $\beta^{\text {margin }}=-0.46$ is $\gamma_{c=30}^{\text {margin }}=0.7$, which results in upward slope. In the case of Chain 8 , the frequency in changing regular price is the highest (87\%), which is translated into high sensitivity to changes in marketing margins, i.e. deviation $\beta^{\text {margin }}=-0.46$ is $\gamma_{c=8}^{\text {margin }}=-0.43$. Summing up the two elements lead to the $\beta^{\text {margin }}+\gamma_{c}^{\text {margin }}=-0.46-0.43=-89$, which results in a steeper downward slope than the average slope.

18 The chains are labelled from 1 to 37 only for illustration purpose. The retail chains are coded the same as in Figure 4.4 . 


\subsection{Conclusion}

In this study, we model the odds of changing retail prices against displaying rigid prices at the retail store level given the previously specified time and state dependent variables. We conjecture that retail chains' decisions to change regular prices are made under two scenarios. The first scenario describes a situation where marketing margins are squeezed. The second scenario describes a situation where the marketing margins are stretched. From these two scenarios we derive four hypotheses that allow us to cast light on the determinants of price changes and transmission at the individual retail chain.

We hypothesize that an increase (a decrease) in marketing margins (reference prices) would lead to a decrease (an increase) in the likelihood of introducing a new price change. We also expect that retail chains that are sensitive to changes in their marketing margins will adjust their prices more frequently than the retail chains that are insensitive to their marketing margins. We expect that an increase in the elapsed time from the last price change would lead to an increase in the likelihood of introducing new changes in retail prices.

To test these hypotheses, we employ scanner data from the German dairy market to characterize both time and state dependence of retail chains' pricing decisions. In order to capture the differences between the retail chains in terms of their sensitivity to marketing margins, we employ generalized linear mixed models.

We derive three main conclusions from this study. First, retail chains react to changes in the wholesale prices; thus they react to changes in their marketing margins with temporary sales prices (TSP). Second, the retail chains react to changes in the prices of competing retail chains by introducing changes in their regular price. Finally, we find that it is more likely to change new prices than changing old prices. This last result is in line with the findings in Campbell \& Eden (2014), who challenge the conventional theories of costly price adjustment.

Last, but not least, we use the frequentist approach to model the odds of raw retail price changes the results are acceptable. However, in the case of filtered retail prices, the result should be interpreted with caution. Further research is needed in order to cast light on what derive the price settings and marketing margins at the store level, such as a Bayesian approach or duration models. 


\subsection{References}

Amirault, D., Kwan, C., \& Wilkinson, G. (2005). A Survey of the Price-Setting Behaviour of Canadian Companies, 2004-2005(Winter), 29-40.

Ball, L., \& Cecchetti, S. G. (1988). Imperfect Information and Staggered Price Setting. The American Economic Review, 78(5), 999-1018.

Baudry, L., Le Bihan, H., Sevestre, P., \& Tarrieu, S. (2005). La rigidité des prix en France: quelques enseignements des relevés de prix à la consommation. Economie et statistique, 386(1), 37-57.

Blinder, A., Canetti, E. R. D., Lebow, D. E., \& Rudd, J. B. (1998). Asking About Prices: A New Approach to Understanding Price Stickiness. Russell Sage Foundation.

Blinder, A. S. (1991). Why are Prices Sticky? Preliminary Results from an Interview Study. The American Economic Review, 81(2), 89-96.

Blinder, A. S. (1994). On Sticky Prices: Academic Theories Meet the Real World, 117-154.

Bolker, B. M., Brooks, M. E., Clark, C. J., Geange, S. W., Poulsen, J. R., Stevens, M. H. H., \& White, J.-S. S. (2009). Generalized linear mixed models: a practical guide for ecology and evolution. Trends in Ecology \& Evolution, 24(3), 127-35.

Breslow, N. E. (2004). Whither PQL? In D. Y. Lin \& P. J. Heagerty (Eds.), Proceedings of the Second Seattle Symposium in Biostatistics (Vol. 179, pp. 1-22). New York, NY: Springer New York.

Breslow, N. E., \& Clayton, D. G. (1993). Approximate Inference in Generalized Linear Mixed Models. Journal of the American Statistical Association, 88(421), 9-25.

Browne, W. J., \& Draper, D. (2006). A comparison of Bayesian and likelihood-based methods for fitting multilevel models. Bayesian Analysis, 1(3), 473-514.

Calvo, G. A. (1983). Staggered prices in a utility-maximizing framework. Journal of Monetary Economics, 12(3), 383-398.

Campbell, J. R., \& Eden, B. (2014). Rigid Prices: Evidence From U.S. Scanner Data. International Economic Review, 55(2), 423-442.

Cecchetti, S. G. (1986). The frequency of price adjustment. Journal of Econometrics, 31(3), 255-274.

Chahrour, R. A. (2011). Sales and price spikes in retail scanner data. Economics Letters, 110(2), 143-146.

Chakrabarti, R., \& Scholnick, B. (2005). Nominal rigidities without literal menu costs: evidence from E-commerce. Economics Letters, 86(2), 187-191.

Danziger, L. (1983). Price Adjustments with Stochastic Inflation. International Economic Review, 24(3), 699-707.

Danziger, L. (1984). STOCHASTIC INFLATION AND THE OPTIMAL POLICY OF PRICE ADJUSTMENT. Economic Inquiry, 22(1), 98-108.

Dhyne, E., Alvarez, L. J., Le Bihan, H., Veronese, G., Dias, D., Hoffmann, J., ... Vilmunen, J. (2006). Price Changes in the Euro Area and the United States: Some Facts from Individual Consumer Price Data. Journal of Economic Perspectives, 20(2), 171-192.

Dotsey, M., King, R. G., \& Wolman, A. L. (1999). State-Dependent Pricing and the General Equilibrium Dynamics of Money and Output. The Quarterly Journal of Economics, 114(2), 655-690.

Dutta, S., Bergen, M., Levy, D., \& Venable, R. (1999). Menu Costs, Posted Prices, and Multiproduct Retailers. Journal of Money, Credit and Banking, 31(4), 683-703.

Eichenbaum, M., Jaimovich, N., \& Rebelo, S. (2011). Reference Prices, Costs, and Nominal Rigidities. American Economic Review, 101(1), 234-262.

Eichenbaum, M., Jaimovich, N., Rebelo, S., \& Smith, J. (2014). How Frequent Are Small Price Changes? American Economic Journal: Macroeconomics, 6(2), 137-155.

Empen, J. (2014, January). Essays on food retail pricing. Universitätsbibliothek Kiel. 
Fabiani, S., Druant, M., Hernando, I., Kwapil, C., Landau, B., Loupias, C., ... Stokman, A. (2006, July 3). What Firms' Surveys Tell Us about Price-Setting Behavior in the Euro Area.

Fahrmeir, L., Kneib, T., Lang, S., \& Marx, B. (2013). Regression Models. In Regression (pp. 389-397). Springer.

Fisher, T. C. ., \& Konieczny, J. D. (2000). Synchronization of price changes by multiproduct firms: evidence from Canadian newspaper prices. Economics Letters, 68(3), 271-277.

Fougère, D., Le Bihan, H., \& Sevestre, P. (2007). Heterogeneity in Consumer Price Stickiness. Journal of Business \& Economic Statistics, 25(3), 247-264.

Gautier, E. (2009). Les ajustements microéconomiques des prix : une synthèse des modèles théoriques et résultats empiriques. Revue d'économie politique, Vol. 119(3), 323-372.

Goldstein, H., \& Rasbash, J. (1996). Improved Approximations for Multilevel Models with Binary Responses. Journal of the Royal Statistical Society. Series A (Statistics in Society), 159(3), 505-513.

Hall, S., Walsh, M., \& Yates, A. (2000). Are UK companies’ prices sticky? Oxford Economic Papers, 52(3), 425-446.

Hassouneh, I., von Cramon-Taubadel, S., Serra, T., \& Gil, J. M. (2012). Recent developments in the econometric analysis of price transmission. Working paper.

Holm, T. (2013, November). Dynamische Preisbeziehungen auf dem deutschen Milchmarkt. Universitätsbibliothek Kiel.

Hong, G. H., \& Li, N. (2015). Market structure and cost pass-through in retail. Review of Economics and Statistics.

Johnson, P. C., \& O’Hara, R. B. (2014). Extension of Nakagawa \& Schielzeth's R (2) GLMM to random slopes models. Methods in Ecology and Evolution / British Ecological Society, 5(9), 944-946.

Kehoe, P., \& Midrigan, V. (2015). Prices are sticky after all. Journal of Monetary Economics, 75, 35-53.

Konieczny, J. D. (1993). Variable Price Adjustment Costs. Economic Inquiry, 31(3), 488498.

Lach, S., \& Tsiddon, D. (1992). The Behavior of Prices and Inflation: An Empirical Analysis of Disaggregated Price Data. Journal of Political Economy, 100(2), 349-89.

Lach, S., \& Tsiddon, D. (1996). Staggering and Synchronization in Price-Setting: Evidence from Multiproduct Firms. The American Economic Review, 86(5), 1175-1196.

Levy, D., Bergen, M., Dutta, S., \& Venable, R. (1997). The Magnitude of Menu Costs: Direct Evidence From Large U. S. Supermarket Chains. The Quarterly Journal of Economics, 112(3), 791-825.

Lloyd, T. A., McCorriston, S., Morgan, C. W., Poen, E., \& Zgovu, E. (2014). Retail price dynamics and retailer heterogeneity: UK evidence. Economics Letters, 124(3), 434-438.

Loy, J.-P., Holm, T., Steinhagen, C., \& Glauben, T. (2015). Cost pass-through in differentiated product markets: a disaggregated study for milk and butter. European Review of Agricultural Economics, 42(3), 441-471.

Loy, J.-P., \& Weiss, C. (2002). Staggering and synchronisation of prices in a low-inflation environment: Evidence from German food stores. Agribusiness, 18(4), 437-457.

Loy, J.-P., \& Weiss, C. R. (2004). Synchronization due to common shocks? Evidence from German grocery prices. Economics Letters, 85(1), 123-127.

Mark Bils, \& Peter J. Klenow. (2004). Some Evidence on the Importance of Sticky Prices. Journal of Political Economy, 112(5), 947-985.

McCorriston, S., Morgan, C., \& Rayner, A. (2001). EBSCOhost | 44396442 | Price transmission: the interaction between market power and returns to scale.

McCorriston, S., Morgan, C. W., \& Rayner, A. J. (1998). Processing Technology, Market 
Power and Price Transmission. Journal of Agricultural Economics, 49(2), 185-201.

McCullagh, P., \& Nelder, J. A. (1989). Generalized Linear Models, Second Edition. CRC Press.

Nakagawa, S., \& Schielzeth, H. (2013). A general and simple method for obtaining R 2 from generalized linear mixed-effects models. Methods in Ecology and Evolution, 4(2), 133142.

Nakamura, A. O., Nakamura, E., \& Nakamura, L. I. (2011). Price dynamics, retail chains and inflation measurement. Journal of Econometrics, 161(1), 47-55.

Nakamura, E. (2008). Pass-Through in Retail and Wholesale. American Economic Review, 98(2), 430-437.

Nakamura, E., \& Steinsson, J. (2008). Five Facts about Prices: A Reevaluation of Menu Cost Models. Quarterly Journal of Economics, 123(4), 1415-1464.

Peltzman, S. (2000). Prices Rise Faster than They Fall. Journal of Political Economy, 108(3), 466-502.

Pinheiro, J. C., \& Chao, E. C. (2006). Efficient Laplacian and Adaptive Gaussian Quadrature Algorithms for Multilevel Generalized Linear Mixed Models. Journal of Computational and Graphical Statistics, 15(1), 58-81.

Rabe-Hesketh, S., Skrondal, A., \& Pickles, A. (2005). Maximum likelihood estimation of limited and discrete dependent variable models with nested random effects. Journal of Econometrics, 128(2), 301-323.

Ratfai, A. (2006). Linking Individual and Aggregate Price Changes. Journal of Money, Credit and Banking, 38(8), 2199-2224.

Raudenbush, S. W., Yang, M.-L., \& Yosef, M. (2000). Maximum Likelihood for Generalized Linear Models with Nested Random Effects via High-Order, Multivariate Laplace Approximation. Journal of Computational and Graphical Statistics, 9(1), 141-157.

Richards, T. J., Gomez, M. I., \& Lee, J. (2014). Pass-Through and Consumer Search: An Empirical Analysis. American Journal of Agricultural Economics, 96(4), 1049-1069.

Rodriguez, G., \& Goldman, N. (1995). An Assessment of Estimation Procedures for Multilevel Models with Binary Responses. Journal of the Royal Statistical Society. Series A (Statistics in Society), 158(1), 73-89.

Rodriguez, G., \& Goldman, N. (2001). Improved Estimation Procedures for Multilevel Models with Binary Response: A Case-Study. Journal of the Royal Statistical Society. Series A (Statistics in Society), 164(2), 339-355.

Rotemberg, J. J. (2005). Customer anger at price increases, changes in the frequency of price adjustment and monetary policy. Journal of Monetary Economics, 52(4), 829-852.

SBKB. (2011). Weekly wholesale prices. Süddeutsche Butter- und Käse-Börse e.V. Kempten (Allgäu).

Schall, R. (1991). Estimation in generalized linear models with random effects. Biometrika, 78(4), 719-727.

Schenkelberg, H. (2013). The Determinants of Sticky Prices and Sticky Plans: Evidence from German Business Survey Data. German Economic Review, n/a-n/a.

Sheshinski, E., Tishler, A., \& Weiss, Y. (1981). Inflation, costs of adjustment, and the amplitude of real price changes : an empirical analysis. Development in an Inflationary World: Proceedings.

Sheshinski, E., \& Weiss, Y. (1977). Inflation and Costs of Price Adjustment. The Review of Economic Studies, 44(2), 287-303.

Sheshinski, E., \& Weiss, Y. (1979). Demand for Fixed Factors, Inflation and Adjustment Costs. The Review of Economic Studies, 46(1), 31-45.

Sheshinski, E., \& Weiss, Y. (1983). Optimum Pricing Policy under Stochastic Inflation. The Review of Economic Studies, 50(3), 513-529. 
SIG (Symphony IRI Group GmbH). (2011). Retail Scanner Data.

Taylor, J. B. (1980). Aggregate Dynamics and Staggered Contracts. Journal of Political Economy, 88(1), 1-23.

Taylor, J. B. (1999). Chapter 15 Staggered price and wage setting in macroeconomics. Handbook of Macroeconomics, 1, 1009-1050.

Vavra, P., \& Goodwin, B. K. (2005). Analysis of price transmission along the food chain (No. 3). France.

von Cramon-Taubadel, S., Loy, J.-P., \& Meyer, J. (2006). The impact of cross-sectional data aggregation on the measurement of vertical price transmission: An experiment with German food prices. Agribusiness, 22(4), 505-522.

Weiss, Y. (1993). Optimal Pricing, Inflation, and the Cost of Price Adjustment (p. 520). MIT Press.

Willis, J. L. (2006). Magazine prices revisited. Journal of Applied Econometrics, 21(3), 337344.

Wohlgenant, M. K. (2001). Marketing, Distribution and Consumers. Handbook of Agricultural Economics (Vol. 1). Elsevier.

Wolfinger, R., \& O’connell, M. (1993). Generalized linear mixed models a pseudo-likelihood approach. Journal of Statistical Computation and Simulation, 48(3-4), 233-243. 
4.8. Annex

Figure A-4.1 The overall effect of different factors on fitted probabilities of price change
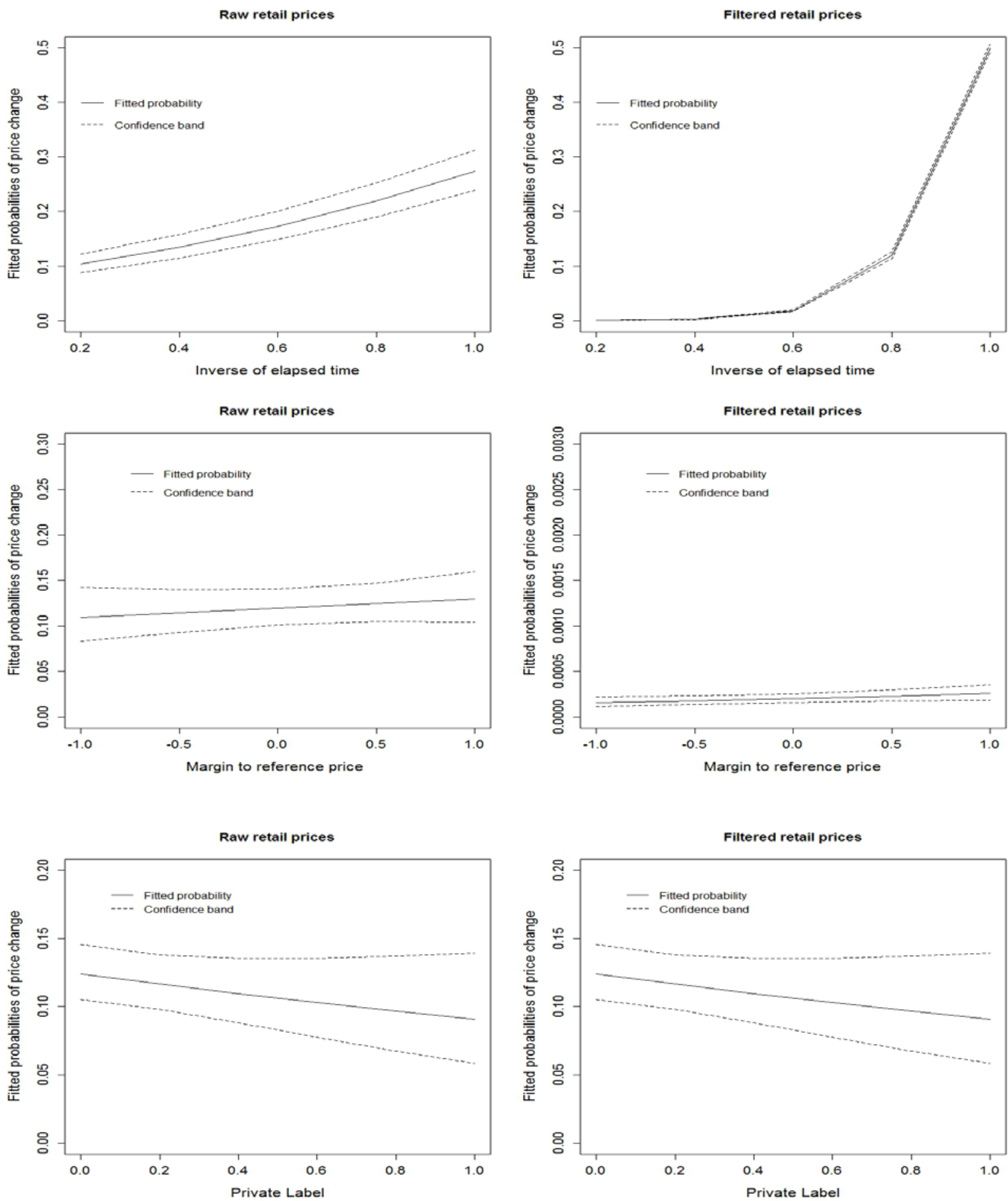

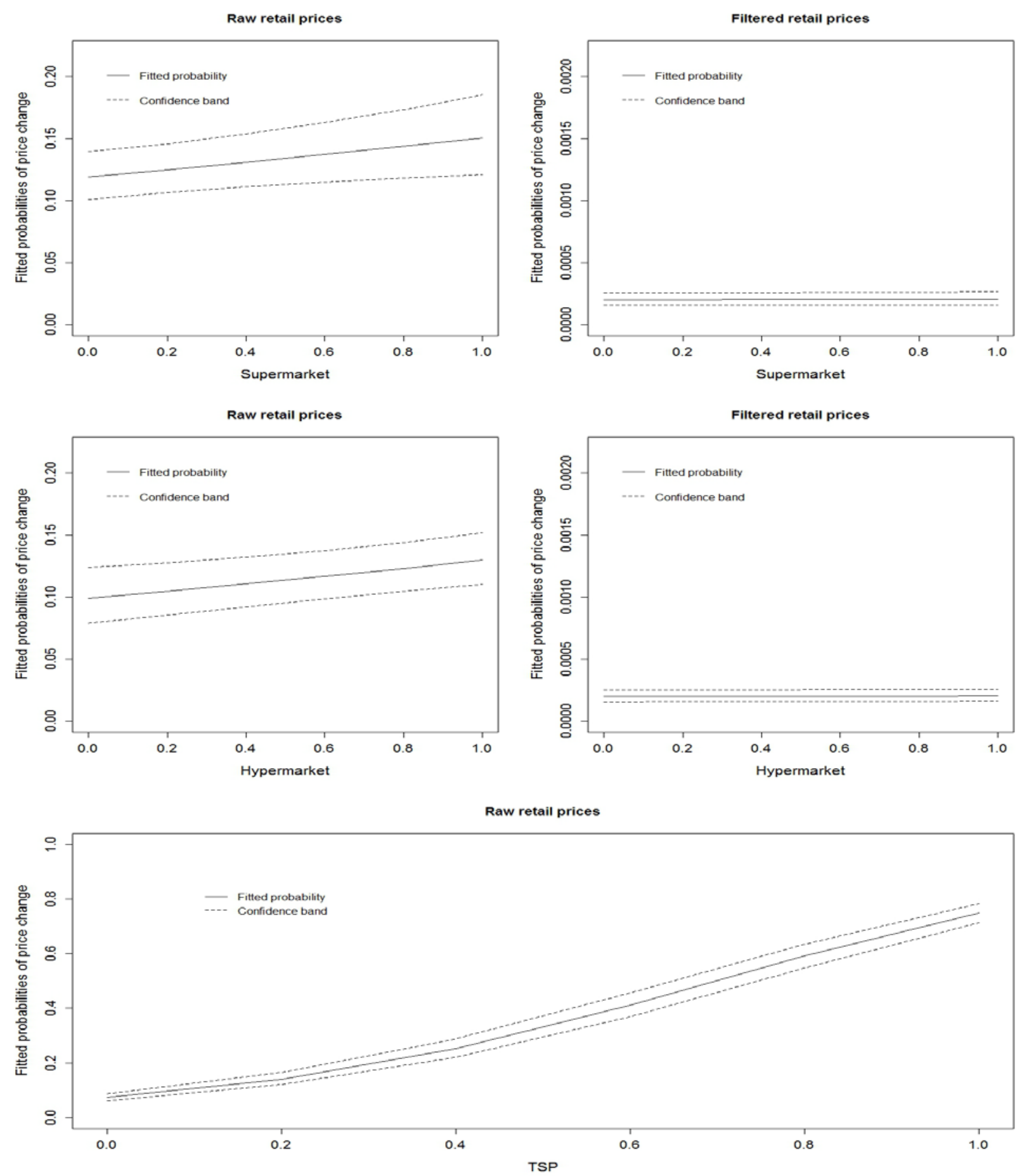


\section{Concluding remarks, study limitations and outlook}

As outlined in the introduction of this dissertation, empirical applications of vertical price transmission (VPT) at the disaggregated level are quite new and they face two difficulties. The first difficulty is related to data availability. The second difficulty is related to applying appropriate methods given the characteristics of the data and their structure. These two challenges are obviously important, because data must first be present as a precondition for analysis and methods influence the outcome of such analysis. In addition, data and methods sections are reviewed in nearly every scientific paper.

With this dissertation we contribute to the literature on VPT that employ disaggregated retail prices mainly by showing the effects of the disaggregated retail price data characteristics on VPT processes. For instance, the results of the first paper of this dissertation are important for future applications of VPT at the disaggregated level. More specifically, to evaluate the effects of agricultural policy reforms on consumers' welfare, public institutions such the EU Commission have asked academic researchers in the past to look into VPT on agro-food, e.g. TRANSFOP (Transparency of Food Pricing) and ULYSSES (Food prices volatility) projects. In the future, similar analyses could be requested again and scanner data would be employed to assess VPT. The prevalence of asymmetric VPT in agro-food markets could be overestimated just because the data were not treated adequately, i.e. TSP are not filtered out. Therefore, the methods tested in this dissertation would help to improve the quality of future analysis.

The second paper of this dissertation contributes also to the literature by explicitly considering the data structure in the analysis. The paper tries to link chains' particularities, such as their pricing strategies to the prevalence of asymmetries in VPT. We show that when chains that employ high-low pricing (HiLo) strategy mimic chains that employ everyday low price (EDLP) strategy and display rigid prices, to avoid markup variation because they can, then price rigidity leads to an increase in the likelihood of asymmetry in VPT. However, the paper suffers from some limitations. The pricing strategies are not documented in the data, but rather approximated by the level of price rigidity and consumer search costs that are combined with the different formats of stores. Nevertheless, the novelty of this study is the exploration of the hierarchical structure of scanner data in order to link the nature of VPT processes to a store membership in a specific chain. We are able to separate chains displaying asymmetry in VPT from those retail chains who do not. Rather than treating all retail chains the same, we show that there are some retail chains that contribute to the enhancement of 
passing along costs. Thus, the argument of (ab)sue of market power applies only for some retail chains.

In the third paper of this dissertation, we propose an approach to retailers' dichotomous choice of changing retail prices against displaying rigid prices at the retail store level. We show that retail chains react to changes in wholesale prices with temporary sales price (TSP). To changes of competing retail prices, retail chains react with changing their regular prices. We also find that it is more likely to change new prices than changing old prices; thus a result that is at odds with the conventional theories of costly price adjustment. We also link the retail chains' sensitivity to marketing margins to the frequency of changing retail prices. However, this paper suffers from some limitations as well. In this paper we treat the same product sold in different stores as if they were completely different products. However, it could be the case that prices of products from the same manufacturer sold at different retail chains are correlated. This is left for further research where the correlations between the prices of the same manufacturer products sold at different retail chains need to be modelled explicitly - perhaps in a Bayesian approach. Moreover, in this third paper, we model only binomial choices of changing retail prices; we do not distinguish between increases and decreases in prices. However, it could be the case that the factors that influence price increases and prices decreases are different. This is left for future research, which can also help to test for asymmetries, i.e. whether retail chains' sensitivity to marketing margins changes depending on when they increase their prices compared to when they decrease their prices.

In all three studies presented in this dissertation we employ a subsample of retail scanner data on dairy products purchased from a commercial provider: Symphony IRI Group GmbH. The use of scanner data prices has helped applications of VPT at the individual store level. Obviously, these data have advantages over the use of weighted averages at the regional national level, but they also suffer from some drawbacks.

The first advantage of scanner data is that they provide detailed and highly disaggregated information on both quantities and markups on a weekly basis for each product sold at different stores from the surveyed retail chains by the Symphony IRI Group GmbH. Nevertheless, the weekly prices are calculated by dividing the average unit revenues on quantities sold each week for a given item at a given store. The calculation of weekly prices in this way may result in small price changes in the data (Eichenbaum et al., 2014; Lloyd et al., 2014) and fractional prices (Campbell \& Eden, 2014). However, by using filtered retail 
prices we circumvent the influence of the small change and fractional prices on the overall results.

The second advantage of the data used in this dissertation, in comparison to previous studies that have employed scanner data, is their rich cross-sectional component. With 37 retail chains covered in the data, it is possible to use statistical inference to test hypotheses on the retail chains behavior, such as the prevalence in asymmetries in VPT and their sensitivity to marketing margins. Moreover, this rich cross-sectional component has also facilitated the application of some relevant methods that deal with aggregation issues, such as mixed models.

Not all retail chains in Germany provide their data to the Symphony IRI Group GmbH. Important retail chains such as ALDI and Lidl do not provide their data to the IRI. This is considered as a drawback for the scanner data employed in this dissertation. More specifically, this could challenge the comparisons made in this study between the discounters and supermarkets/hypermarkets, because ALDI and Lidl are the two largest discounters in Germany. This issue is also closely related to the testing for the effect of double marginalization on VPT processes. The private labels in our subsample covers only $7 \%$ of the items; however, these two retail chains supply mostly private labels. This makes the discussion of the effect of double marginalization on VPT processes at the disaggregated level open for further research.

Another drawback of the data is related to buying-in prices for the individual retail chains that are not made available by the data provider. Some published studies in the USA have access to both retail and buying-in prices, but retailers in Germany are quite reluctant in sharing their buying-in prices and disclose their margins (Empen, 2014). In all three papers of this dissertation we use average wholesale prices at the national level to approximate input prices when we assess VPT. The availability of the wholesale prices for the individual retailer chain may allow researchers to identify the exact marketing margins; thus allowing for increased accuracy in the identification of the role of wholesalers and retailers in VPT outcomes. However, this issue of availability of disaggregated data at the wholesale level does not compromise the results presented in this dissertation. For instance, the issue of asymmetric VPT that is often discussed in the literature, is at the retail level after all.

Last, but not least, the location of retail stores is only indicated by a dummy variable indicating the location in four regions in Germany. The availability of exact spatial 
coordinates of retail store or zip code, could be explored to check spatial dependencies in VPT, e.g. what is the effect of stores surroundings on how they change and transmit their prices. The investigation on effects on the VPT processes of competing retail chains in a single neighborhood is also an area of future research.

The difficulties faced while analyzing VPT at the disaggregated level in terms of methods are even greater. In particular, how to capture price dynamics when prices are rigid. Loy et al. (2015) suggest some jump processes without going into details. We have documented along this dissertation different ways, e.g. graphs, duration of unchanged prices, that retail prices at the individual retail stores are non-continuous and show some jumping processes. Thus, developing time series models of the evolution of prices at the individual retail store level, such as multistate duration models, might bring new insights on how prices are determined, and more importantly how they are transmitted at the disaggregated level. However, the challenge is then how consistent are the duration models for example with the economic theory and with VPT analysis. For instance, VPT analysis focuses more on how prices change, whereas duration models focus more on why an event takes places during time, such as the duration of a regular price spell. Yet, panel data methods have been suggested and applied in the literature because they increase the power of estimates (Empen, 2014; Holm, 2013; Loy et al., 2015; Richards, et al, 2014). However, in addition to the time and crosssectional dimensions that are considered in panel data, scanner data have an additional and important component: their hierarchal structure.

Previous studies that have employed panel data techniques for the same product sold in different stores are considered as if they were independent units to study. This is obviously not the case because if the same product is provided to several retail chains by a manufacturer, there might be a relationship between the price dynamics of the same product between retail chains. Our third paper also suffers from this drawback. We try to model the information contained in the level of the hierarchy, but only partially. We only consider nested random effects, but not crossed random effects. A way to circumvent crossed random effects is to study private label apart as subsample, because private labels are only sold by only one retail chain. However, as mentioned before the private labels are limited in our dataset; thus considering private labels would only lead to time dimensions that exceeds the cross-sectional component of the data. This is left for future work.

Moreover, this dissertation focuses on one product in isolation, but retailers presumably pursue linked pricing strategies for groups or assortments of food products. So whether a 
retailer changes butter prices for example in response to a wholesale price change for butter might also depend on what prices for substitutes, e.g. margarine. This is left for further research.

In summary, academic research that investigate how prices are transmitted at the disaggregated level is scare. There is of course room for future developments in studies of VPT with disaggregated retail prices, in particular in the methods aspect. We have shown in this dissertation that there are important aspects in the data that need researcher' attention such as their structure. It took almost four decades for the applications of VPT using aggregated prices to reach their level of maturity in nowadays. Perhaps in the near future, we will see more focus of academic research on how prices are transmitted at the disaggregated level. 


\section{References}

Campbell, J. R., \& Eden, B. (2014). Rigid Prices: Evidence From U.S. Scanner Data. International Economic Review, 55(2), 423-442. http://doi.org/10.1111/iere.12055

Eichenbaum, M., Jaimovich, N., Rebelo, S., \& Smith, J. (2014). How Frequent Are Small Price Changes? American Economic Journal: Macroeconomics, 6(2), 137-155. http://doi.org/doi: 10.1257/mac.6.2.137

Empen, J. (2014, January). Essays on food retail pricing. Universitätsbibliothek Kiel.

Holm, T. (2013, November). Dynamische Preisbeziehungen auf dem deutschen Milchmarkt. Universitätsbibliothek Kiel.

Lloyd, T. A., McCorriston, S., Morgan, C. W., Poen, E., \& Zgovu, E. (2014). Retail price dynamics and retailer heterogeneity: UK evidence. Economics Letters, 124(3), 434-438. http://doi.org/10.1016/j.econlet.2014.06.032

Loy, J.-P., Holm, T., Steinhagen, C., \& Glauben, T. (2015). Cost pass-through in differentiated product markets: a disaggregated study for milk and butter. European Review of Agricultural Economics, 42(3), 441-471. http://doi.org/10.1093/erae/jbu031

Richards, T. J., Gomez, M. I., \& Lee, J. (2014). Pass-Through and Consumer Search: An Empirical Analysis. American Journal of Agricultural Economics, 96(4), 1049-1069. http://doi.org/10.1093/ajae/aau009

SIG (Symphony IRI Group GmbH). (2011). Retail Scanner Data.

TRANSFOP (Transparency of Food Pricing). (n.d.). Retrieved from http://cordis.europa.eu/result/rcn/141608_en.html

ULYSSES (Food prices volatility). (n.d.). Retrieved from http://www.fp7-ulysses.eu/ 


\title{
6. Annex
}

This annex was prepared in collaboration with Simon Kofoed-Dam from the university of Copenhagen who wrote his master thesis when he was student assistant at the Chair of Agricultural Policy of the university of Goettignen.

\subsection{Price filter: an overview}

\begin{abstract}
In this chapter, we document the preliminary work that has been conducted with the raw scanner data before their use for the statistical analyses of the vertical price transmission (VPT). In particular, we document some data issues that we faced and how we circumvent them. We also document some features of the time series of prices at the smallest possible scale of the value chain, i.e. individual retail store. We briefly introduce the potential impact of these features on the measurement of VPT. In order to avoid misleading conclusions from the analyses of cost-pass-through from the wholesale to the retail level, we calculate the reference prices. Since different methods to calculate the reference prices are suggested in the literature, we first briefly review the different methods of calculation, their advantages and drawbacks and we justify our choice of the adequate method based on some performance criteria.
\end{abstract}

Keywords: price filter, reference price and scanner data. 


\subsubsection{Introduction}

The scanner data as collected by the SIG (2011) are not directly appropriate for statistical analysis; therefore some preliminary work on data cleaning was necessary to deal with some issues that we explain hereafter. For instance, SIG (2011) provide us with the data in two subsamples 2005-2008 and 2009-2010. The items included in the scanner data are identified with the European Article Number (EAN), and there were some changes in some EANs between the two subsamples; therefore, we had to match up the two subsamples to get the final sample.

Fougère et al (2007) highlight some problems that occur when raw scanner data are used for academic research. Attrition and censoring are the most common problems. Attrition occurs when some statistical units, in our case food items sold at a specific outlet, leave the sample before the end of the survey. Two sources of attrition in price records are possible. First, if a product leaves the market or got replaced by a new product, then the time series of price records are interrupted. Second, the outlets could go in bankrupt, which leads to the termination of the survey for some items. The second issue is related to censoring. There are two reasons that can lead to the censoring of price spells. First, the observation period is restricted by the data availability. For instance, our dataset starts with price records of the first week of January 2005 through last week of December 2010, and some prices recorded at that date were set before the beginning of the sampling. Second, outlets and firms may decide to stop selling a product while the SIG (2011) still has it on the survey for some additional period of time.

In addition to attrition and censoring, and since the prices provided by the SIG (2011) for a given week are calculated by the division of revenues by units sold each week for each item, there is the presence of small price changes. It is not easy to explain the small price changes, and it is hard to justify them with economic motivation, in particular within the menu cost price settings models. The vast majority of the small price changes are due to measurement error (Eichenbaum et al., 2014). Campbell and Eden (2014) argue that the small changes in prices might be related to the price reporting and they use the concept of fractional prices to characterize these small price changes. Fractional prices could result either from technical errors in price settings or from time aggregation. More specifically, the displayed price and the price on the computer are different. Campbell and Eden (2014) provide examples on how the fractional prices create artificial price changes. 
There is also the presence of missing values in the raw data that are due to temporary stockouts or holidays. Some studies choose to impute missing values or replace them with the last observed price. Four our purpose, it was more suitable to work rather with the complete time series of prices. This would avoid creating artificial price changes that we would further include and compound in the VPT analyses and that might affect our results and conclusions. Another reason for leaving incomplete time series out of the subsample that we use for the VPT analyses is the paucity of observations, where sometimes some item is only displayed at the surveyed outlets for some weeks and it was included in the data collection.

The extent to which retailers use promotional prices is a source of heterogeneity in price adjustments Lloyd et al. (2014). The temporary sales prices (TSP) is the most common used form of promotional prices. Hosken and Reiffen (2001, p. 115) define TSP: “a temporary reduction in the price of an item which is unrelated to cost changes". In the studies of VPT, we are interested in looking at how changes in prices at some level of the value chain are transmitted to another level of the value chain, i.e. it is therefore important to distinguish the changes in the regular prices from the TSP.

Figure 6.1 graphically illustrates the distinction between the changes introduced in the "regular price" denoted by " $\mathrm{R}$ " from the changes that correspond to the temporary sales prices denoted by "S". The two panels (A and B) from Figure 6.1 display ten observations for two hypothetical price series from Nakamura and Steinsson (2008).

Figure 6.1 Illustration the changes is prices due to TSP and regular price changes.
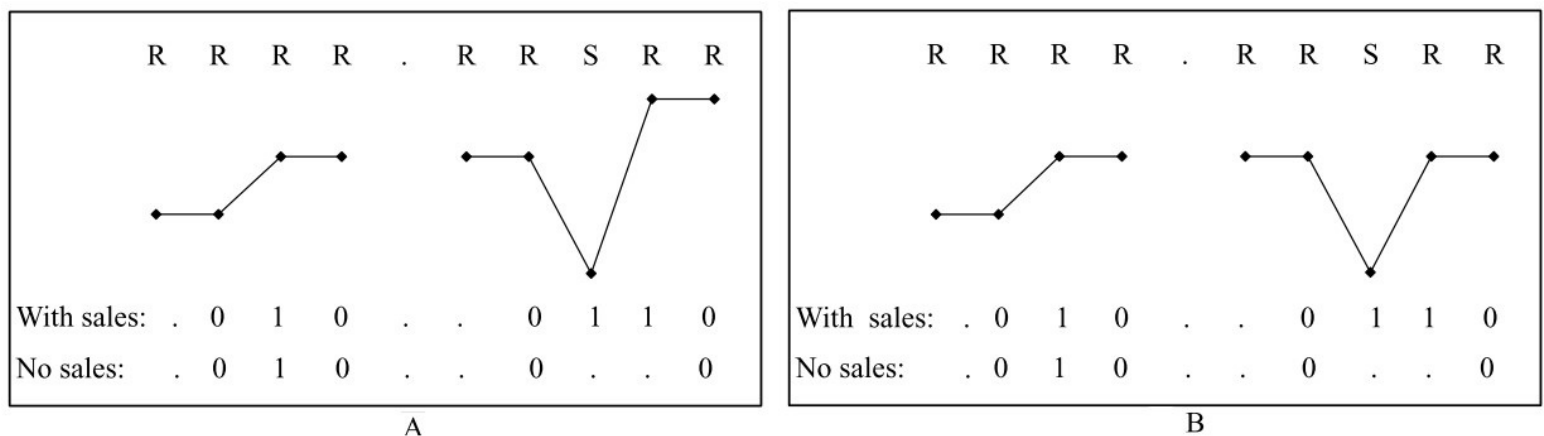

$$
\begin{aligned}
& \text { "R" : regular price } \\
& \text { "S" : temporary sales price } \\
& \text { "." : missing value }
\end{aligned}
$$

Source: Nakamura and Steinsson (2008)

To circumvent some of the data issues highlighted above, e.g., fractional prices and TSP, we use price filters. Price filters were first introduced in the macroeconomics literature, and then extend to other areas such as international economics and agricultural economics. Since some 
of price filters proposed in the literature are based on subjective definitions of TSP, the choice of the adequate filter to use is ambiguous. We base our choice on the basis of criteria of performance.

In this chapter, we aim to give an overview of the issues that researchers face when they work with raw scanner data. In section 6.1.2, we give descriptions of the features of the price records at the smallest possible scale and the potential of using these features to the design of research questions. In section 6.1.3 includes some arguments to justify the use of price filters. In section 6.1.4, we present an overview of the most commonly price filters sales filter and reference prices. In section 6.1.5, we compare the filters by using some indicators on performance of the different filters. Section 6.1.6 concludes.

\subsubsection{Feature of the times series on price records at the smallest possible scale}

Before carrying out any statistical analysis it is always useful to become familiar with the data at hand by using graphical tools. Figure 6.2 displays the evolution of weekly prices of three (P1, P2, P3) randomly selected price series of butter for 250-gram foil-wrapped packages sold at a randomly selected retail store for the period 2005-2010 in Germany. The weighted average of retail and wholesale prices for the same category of butter during the same time period are also displayed.

\section{Figure 6.2 Retail prices at different levels of spatial aggregation}

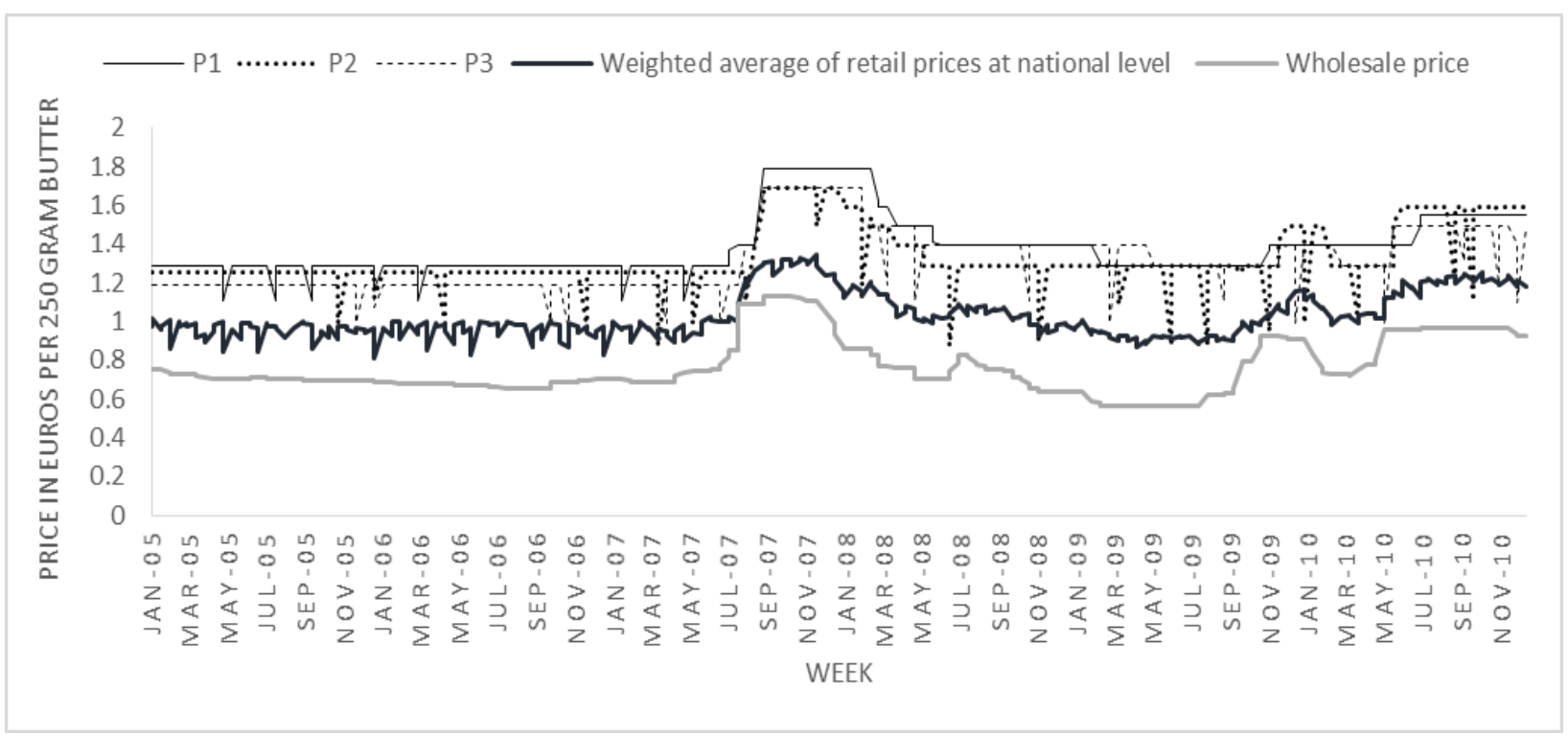

Source : Authors’ calculation from SIG (2011) 
Three main features are present in almost ${ }^{19}$ all of the individual retail price series, which are similar to those displayed for of P1, P2 and P3. Namely, for a typical product P1 sold at a specific store, the time series of prices exhibit a pattern that is characterized by rigidity, following a "staircase” like path, with sudden changes, which represent TSP for most of the time TSP and the presence of "psychological pricing".

The exploration of effects for these features of the data at the smallest possible scale on the measurement of the VPT, e.g., the effect of the TSP on the speed of the VPT, is not systematically investigated in the literature. In Chapter 2 of this thesis, we explicitly investigate the effects of the TSP on the measurement of VPT. More specifically, our results show that TSP biases the results toward finding more cases of asymmetry in the VPT.

Moreover, Figure 6.3 illustrates the possible link between the number of TSP and the difference between the $\alpha^{+}$, which measures the reaction of retail prices (e.g., P1 from Figure 6.2) to the increase in wholesale prices, and $\alpha^{-}$which measures the reaction of retail prices to the decrease in the wholesale prices.

Figure 6.3 The link between the number of TSP and the finding asymmetries in the VPT

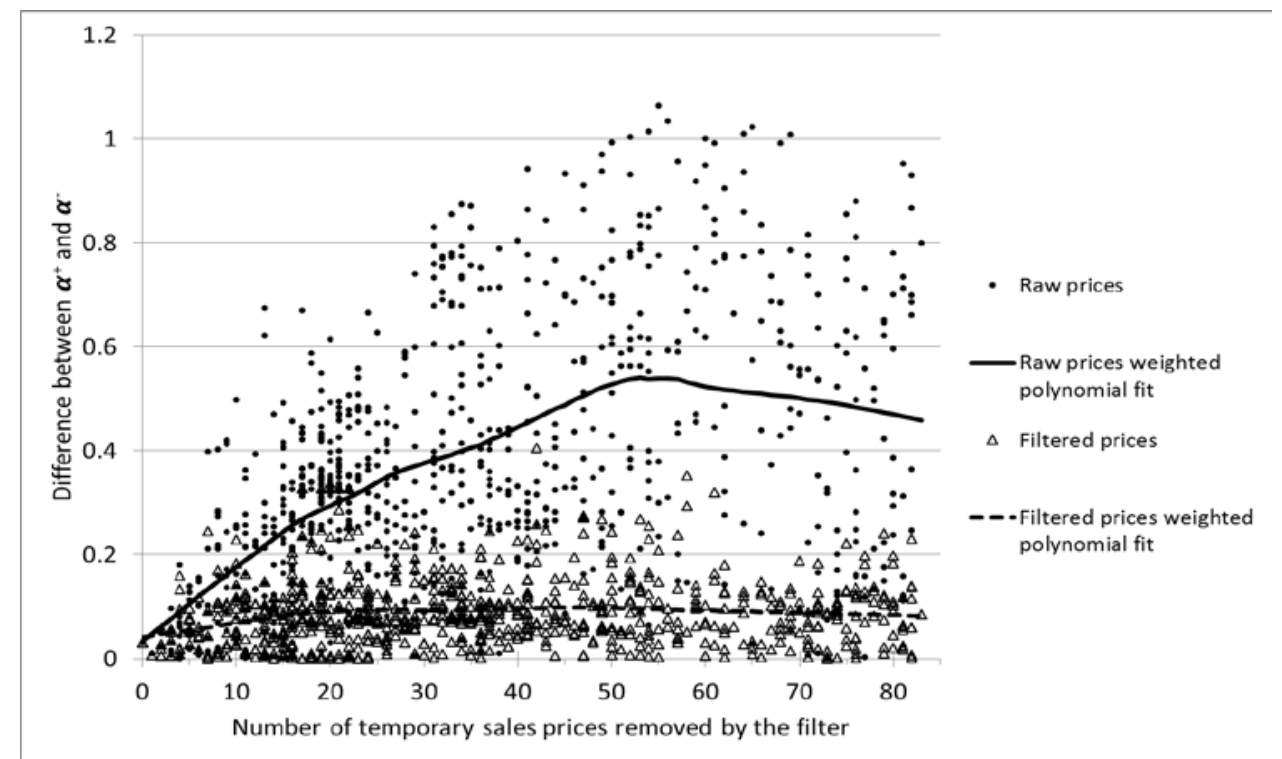

Source : Authors' calculation from SIG (2011)

An overview of the relationship between the number of the TSP identified by the filter for a selected sample of 800-time series and the test for asymmetry in the VPT are displayed in Figure 6.3. The scatter plot illustrating the frequency of the TSP versus the magnitude of the

19 Exception would be time series of prices that remain constant for the whole period under study. We have left them out the sample. 
difference between estimates of $\alpha^{+}$and $\alpha^{-}$in the VECM is estimated with raw retail data and filtered prices. Each point corresponds to a unique item. The solid line is estimated with the raw retail prices and it displays a positive relationship between the two variables. We can see that the higher the frequency of TSP use, so larger is the magnitude of the difference between estimates of $\alpha^{+}$and $\alpha^{-}$, i.e. the greater likelihood to conclude in favor of the asymmetry in VPT. However, the dashed line estimated with the filtered retail prices is almost flat and it does not display an evident positive relationship that with raw retail prices. The contrast between the solid line and the dashed line illustrates and confirms our findings that the magnitude of TSP plays a role in explaining the bias towards the rejection of the null hypothesis of symmetric price transmission in the raw retail prices.

Moreover, Figure 6.4 displays a box plot of the total number of TSP out of 312 observations used for each of the items in our data against the different format of stores.

Figure 6.4 The use of Temporary Sale Prices (TSP) by format of store

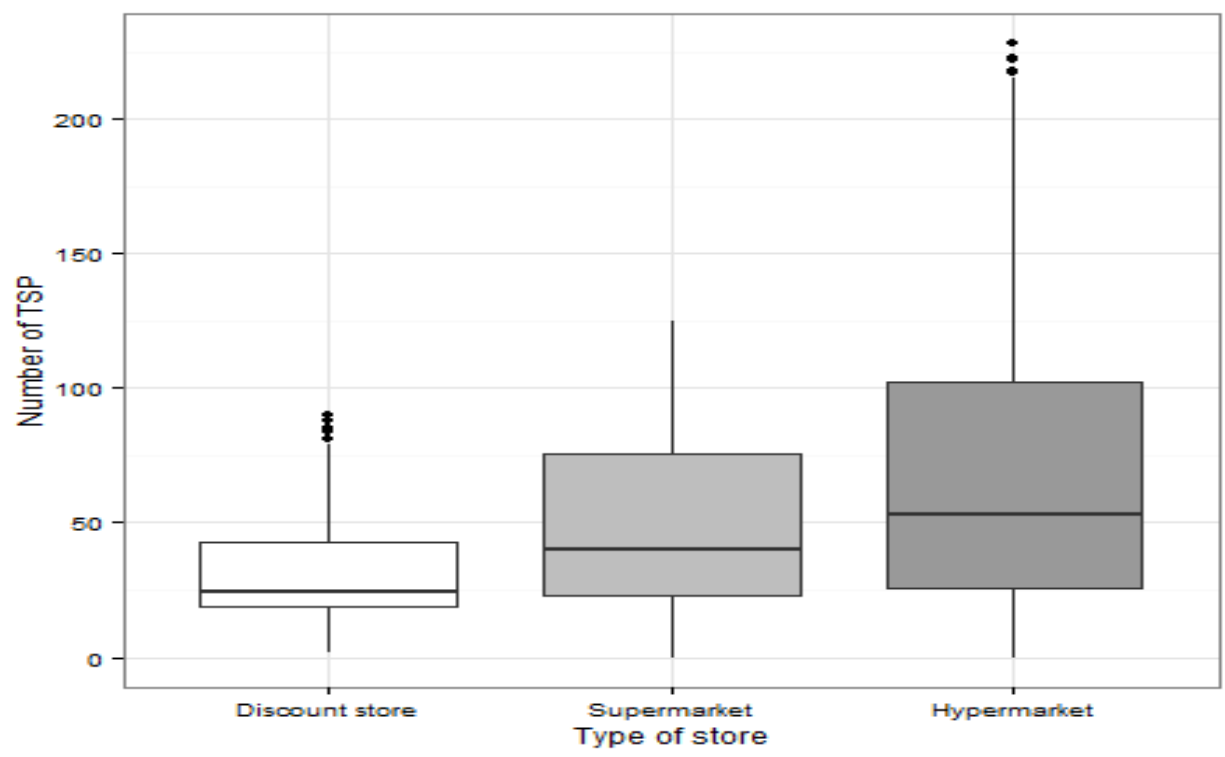

Source : Authors’ calculations using data from SIG (2011)

The hypermarkets and the supermarkets use TSP more frequently than the discount stores. This is partially due to the High-Low (HiLo) pricing strategy followed by the supermarkets and hypermarkets in comparison to Every Day Low Price (EDLP) strategy followed by the discount stores. After filtering out the TSP, the influence of the pricing strategy on the nature of the VPT is explicitly investigated in Chapter 3 of this thesis. 


\subsubsection{Why price filters}

We have already mentioned some specific cases where it is useful to use price filters to deal with some features of raw scanner data. Dealing with the features of the time series collected on price records using scanner data is not new though. Interestingly, a pioneer price filter is introduced within the macroeconomics literature to verify theoretical pricing models using micro-data. Even though the context and the objectives of the use of scanner data in those fields are quite different from ours, the aim remains the same, i.e., we do not want those features, e.g. TSP, to affect our results and conclusions. Since the pioneering paper by Bils and Klenow (2004), many papers have been published to reconcile frequent price changes in micro-level data with sickness aggregate price indexes (Chahrour, 2011). This leads to the studies of the stickiness of prices to becoming one of the most stylized facts about prices with micro-level data. This is of importance because the stickiness of prices at the micro-level data is a major assumption for an effective monetary policy (Kehoe \& Midrigan, 2015).

Bils and Klenow (2004) explore data from the Bureau of Labor Statistics (BLS) for the years 1995-1997 and find that prices change every 4.3 months and they conclude that prices are flexible at the micro-level. Nakamura and Steinsson (2008) study a more detailed data set from the BLS, but with filtered TSP, and find prices to be stickier than reported by Bils and Klenow (2004), namely up to 7-11 months. Bils and Klenow (2004, p. 955) argue that TSP should not be filtered because: "the magnitude and duration of temporary sales respond to shocks". Nakamura and Steinsson (2008, p. 1417) argue that TSP can be ignored because some of them may be “orthogonal to macroeconomic conditions”. They use an algorithm to filter the temporary sales price and do the analysis on how often price changes in the US economy. So, the answer to the question on how frequently prices change in an economy for instance, or other related research questions which involve the study of price changes, will depend on how TSP are treated in the data. Particularly, when the context is such as that the individual price series are available for the researcher but no information are available on the actual underlying decisions of the retail manager to changing prices.

Eichenbaum et al. (2011) challenge the sticky price models by introducing the concept of reference price to evaluate the theoretical models of price setting with micro-level data. The first challenge regards the time dependent models (better known as Calvo models), which assume that firms regularly adjust their prices independently of the economic environment, in that they are inconsistent with the key features of the data available at the microeconomics level. More specifically, the features of the micro-data on prices and costs show evidence of 
state dependence (better known as menu cost models), i.e., firms adjust their prices accordingly to the changes in their economic environment. The second challenge is regarding the menu cost models where they argue that the prices are more volatile than costs at the micro-data level. Eichenbaum et al. (2011) imply that nearly all price changes are associated with cost changes and menu cost models cannot generate both of these features simultaneously. Moreover, menu cost models cannot generate the format of high and low frequency price variation observed in the data.

In agricultural economics, Lloyd et al. (2014) study the retail heterogeneity in price adjustments in the major food retailers in the UK. They employ a decomposition analysis of price variation into sales and reference prices and they conclude that the price adjustment is equally split between sales (43\%) and the reference prices (44\%).

\subsubsection{An overview of the different price filters used in the literature}

Different techniques to deal with TSP and fractional prices have been suggested by often relying on some sort of price filtering process of the "raw" time series, before using the filtered price series in the actual empirical analysis. Table 6.1 summarizes the different price filters that we describe in this section.

Table 6.1 Overview of price filters

\begin{tabular}{|c|c|c|}
\hline Type of filter & Authors & Characteristics of filter \\
\hline Sales filter & $\begin{array}{l}\text { Kehoe and Midrigan } \\
\text { (2007) } \\
\text { Nakamura and } \\
\text { Steinsson (2008) } \\
\end{array}$ & $\begin{array}{l}\text { Sale as a drop in price followed by any price } \\
\text { increase } \\
\text { V shape temporary sale }\end{array}$ \\
\hline $\begin{array}{c}\text { Reference } \\
\text { price: } \\
\text { Fixed window } \\
\end{array}$ & $\begin{array}{l}\text { Eichenbaum et al. } 2011 \\
\text { Our filter }\end{array}$ & $\begin{array}{l}13 \text { weeks, fixed window } \\
13 \text { weeks, multiple modal values: max } \\
13 \text { weeks, multiple modal values: min }\end{array}$ \\
\hline $\begin{array}{l}\text { Reference } \\
\text { price: } \\
\text { rolling window }\end{array}$ & Chahrour 2011 & $\begin{array}{l}13 \text { weeks, algorithm to choose max in } \\
\text { transition periods } \\
9 \text { weeks, multiple modal values: max } \\
9 \text { weeks, multiple modal values: min } \\
17 \text { weeks, multiple modal values: max } \\
17 \text { weeks, multiple modal values: min }\end{array}$ \\
\hline
\end{tabular}

Source: Authors' summary

In general, a price filter tries to capture temporary price sales and fractional prices, which are price decreases that are quickly reversed. But how the reverse price change is defined depends on the author's definition. 


\subsubsection{Sales filters}

Different suggestions on how a temporary sales price can be defined and importantly how it can be distinguished from a regular price change have been made. Yet there is no consensus on a final definition in the literature.

\section{a. Koheo and Midrigan filter}

Kehoe and Midrigan (2007) use the AC Nielsen algorithm, which looks at the pattern of price changes and classifies price reduction as sales if they are reversed sufficiently quickly and classifies the rest as regular price changes. So the procedure is simple. The algorithm is run throw a single time series of prices $P_{t}$. For each price cut, i.e., $P_{t}<P_{t-1}$, for $t \geq 2$, the algorithm checks if it is followed by a price increase within 5 weeks period. If the price within these 5 weeks period does not go above the price level at the period $t$, i.e., $P_{t}=$ $P_{t+1}=\cdots=P_{t+5}$, then the change is considered to be made in the regular price; therefore the price $P_{t}$ would not be replaced by $P_{t-1}$. In contrast, if the price within these 5 weeks period rise above the price level in period, i.e., $P_{t+j}>P_{t}$, for at least one of the weeks $\mathrm{J}=\{1,2,3,4,5\}$, then replace $P_{t}, P_{t+1} \ldots$ and $P_{t+\hat{\jmath}-1}$ with the price immediately before the price drop: $P_{t-1}$, where $\hat{\jmath}$ denotes the minimum of $\mathrm{J}$ for each iteration.

\section{b. Nakamura and Steinsson sales filter}

Nakamura and Steinsson (2008) propose a filter that captures only V-shape sales, i.e., a price decrease that is followed by a return to the price that was in effect just before the drop in the price. Rotemberg (2011) justify the V-shape of TSP. He argues that changing the list of prices is costly to the firms. Obviously, for this additional restriction, which consists in detecting only V-shape sales, the Nakamura and Steinsson' sales filter will identify fewer temporary sales prices than the Koheo and Midrigan's sales filter.

Nakamura and Steinsson (2008) use an algorithm to filter temporary sales prices. The algorithm includes a function of three parameters: L, K, J. As in any function, varying these three parameters changes the way the sales are defined and filtered. Therefore, for different values of $\mathrm{L}, \mathrm{K}, \mathrm{J}$, the algorithm can capture V-shaped sales only, V-shaped sales that are followed by a different regular price, multi-period sales, etc. Nakamura and Steinsson (2008) provide a supplement of their paper where the suggested algorithm used to filter out the temporary sales is explained. As before, consider that $p_{t}$ is the raw price series, and $r_{t}$ is the "regular price" or the filtered price series. The algorithm works in six steps that are carried 
out in sequence to each observation (i.e. step 0 has precedence over step 1, etc.). The steps are easy to follow and to implement and they are given as follows:

Step 0: if $p_{t}=r_{t-1}$ then $r_{t}=r_{t-1}$.

Step 1: if $p_{t}>r_{t-1}$ then $r_{t}>r_{t-1}$

Step 2: if $r_{t-1} \in\left\{p_{t+1}, \ldots, p_{t+J}\right\}$ and the price never rises above then $r_{t-1}$ before returning to $r_{t-1}$, then $r_{t}=r_{t-1}$.

Step 3 if the set $\left\{p_{t}, p_{t+1}, \ldots, p_{t+L}\right\}$ has K or more different elements, then $r_{t}=p_{t}$

Step 4 define $p_{\max }=\max \left\{p_{t+1}, p_{t+2}, \ldots, p_{t+L}\right\}$ and

$t_{\text {max }}=$ first_time $\max \left\{p_{t+1}, p_{t+2}, \ldots, p_{t+L}\right\}$.

If $p_{\max } \in\left\{p_{t_{\text {max }}+1}, p_{t_{\text {max }}+2}, \ldots, p_{t_{\text {max }}+L}\right\}$, then $r_{t}=p_{\text {max }}$.

Step $5 r_{t}=p_{t}$

In the first time period the algorithm begins at step 3 (the first step does not refer to the previous regular price) and it looks for the first possible regular price for $L$ periods of time.

Nakamura and Steinsson ( 2008) propose two different sales filters, A and B. For the sales filter $\mathrm{B}$ the parameters are set to $\mathrm{L}=1, \mathrm{~K}=1$ and $\mathrm{J}=\mathrm{n}$, where $n \in\{1,2, \ldots, 5\}$ and it is designed to remove only price patterns in which price returns to the previous price within a set number of weeks without going above the original price. In the case of the sales filter A, the chosen parameters are: $\mathrm{L}=3, \mathrm{~K}=3$ and $\mathrm{J}=\mathrm{n}$, where $n \in\{1,2, \ldots, 5\}$. Filter $\mathrm{A}$ is designed to remove the price patterns where a sale is followed by a change in the regular price, i.e. asymmetric V's.

In both sales filters described above, one should mention that there is no restriction on how significant the price drops (and subsequently increases) in order to be considered a temporary sales price. Loy et al. (2015), following Hosken and Reiffen (2001), define a temporary sale as a temporary significant drop in price, they only identify a sales price when the price reduction is at least $5 \%$, and that it holds that price for a maximum of 4 weeks, before it increases again by at least $5 \%$. Lloyd et al. (2014) consider different sets of significant levels, $10 \%, 25 \%$ and $35 \%$, of price drops within a period of 12 time periods. Not surprisingly, they find that $8 \%, 3.5 \%$ and $1.4 \%$ of the prices in their dataset were classified as sales prices, respectively. This restriction on how much a price drops (and subsequently increases) to be considered significant enough to be a temporary sales price results in some small price changes, mostly fractional prices, being left unfiltered. 
In general, sales filters face two weaknesses. First, the sales filter depends on a subjective definition of the temporary sales price. Second, the problem of fractional prices is not treated. These issues are circumvented by the use of reference price (Lloyd et al., 2014).

\subsubsection{Reference prices}

The reference price offers an interesting alternative to overcome the problems faced by sales filters. The introduction of the reference price concept helps authors to avoid giving a subjective definition of what a temporary sales price is. It also allows for the explicit treatment of fractional prices. The idea of the reference prices was introduced in Eichenbaum et al. (2011) using the fixed window method for the calculations and it was extended by Chahrour (2011) to the rolling window method of calculation.

\section{a. Fixed window method}

To assess menu cost models and the non-neutrality of monetary shocks, Eichenbaum et al. (2011) argue that in terms of a firm's pricing schedules what matters is their reference price and not their nominal prices. They suggest thinking in terms of reference price when it comes to assess pricing strategies of a firm in an economy. Eichenbaum et al. (2011) explain that the individual raw retail prices are characterized by fluctuations around (both below and above) an underlying reference price. Therefore, firms/retailers have a pricing 'plan' for the individual products where they alternate between the underlying profit maximizing price (i.e. the reference price/regular price) and the temporary sales price. Eichenbaum et al. (2011) define the reference price as the modal price in each quarter.

As in the case of sales filters, consider $p_{t}$ is the raw price series, and $r_{t}$ is the "reference/regular price". In addition to these two components, a third part $\varepsilon_{\mathrm{t}}$ is added in order to capture deviations of the $p_{t}$ from the $r_{t}$, so that:

$$
p_{t}=r_{t}+\varepsilon_{t}
$$

Some restrictions should be made on $\varepsilon_{t}$ in order to identify the underlying $r_{t}$ of $p_{t}$. For instance, in the case of the sales filter, $\varepsilon_{\mathrm{t}}$ is assumed to be negative because of all the deviations of $p_{t}$ from $r_{t}$ are temporary price reductions. This is the restriction that Eichenbaum et al. (2011) relax. More specifically they take the modal value for a 13-week fixed window and apply this modal value (one value) as the reference price for the full period of 13 weeks. As an example for the first 13 weeks in the price series $p_{t}$ :

$$
\left\{r_{1}, r_{2}, r_{3}, \ldots, r_{13}\right\}=\text { modal value }\left\{p_{1}, p_{2}, p_{3}, \ldots, p_{13}\right\}
$$


However, Lloyd et al. (2014) argue that the fixed window method restricts the changes in the reference price/ regular prices to taking place at the beginning of each quarter irrespective to their actual timing. In order to circumvent this problem, they suggest a rolling reference price that they define as the modal non-sale price six weeks either sides of each point of time.

$$
r_{t}=\text { modal value }\left\{p_{t-w}, p_{t-w+1}, \ldots, p_{t-1}, p_{t}, p_{t+1}, \ldots p_{t+w-1}, p_{t+w}\right\}
$$

where $2 w+1$ is the window's length.

It should be highlighted that the filters based on a modal value can have the problem that there are multiple modal values within a given window (both the fixed and rolling version). This problem is not mentioned in Eichenbaum et al. (2011). To overcome the situation of multiple modal values, on the basis the fixed window setup, we have setup two additional filters. The two filters differ from Eichenbaum et al.'s filter in terms of how we choose reference price in the case of multiple modal values within a given window, namely either the maximum or minimum of these modal values.

\section{b. Rolling window method}

Chahrour (2011) studies the impact of using different types of price filters when estimating (stylized) facts on pricing behavior in the USA. He compares the different aforementioned filters ((Eichenbaum et al., 2011; Kehoe \& Midrigan, 2007; Nakamura \& Steinsson, 2008). He argues the sales filters constrain $r_{t}$ to have no price spikes ${ }^{20}$ and that Eichenbaum et al. 's filter may identify spurious sales and price spikes. To correct for these weaknesses, Chahrour (2011) suggests a new price filter based on a rolling window method ${ }^{21}$.

Chahrour (2011) chooses a different path than trying to use the maximum/ minimum modal value and instead he suggests an algorithm consisting of five different sub-cases. At some transition points, the new and old modal values appear in overlapping periods, where the most common price appearing during the overlapping periods is chosen. In other cases, the observed price varies among non-reference price levels just around the transition point, which obscure its actual date. In these cases, he suggests a procedure which places the transition to the new reference price in the first week that the new reference price occurs.

The starting point is to define a $\Omega_{t}=\left\{p_{t-w}, p_{t-w+1}, \ldots, p_{t}, \ldots, p_{t+w}\right\}$ set of observed prices within a window $2 w+1$ weeks, $w_{t}=\{(t-w),(t-w+1), \ldots, t, \ldots, t+w\}$, centered at

\footnotetext{
20 Price spikes are defined as deviations of $p_{t}$ prices both above and below from the $r_{t}$ prices.

${ }^{21}$ Chahrour (2011) provides a supplement of his paper where he explains the procedure on how to calculate reference using the rolling window method.
} 
time $t$. Then he defines a sequences, $\hat{r}_{0}, \ldots, \hat{r}_{t-1}$, of possible candidates to be the reference price, where $\widehat{r}_{t}$ is the modal value of $\Omega_{t}$ and $r_{t}$ is the final reference price. The proposed filter loops over $2 w+1$ week windows with the following situations:

- Case 1: if the reference price remains unchanged between $t-1$ and $t, \hat{r}_{t}=\hat{r}_{t-1}$, then increase index $t$ by one period and repeat the procedure.

- Case 2: if $\hat{r}_{t} \neq \hat{r}_{t-1}$, then define $\tau^{a} \in w_{t}$ as the last period such that $p_{\tau^{a}}=\hat{r}_{t-1}$, which is the last occurrence of $\hat{r}_{t-1}$ within the window, and $\tau^{b} \in w_{t}$ as the first period such that $p_{\tau^{b}}=\hat{r}_{t-1}$, which is the first occurrence of $\hat{r}_{t-1}$ within the window.

o Subcase 2a:

$$
\text { If } \tau^{a} \geq t \text { and } \tau^{b}>t \text {, then assign } \hat{r}_{t}=\hat{r}_{t-1}
$$

This is the case, where $\hat{r}_{t}$ has jumped too soon, as the old candidate reference price $\left(\hat{r}_{t-1}\right)$ appears again at time $t$ or later; and the new candidate reference price $\left(\hat{r}_{t}\right)$ does not first appear (within the window) until after time t.

o Subcase 2b:

Otherwise, If $\tau^{a}<t$ and $\tau^{b}<t$, and $\tau^{a}<\tau^{b}$ then assign $\left\{\hat{r}_{\tau^{a}+1}, \ldots, \hat{r}_{t-1}\right\}=$ $\hat{r}_{t}$

This is the case where the algorithm jumped too late, as the new candidate reference $\left(\hat{r}_{t}\right)$ appears before time $t$ and after the last appearance of the old candidate reference price $\left(\hat{r}_{t-1}\right)$.

o Subcase 2c:

Otherwise, if $\tau^{a} \geq \tau^{b}$ letting $\hat{r}_{t}$ be the most frequently occurring (observed) price in the set $\left\{p_{\tau^{a}}, \ldots, p_{\tau^{b}}\right\}$

This is a case of overlap, where the first occurrence of the new candidate reference price $\left(\hat{r}_{t}\right)$ is prior to the last occurrence of the old candidate reference price $\left(\hat{r}_{t-1}\right)$.

o Subcase 2d:

Otherwise, if $\tau^{a}<\tau^{b}$ defined $\tilde{\tau} \in w_{t}$ as the first period where $\left|p_{\tilde{\tau}}-\hat{r}_{t}\right|<$ $\left|p_{\tilde{\tau}}-\hat{r}_{t-1}\right|$, then let $\left\{\hat{r}_{, \tau^{a}+1}, \ldots, \hat{r}_{\tilde{\tau}-1}\right\}=\hat{r}_{t-1}$ and $\left\{\hat{r}_{\tilde{\tau}}, \ldots, \hat{r}_{, \tau^{b}}\right\}=\hat{r}_{t}$.

This is a case where there is a gap between the last occurrence of the candidate reference price and the first occurrence and first occurrence of the new price.

o Subcase 2e:

Otherwise, leave $\hat{r}_{t}$ at its original value.

The length of a 13 week window is reasonable in macroeconomics because the data are often published on a quarterly basis by the public authorities. In order to assess the effects of the window's length on the performance of the filter, we have defined several price filters that 
only vary the window's length, to include 9, 13 and 17 weeks. Similar to the fixed window setup, for each of these windows, we have chosen to further include, in the case of multiple modal values in a given window, both the minimum and the maximum and choose the one with the smaller fraction of the non-filtered prices.

\subsubsection{Performance of the different price filters}

To compare the filters we use a retail scanner dataset ${ }^{22}$ from the SIG, (2011). The data contain weekly scanner price observation for 1087 items from which three examples (P1, P2 and P3) are displayed in Figure 6.2. Table 6.2 summarizes some of the basic statistics ${ }^{23}$ used in the literature to evaluate the performance of filters. The majority of the prices coincide with the reference prices (above 70\% for all filters). Consistently, most of the quantities sold by the retailers are at their regular price. Interestingly, the increases and the decreases in regular prices are evenly distributed. This result is not in line with the previous studies (e.g., Chahrour (2011) report that about two-thirds of price changes in the regular price are increases).

\section{Table 6.2 Performance of the different price filters}

\begin{tabular}{|c|c|c|c|c|c|c|c|c|c|}
\hline & \multicolumn{2}{|c|}{ Sales Filter } & \multicolumn{2}{|c|}{ Fixed window } & \multicolumn{5}{|c|}{ Rolling window } \\
\hline & \multirow{3}{*}{$\begin{array}{l}\text { Nakamura \& } \\
\text { Steinsson, } \\
2008\end{array}$} & \multirow{3}{*}{$\begin{array}{l}\text { Kehoe \& } \\
\text { Midrigan, } \\
2007\end{array}$} & \multicolumn{2}{|c|}{ Eichenbaum } & \multicolumn{4}{|c|}{ Own calculation } & \multirow{3}{*}{$\begin{array}{l}\text { Chahrour } \\
2011\end{array}$} \\
\hline & & & 2011 & & & & & & \\
\hline & & & & & & & & & \\
\hline Window's length & - & - & 13 & 13 & 9 & & 17 & & 13 \\
\hline Modal value & - & - & Max & Min & Max & Min & Max & Min & Transition \\
\hline Fraction spent at the reference price & $92 \%$ & $90 \%$ & $77 \%$ & $77 \%$ & $85 \%$ & $82 \%$ & $90 \%$ & $90 \%$ & $90 \%$ \\
\hline $\begin{array}{l}\text { Fraction of quantity sold at the } \\
\text { reference price }\end{array}$ & $81 \%$ & $70 \%$ & $57 \%$ & $59 \%$ & $65 \%$ & $67 \%$ & $62 \%$ & $63 \%$ & $65 \%$ \\
\hline $\begin{array}{l}\text { Fraction of non-filtered prices above } \\
\text { the reference price }\end{array}$ & $0 \%$ & $0 \%$ & $33 \%$ & $42 \%$ & $19 \%$ & $39 \%$ & $27 \%$ & $38 \%$ & $25 \%$ \\
\hline $\begin{array}{l}\text { Fraction of price changes which are } \\
\text { decreases }\end{array}$ & $49 \%$ & $48 \%$ & $49 \%$ & $49 \%$ & $49 \%$ & $49 \%$ & $51 \%$ & $50 \%$ & $50 \%$ \\
\hline $\begin{array}{l}\text { Fraction of price changes which are } \\
\text { increases }\end{array}$ & $51 \%$ & $52 \%$ & $51 \%$ & $51 \%$ & $51 \%$ & $51 \%$ & $49 \%$ & $50 \%$ & $50 \%$ \\
\hline
\end{tabular}

Source: Authors' calculations

Despite the similarities between the filters, some differences are of particular interest and need to be highlighted here. First, the striking difference between the sales filters and the reference price filters is in the fraction of non-filtered prices above the regular price. This fraction is per definition zero for the sales filters because of the restriction $\varepsilon_{t} \leq 0$ explained

\footnotetext{
${ }^{22}$ We present more details on the data in the chapters 2, 3 and 4 of this thesis.

Details of the calculation of the basic statistics can be found in (Chahrour, 2011) and (Eichenbaum et al., 2011).
} 
above. In this regard, Eichenbaum et al. 's procedure leads to a higher fraction (42\%) of nonfiltered prices above the reference prices and the Chahrour's procedure leads to only $25 \%$. Therefore, for this first criterion, Chahrour's filter shall be preferred to the other filters. Second, Chahrour's filter performs better than the Eichenbaum et.al's filter in terms of fraction spent at the reference price (90\% vs $77 \%$ ) and the fraction of quantity sold at the reference price (65\% vs 59\%).

Now that we show that the rolling window is preferred to the fixed window method, the question is whether the windows' length matters. The results from varying the window's length from 13 weeks to 9 and to 17 weeks in comparison to the Chahrour's method were not conclusive. For instance, when we decrease the window length to 9 weeks $19 \%$ is the fraction of non-filtered prices above the reference price. This is lower than the $25 \%$ in the case of the Chahrour's filter, but the fraction spent at the reference price is lower (90\% vs 85\%). Increasing the window's length from 13 to 17 weeks improves the fraction spent at the reference to $90 \%$, but this does not improve the performance of the filter in terms of capturing the price spikes.

\subsubsection{Conclusion}

In general, the reference price filters are preferred to the sales filters because they are less restrictive in filtering the prices and they do not rely on a subjective definition of TSP required in determining sales filers. To calculate the reference prices there are two procedures: the fixed and rolling window methods. Based on some basics statistics, we show that the rolling window performs better than the fixed window procedure for two main reasons. First, the fixed window method restricts price changes to take place only on certain dates, say at most once per quarter. Second, the fixed window method has a problem in treating price spikes. We have also checked whether the window's length affects the criteria of choosing a filter. We do not find an impact of the window's length to affect our choice of the Chahrour's filter, compared to other filters. Therefore, we decide to employ the Chahrour's filter for the remaining work of this thesis. 


\subsubsection{References}

Campbell, J. R., \& Eden, B. (2014). Rigid Prices: Evidence From U.S. Scanner Data. International Economic Review, 55(2), 423-442.

Chahrour, R. A. (2011). Sales and price spikes in retail scanner data. Economics Letters, 110(2), 143-146.

Eichenbaum, M., Jaimovich, N., \& Rebelo, S. (2011). Reference Prices, Costs, and Nominal Rigidities. American Economic Review, 101(1), 234-262.

Eichenbaum, M., Jaimovich, N., Rebelo, S., \& Smith, J. (2014). How Frequent Are Small Price Changes? American Economic Journal: Macroeconomics, 6(2), 137-155.

Fougère, D., Le Bihan, H., \& Sevestre, P. (2007). Heterogeneity in Consumer Price Stickiness. Journal of Business \& Economic Statistics, 25(3), 247-264.

Hosken, D., \& Reiffen, D. (2001). Multi-Product Retailers and the Sale Phenomenon. Agribusiness, 17(1), 115-137.

Kehoe, P. J., \& Midrigan, V. (2007). Sales and the real effects of monetary policy. Working Papers.

Kehoe, P., \& Midrigan, V. (2015). Prices are sticky after all. Journal of Monetary Economics, 75, 35-53.

Lloyd, T. A., McCorriston, S., Morgan, C. W., Poen, E., \& Zgovu, E. (2014). Retail price dynamics and retailer heterogeneity: UK evidence. Economics Letters, 124(3), 434-438.

Loy, J.-P., Holm, T., Steinhagen, C., \& Glauben, T. (2015). Cost pass-through in differentiated product markets: a disaggregated study for milk and butter. European Review of Agricultural Economics, 42(3), 441-471.

Mark Bils, \& Peter J. Klenow. (2004). Some Evidence on the Importance of Sticky Prices. Journal of Political Economy, 112(5), 947-985.

Nakamura, E., \& Steinsson, J. (2008). Five Facts about Prices: A Reevaluation of Menu Cost Models. Quarterly Journal of Economics, 123(4), 1415-1464.

Rotemberg, J. J. (2011). FAIR PRICING. Journal of the European Economic Association, 9(5), 952-981.

SIG (Symphony IRI Group GmbH). (2011). Retail Scanner Data. 


\section{Curriculum vitae}

Born in Draa El Mizan, Tizi-Ouzou

1981

High School and Baccalauréat (Abitur), Lycée Ali Mellah, Draa El Mizan 1997-2001 Ingénieur d'Etat en planification et de la statistique à l’INPS, Alger, 2001-2006 Algeria

Études universitaire de post-graduation (Magistère), à l’INPS Alger, 2006-2009 Algeria

Master of science in Agro-food marketing, IAMZ , Zaragoza, Spain

2009-2011

International Ph.D. Program for Agricultural Sciences in Goettingen 2011-2016 (IPAG) 
